\title{
Land Security, Efficiency and Productivity, and Rural Income in China
}

\author{
Dissertation \\ to obtain the $\mathrm{Ph}$. D. degree \\ in the Faculty of Agricultural Sciences, \\ Georg-August-University Göttingen, Germany \\ presented by \\ Yanjie Zhang \\ born in Hubei, China
}

Göttingen, May 2011 
1. Name of referee: Prof. Dr. Bernhard Brümmer

2. Name of co-referee: Prof. Dr. Thomas Glauben

Date of dissertation: 21.07.2011 


Whenever there is in any country, uncultivated lands and unemployed poor, it is clear that the laws of property have been so far extended as to violate a natural right. The earth is given as commonstock for man to labor and live on. If for the encouragement of industry we allow it to be appropriated, we must take care that other employment be provided to those excluded from the appropriation. If we do not, the fundamental right to labor the earth returns to the unemployed. 



\section{Contents}

List of Tables . . . . . . . . . . . . . . . . . . . . . . . . . 10

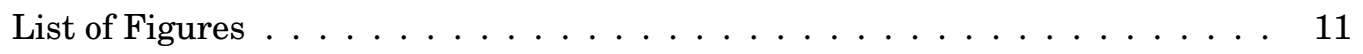

List of Abbreviations . . . . . . . . . . . . . . . . . . 13

Acknowledgement . . . . . . . . . . . . . . . . . . . . 13

1 Introduction 1

1.1 Motivations behind the research $\ldots \ldots \ldots \ldots 2$

1.2 Objectives and research topics of the study $\ldots \ldots \ldots \ldots$

1.3 Outline of the chapters $\ldots \ldots \ldots \ldots \ldots \ldots$

2 Productivity change and the effects of policy reform in China's agricul$\begin{array}{ll}\text { ture in the past three decades } & 10\end{array}$

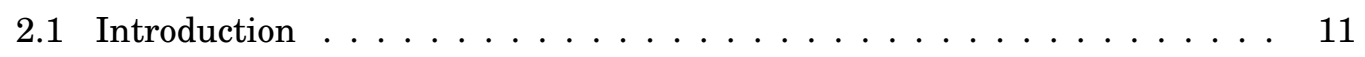

2.2 Policy reform and agricultural TFP growth in China . . . . . . . . . . 13

2.2.1 Rural reform in China since $1979 \ldots \ldots \ldots$. . . . . . . . . . . 13

2.2.2 Empirical results on TFP change and policy reform impacts $\ldots .20$ 
2.3 Analytical framework . . . . . . . . . . . . . . . . . . . . 24

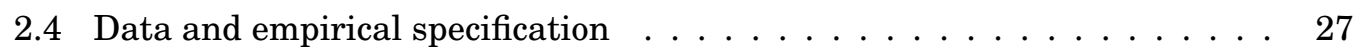

2.4 .1 Data description . . . . . . . . . . . . . . . 27

2.4.2 Translog specification of the production frontier . . . . . . . . 32

2.5 Empirical results and discussion $\ldots \ldots \ldots \ldots \ldots \ldots$

2.5.1 Description of the parameter estimates and hypotheses tests . . . 35

2.5 .2 Technical efficiency $\ldots \ldots \ldots \ldots \ldots$

2.5.3 TFP change and its decomposition . . . . . . . . . . . . 43

2.5.4 Analysis of annual average growth rate across regions $\ldots \ldots 48$

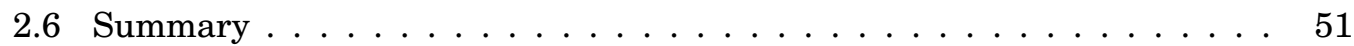

3 The impact of land reallocation on technical efficiency 56

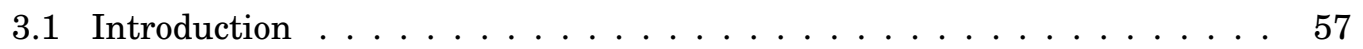

3.2 Conceptual framework and econometric model . . . . . . . . . . . . 61

3.2 .1 Conceptual framework . . . . . . . . . . . . . . . 61

3.2 .2 Econometric model . . . . . . . . . . . . . . . . . . 65

3.3 The incidence of land reallocation and data description $\ldots \ldots$. . . . . 68

3.4 Empirical results $\ldots \ldots \ldots \ldots \ldots \ldots \ldots$

3.4.1 Fixed-effects model with instrumental variables estimations . . . . 78

3.4 .2 The SFA production function $\ldots \ldots \ldots \ldots$

3.4 .3 Technical efficiency . . . . . . . . . . . . . . . . 88

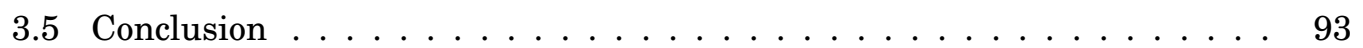


4 The impact of land security and input allocation on farm household income

4.1 Introduction . . . . . . . . . . . . . . . . . . . 96

4.2 Theoretical framework . . . . . . . . . . . . . . . . . . . . . 99

4.3 Econometric model . . . . . . . . . . . . . . . . . . . . . . . . 105

4.4 Data source and descriptive statistics f . . . . . . . . . . . . . 108

4.4 .1 Data Source . . . . . . . . . . . . . . . . . . . . 108

4.4 .2 Descriptive statistics $\ldots \ldots \ldots \ldots \ldots 111$

4.5 Estimation results . . . . . . . . . . . . . . . . . . . . 117

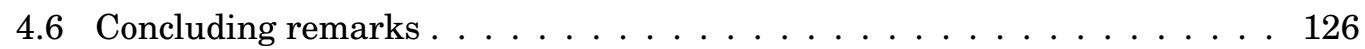

5 Summary $\quad 129$

5.1 Main results . . . . . . . . . . . . . . . . . . . . 130

5.2 Policy implications . . . . . . . . . . . . . . . . . . . . 133

$\begin{array}{ll}\text { Bibliography } & 138\end{array}$ 


\section{List of Tables}

2.1 Descriptive statistics of the sample . . . . . . . . . . 28

2.2 Parameter estimates of the stochastic production frontier . . 36

2.3 TFP change and its decomposition, $1979-2008 \ldots 44$

2.4 Annual average growth rate of TFP change and its components across regions, 1979-2008(\%) . . . . . . . . . 49

3.1 Summary statistics of land reallocation and land rental mar$\operatorname{ket}(1995-2002) \ldots \ldots \ldots \ldots \ldots$

3.2 Descriptive statistics of the variables in stage 1 model . . . 76

3.3 Descriptive statistics of the variables in stage 2 model . . . . 77

3.4 Determinants of land reallocation with fixed-effects models . 78

3.5 Estimated results from the translog stochastic frontier production functions ................. . . 84

3.6 Level of technical efficiency from 1996 to 2002 by provinces . 88 
4.1 Summary statistics of characteristics of farm households in Zhejiang . . . . . . . . . . . . . . . . 112

4.2 Summary statistics of characteristics of farm households in Hubei . . . . . . . . . . . . . . . . . . . . . . 113

4.3 Descriptive statistics of the variables . . . . . . . . . 116

4.4 Results of the normalized quadratic profit functions with fixed effects model estimates . . . . . . . . . . . . . . . . . 118

4.5 The Hessian matrix and its eigenvalues . . . . . . . . . 121

4.6 Uncompensated (Marshallian) price elasticities of outputs and variable inputs at the sample means . . . . . . . 125 


\section{List of Figures}

2.1 Output and inputs in the whole sample period . . . . . . . 31

2.2 Average yearly degree of technical efficiency by regions, 1979-2008 40

2.3 TFP change and its decomposition on the national average, 1979-

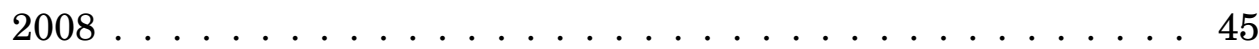

2.4 TFP change and its decomposition by regions, 1979-2008 . . . . . 46

3.1 Assumed relationships in the two stages model . . . . . . . . . . . . 64

3.2 The kernel density of changed arable land due to land reallocation by provinces $(1996-2002) \ldots \ldots \ldots \ldots$. . . . . . . . . 72

3.3 The kernel density of technical efficiency across villages in Zhejiang province $(1996-2002) \ldots \ldots \ldots$. . . . . . . . . 90

3.4 The kernel density of technical efficiency across villages in Hubei province $(1996-2002) \ldots \ldots \ldots$. . . . . . . . . . . 91

3.5 The kernel density of technical efficiency across villages in Yunnan province $(1996-2002) \ldots \ldots$. . . . . . . . . . . . . 92

4.1 Profit loss due to misallocation of labor input . . . . . . . . . . . 104 


\section{List of Abbreviations}

$\begin{array}{ll}\text { CRTS } & \text { Constant returns to scale } \\ \text { DEA } & \text { Data envelopment analysis } \\ \text { HRS } & \text { Household responsibility system } \\ \text { IFPRI } & \text { International Food Policy Research Institute } \\ \text { IV } & \text { Instrumental-variables (estimation) } \\ \text { MFP } & \text { Multifactor productivity } \\ \text { MR } & \text { Marginal revenue } \\ \text { NBSC } & \text { National Bureau of Statistics of China } \\ \text { NDRC } & \text { National Development and Reform Commission } \\ \text { OECD } & \text { Organisation for Economic Co-operation and Development } \\ \text { RCRE } & \text { Research Center for Rural Economy, China } \\ \text { SFA } & \text { Stochastic frontier analysis } \\ \text { SGEs } & \text { State-owned grain enterprises }\end{array}$


Technical efficiency

TFP

Total factor productivity

TVEs

Township and village enterprises 


\section{Acknowledgements}

This $\mathrm{PhD}$ thesis was written at the Chair of Agricultural Market Analysis at the University of Göttingen. I am greatly indebted to Prof. Dr. Bernhard Brümmer, who accepted me as a PhD student under his supervision after I finished my master study in Göttingen. During my study period, I benefited greatly from his rich academic advice and patient methodological guidence. I would like to express my sincere thanks to my advisor, Prof. Dr. Thomas Glauben at the Institute of Agricultural Development in Central and Eastern Europe (IAMO) for giving good advice at all stages of my research. I am very thankful to Dr. Xiaobing Wang at the Center for Chinese Agricultural Policy (CCAP), Chinese Academy of Sciences for providing helpful idea and comments on the articles we coauthored. My thanks also goes to Prof. Dr. Stephan von Cramon-Taubadel and Prof. Xiaohua Yu at the University of Göttingen, Prof. Nico Heerink at the Wageningen University, and Dr. Jarmila Curtiss at the World Association of Young Scientists (WAYS) for their valuable comments and suggestions.

I am also grateful to my colleagues and many graduate students at the University of Göttingen and IAMO for their friendly help and sincere assistance. Special thanks go to Mr. Tinoush Jamali Jaghdani, who gave 
me a lot of help on the typesetting of the thesis. I am also thankful for the help of Ms. Leanora Lange for proofreading this thesis.

Most of all I am grateful to my parents and my wife for their encouragement and support during all these years.

The financial support of the University of Göttingen and the Leibniz Institute of Agricultural Development in Central and Eastern Europe (IAMO) Foundation is gratefully acknowleged. 


\section{Chapter 1}

\section{Introduction}

HIS thesis consists of three essays which measure land security, es-
timate agricultural efficiency and farm productivity, and analyze their impacts on farm income in rural China. The rural reform starting in the late 1970s improved farmers' incentives and has had great impacts on China's agricultural production and farm income growth. Since the onset of the reform with the implementation of the household responsibility system (HRS), the former communal production system was decentralized, the state-monopolized procurement and marketing system for agricultural products was gradually reformed, the rural labor forces and other relevant production endowments of farm households were largely liberalized and were given control of their own matters. As a result, agricultural output has increased enormously from 139.7 billion Chinese Yuan in 1978 to 6036.1 billion Chinese Yuan in 2009, and the per capita net income of a farm household has grown dramatically from 133.57 Chi- 
nese Yuan in 1978 to 5153.17 Chinese Yuan in $2009 .^{1}$

\subsection{Motivations behind the research}

Numerous authors interested in China's dramatic agricultural development since the reform have made efforts to explain changes in productivity and explore the growth sources behind it, including Lin (1992); Wu (1995); Kalirajan et al. (1996); Fan (1997); Mao and Koo (1997); Lambert and Parker (1998); Fan (1999); Wu et al. (2001); Brümmer et al. (2006); Chen et al. (2008) and so on. These studies convey some core messages: Over the past three decades, the improvement of productivity has been spectacular and has resulted mainly from technical progress, whereas the efficiency change is not so inspiring after the completion of HRS reform in 1984. In transition countries, there is evidence of institutional incompleteness or failure and even the lack of complementary institutions accompanying the reform course. For instance, market uncertainties and incompleteness, poorly developed credit markets, an incomplete legal system, information asymmetries and path-dependencies influencing the efficiency of the privatization process have all been found to have significant implications for efficiency and growth (see Brandt et al., 2002; Curtiss, 2002).

Considering the various land related issues that are currently being hotly disputed in China, the remaining ambiguity over land tenure rights seems

\footnotetext{
${ }^{1}$ These data are taken from the 1985 China Rural Statistical Yearbook and the 2010 China Statistical Yearbook provided by the National Bureau of Statistics of China (NBSC).
} 
to be closely connected to the deterioration of technical efficiency after 1990. One event highlights the necessity of further study regarding land tenure security and its relationships with efficiency and productivity and hence rural income. After eight years of controversy and discussion, the Property Law of the People's Republic of China was approved on March 16, 2007 and went into effect on October 1, 2007. The law stipulates equal protection of state, collective and private property rights. As for rural land issues, it says: In order to give farmers a long-term, guaranteed land-use rights, after expiry of the contract of arable land, grassland and woodland, those who own the contracted land use rights have the rights to continue to contract in accordance with the relevant state regulations. Taking into account the former codified laws of the Land Management Law (1998) and the Land Contracting Law (2003), the government has consistently been concerned about strengthening individual farm household rights to land.

In spite of all of these efforts, the new land tenure system under HRS is inadequate, and individual farm household rights are incomplete. As Dong (1996) and Yao (2010) point out, this land tenure system is actually a two-tier land tenure system in which the village collective and the individual household share the land rights, and the balance point can be anywhere from complete collective ownership to complete individual ownership. This also explains the considerable variations in land rights or land tenure security across regions in rural China. ${ }^{2}$ Conceptu-

\footnotetext{
${ }^{2}$ See Liu et al. (1998); Yao (2000a); Brandt et al. (2002) for more comprehensive discussions of a wide variety of land tenure arrangements in Chinese villages regarding the delineation of rights, the security of rights, and the procedure to make changes.
} 
ally, Deininger and Feder (2001) associates land tenure insecurity with the lack of well-defined property rights. They argue that the improved institutional environment, no matter whether it is made up of formal institutions (land titles) or informal institutions (customary tenure) that help mitigate or even eliminate the threat of insecurity, will clearly increase the benefit to farm households through productivity-enhancing, long-term investments, and, in turn, the farmers will be more willing to invest in the land. In rural China, individual farm households do not have the legal titles to the land they farm, and as a result, they usually face the risk of administrative land reallocation and adjustment. The possibility of land reallocation gives rise to the problem of tenure insecurity, which is similar to a random tax levied on a farmer's land investment because there is a risk that the farmer will lose his or her land in the future. This induced land tenure insecurity reduces farm households' incentives to invest in the land and to use the labor forces efficiently, and it may decrease agricultural productivity and hence negatively affect farmers' income. $^{3}$

\subsection{Objectives and research topics of the study}

The objectives of this study are to contribute to the ongoing estimation and explanation of China's agricultural productivity growth since the rural reform and to explore the impact of land tenure security on farm households' productive efficiency and income in China's unique land tenure

\footnotetext{
${ }^{3}$ See Kung (2000); Deininger and Feder (2001); Brandt et al. (2002) for more detailed discussions of land tenure security and land reallocation issues.
} 
system. Starting from the research motivations, the following three topics are proposed to study land security, efficiency and productivity, and farm income in rural China:

1. Productivity and efficiency change since the reform in the past three decades.

2. Administrative land reallocation, which induces land tenure insecurity, and its impact on technical efficiency (TE).

3. Land tenure security, input allocative efficiency, and their impact on farm household income.

These three research topics are implicitly connected, and the logic behind them is the following. First, interested in China's great achievement in rural reform and impressive improvement in agricultural production, this study follows the previous empirical research done by Lin (1992); Fan (1997); Lambert and Parker (1998); Fan (1999); Brümmer et al. (2006); Chen et al. (2008), and extends their work by covering a longer research period of China's rural reform, from 1979 to 2008. On the macro level, we use aggregate provincial level data, which are provided by the International Food Policy Research Institute (IFPRI) and the National Bureau of Statistics of China (NBSC) to calculate indices of total factor productivity (TFP) change and its three components: technical change (TC), technical efficiency (TE) change, and a scale effect. Consistent with the previous empirical results, we find that the impressive improvement of TFP change (222\%) over the past three decades is dominated by the outstanding performance of technical change (360.5\%). At the same time, both 
technical efficiency change $(-18.5 \%)$ and the scale effects $(-3.6 \%)$ however have negative impact on the improvement in TFP. What impresses us is that the best performance in terms of technical efficiency is exhibited in the first reform phase (1979-1984) and that technical efficiency deteriorated substantially after that period. At the same time, the trend of divergence across provinces in terms of technical efficiency is obvious in the whole sample period.

From an institutional environment perspective, we continue our work on the causes or sources of bad performance in terms of efficiency with a special focus on the inadequate land tenure system accompanying HRS. This leads to our second research topic. The dataset used for the study is provided by the Research Center for Rural Economy (RCRE) of China, and includes individual farm household data and the associated village data of the three representative provinces (Zhejiang, Hubei and Yunnan) covering the period from 1995 to 2002 . This rich dataset provides us with an opportunity to simultaneously study land reallocation at the farm household level, as well as the potentially important affecting factors at the village level, which has not yet been conducted by other researchers. The fact that each province has a specific economic environment and distinct land tenure arrangement allows us to compare the impact of land reallocation on technical efficiency among the three provinces.

As is already discussed in Section 1.1, Deininger and Feder (2001) asserts that the improved institutional environment, which helps mitigate or even eliminate the threat of insecurity, will clearly increase the benefit to farm households through productivity-enhancing, long-term in- 
vestments, and, in turn, farmers will be more willing to invest in the land. Considering that the number of rural enterprises has grown rapidly and that off-farm income has accounted for a large proportion of the total income for farm households since the reform, we extend the analysis beyond agricultural production to incorporate both agricultural and non-agricultural activities. For the third research topic, individual farm household data of the Zhejiang and Hubei provinces covering the period from 1995 to 2002 provided by RCRE are used to study land tenure security and input allocative efficiency in the two sectors, and to examine their impact on farm household income.

\subsection{Outline of the chapters}

An outline of the contents of the subsequent chapters is provided in this section. Chapters 2, 3, and 4 form the main body of this thesis, dealing with the three topics discussed in the above section, respectively. Chapter 5 summarizes the results from the studies and presents the policy implications.

Chapter 2: In this chapter, a stochastic frontier analysis (SFA) approach is applied to estimate the production function of China's agricultural activity and to explain variation in technical efficiency. After that, cumulative (chained) indices are calculated for TFP change and its three components: technical change, a scale component, and technical efficiency change. For the explanation of variation in technical efficiency, besides the conventional control variables, we additionally introduce a series of 
variables in the model to capture the effects of rural policy reforms in the past three decades and the impact of different regional development levels. Then the effects of the government's rural policies in different reform phases and the regional variations in TFP change and its three components are discussed comprehensively in the rest of the chapter.

Chapter 3: In this chapter, we first check our sample for the incidence of administrative land reallocation, which is proven to be common, and the results are consistent with that of other empirical studies. Benefiting from the data structure of including both individual farm household data and the associated village data, we then investigate whether and how the relevant factors affect administrative land reallocation (stage 1 model). The presumed influencing factors consist of variables representing farm and household characteristics (household level data), social and economic development conditions of the village (village level data), and relevant government policies (yearly dummy variables). Lastly, we estimate the impact of administrative land reallocation on technical effciency using a stochastic production frontier model (stage 2 model). Some interesting empirical results from the stage 1 and stage 2 models are presented in this part, and they are explained and discussed in detail.

Chapter 4: In this chapter, we assume that land tenure insecurity negatively affects input allocative efficiency (within agricultural production, and between agricultural and non-agricultural activities) and, in turn, the income of the farm household. Theoretically, the farm household profit maximization problem in the neoclassical production theory setting is modified by adding a series of institutional environment and mar- 
ket constraints. In the econometric estimation, the normalized quadratic profit function with the addition of a vector of control variables representing the effects of land tenure insecurity, input less-than-optimum allocation, and their interactions are applied to study the profit maximization problem of farm household in our sample. The empirical results show that land tenure insecurity has no direct effect on farm household income in both provinces, but its indirect effects through the interactions with other input allocations are observed in the Hubei province.

Chapter 5: In this chapter, we summarize the empirical results from Chapters 2,3 , and 4 . After that, we present the policy implications. 


\section{Chapter 2}

\section{Productivity change and the effects of policy reform in}

\section{China's agriculture in the past}

\section{three decades}

The main contents of this chapter are based on the article "Productivity change and the effects of policy reform in China's agriculture since 1979", and this article is a cooperation with Bernhard Brümmer. It has been accepted for publication in the journal Asian-Pacific Economic Literature. It will appear in print for issue 25(2), November 2011. 


\subsection{Introduction}

${ }^{\text {HE }}$ rural reform that started in the late 1970s improved farmers' incentives and has had great impacts on China's agricultural production and productivity growth. Agricultural output has increased enormously from 139.7 billion China Yuan in 1978 to 6036.1 billion China Yuan in 2009, and per capita net income of the farm household has dramatically grown from 133.57 China Yuan in 1978 to 5153.17 China Yuan in $2009 .^{1}$

Whether or not agriculture features slow productivity growth relative to other sectors has been an important and long-disputed topic. Martin and Mitra (2001) show that agriculture generally had faster TFP growth than manufacturing. They also find evidence of a tendency towards relatively rapid convergence in agricultural productivity across countries. Similar results are also obtained in other international studies, such as Moutinho and Machado (e.g. 2003). This information about agricultural productivity is useful for the design of the economic growth strategy of developing countries like China. Moreover, considering agricultural productivity by looking at China as a small world consisting of regions (or provinces) with different development levels and unique resources is also instructive for policymakers who are seeking ways of closing the ever-growing income gaps among regions. A recent research by Chen et al. (2008) indicates that provinces with high income usually had better agricultural productivity performance than those with low income. Their empirical results

\footnotetext{
${ }^{1}$ These data are taken from the 1985 China Rural Statistical Yearbook and the 2010 China Statistical Yearbook provided by National Bureau of Statistics of China (NBSC).
} 
further find that regional disparities in terms of cumulative TFP growth have increased over time, and that eastern and coastal provinces consistently outperformed the other regions in China.

China's agricultural production and rural development have experienced comprehensive changes in the past three decades. Tracing the course of the rural reform, we could see clear phases with different policy focuses in each of the stages. There are varying classifications of rural reform phases in the literature. In general, the rural reform started with a focus primarily on decentralizing the system of agricultural production and reforming the agricultural procurement system. Then policies were designed aiming at liberalizing both the factor and the product markets, reforming the united procurement and marketing system. During this period, policies were frequently adjusted in response to market price changes and food security concerns, especially those policies connected to grain market. With the final elimination of the grain quota procurement system in 2001 and an accomplishment of the marketization reform of grain in 2004, the government major policy directives has concentrated on addressing questions of rural social welfare and income distribution.

Hence, it is useful to examine how the agricultural productivity of different regions developed, and in which way rural reform affected China's agricultural production in the past. Of great interest will be whether previous or current policies have contributed to or worked against improvement in productivity and efficiency. Identifying the sources of China's agricultural productivity change in different reform phases is also important for the future course of rural reform in China. This chapter is or- 
ganized as follows. The next section will review the major policy reforms in China over the past three decades and then give an overview of the previous empirical results regarding China's TFP change and the impact of policy reform. The third section will be devoted to measuring productivity change and its decomposition. Data description and the specified translog production frontier model will be presented in section 2.4. We will present and discuss the empirical results in the subsequent section, and the last section will conclude with the main findings and implications of the study.

\subsection{Policy reform and agricultural TFP growth in China}

\subsubsection{Rural reform in China since 1979}

Rural reform in China since the initiation of reform in 1979 can be roughly divided into six phases (1979-1984, 1985-1989, 1990-1993, 1994-1997, 1998-2003, and post-2003). The first period (1979-1984) focused on the decentralization of the production system and reforming the agricultural procurement system (Fan et al., 2002). The commune system was dismantled, and land use rights were granted to individual farm households. At the end of this phase, the newly introduced household responsibility system (HRS) was adopted by most of the rural communities as a repacement. This family based production system endows farmers with the freedom to control their production with the exception of the obligation 
to first fulfill government procurement quotas. In addition to reductions of quota quantities and increases in procurement prices over this period, more and more commodities were phased out of the government procurement programs, ${ }^{2}$ and were allowed to be traded in rural markets. As a result, both agricultural output and factor productivity grew significantly.

Meanwhile, a series of problems emerged which centered on the existing procurement system. Since above-quota or market prices were much higher than the quota prices, farmers usually preferred to find ways of evading quota fulfillment. A second problem was that the procurement system was designed to operate in a shortage economy and was ill-suited to handle emerging agricultural surpluses, which burdened the state with having to buy ever-increasing quantities of products at high above-quota prices. Other problems of the procurement system are related to the differences in demand and the inequalities among regions (see Sicular, 1988, for more details).

These problems led to the second stage of reforms. The second phase (1985-1989) was designed to further liberalize the country's agricultural pricing and marketing systems (Fan et al., 2002). Attempting to reform the united procurement and marketing system for the first time, the government cut the above-quota prices for grain and other main products and established a new pricing system based on a weighted average of the quota and above-quota prices (a thirty-seventy ratio for grain and a fortysixty ratio for oilseeds). Correspondingly, a system of negotiated purchase contracts was implemented, where farmers negotiated and signed

\footnotetext{
${ }^{2}$ The number of commodities under the government procurement system was reduced from 113 to 38 by 1984 (Fan et al., 2002).
} 
purchase contracts with the government before planting, but were free to trade the above-contract production in rural markets. Meanwhile, the amount of production under the contract system was further reduced and more products were liberalized. However, the government still maintained control over strategic products (grain, cotton, etc.). Thus a twotiered system consisting of both market and central planning elements existed during this period (Wu, 1997; Gabre-Madhin et al., 2003).

In regard to the effects of the reform in the second phase, Sicular (1988) points out that in practice the grain contracts were not always voluntary, but often similar to the old procurement quotas, only with a limitation of state procurement to the contract amount, which helped ease public storage and budgetary problems. Meanwhile, input prices increased much faster than the government's output procurement prices, raising production costs (Fan et al., 2002). The resulting lower output growth compared with the former phase raised questions about the new procurement and pricing system.

From the beginning of 1990s, China's agriculture entered a new development stage. Accompanied by an acceleration of economic reform in urban areas, the state further reformed the united procurement and marketing system. The number of commodities subject to state procurement programs declined from 38 in 1985 to only 9 in 1991 (Fan et al., 2002). The grain market system, which already had low procurement prices and even lower subsidized prices for urban consumers, was changed as ration prices were raised by 68\% in 1991 and by another 45\% in 1992, almost eliminating the gap between procurement prices and retail prices $(\mathrm{Wu}$, 
1997). In 1993, the grain market was further liberalized as the grain rationing system was abolished, which had existed for 40 years. Meanwhile, more than $90 \%$ of all agricultural production was sold at marketdetermined prices, indicating China's agriculture had been transformed from a command-and-control system to a largely free-market one (Fan et al., 2002).

However, even with these attempts at comprehensive liberalization, various price and quantity controls (for grain, cotton, and oil crops vs. livestock and vegetables) remained in operation for certain commodities domestically, between regional markets, and towards world markets, thereby effectively keeping regional markets segmented and decoupled from international markets (Brümmer et al., 2006).

Most reforms in the fourth period (1994-1997) were focused on the rebirth of the self-sufficiency objective. In 1992, some local governments liberalized both procurement and retail prices in local grain markets, which finally ended the unified procurement and marketing system for grain across the country. However, food prices increased excessively in some regions at the end of 1993. As a result, the provincial governor's responsibility system was introduced to balance local grain supply and demand. Under this system, the governor of a province is required to take full responsibility for the province's grain economy, which intensified the local governments' intervention in the grain market. This policy measure meant, to some extent, a return to the objective of regional grain selfsufficiency, which caused severe misallocations of resources within and among provinces. However, it eventually also put an end to the central- 
ized control of grain production, which could facilitate grain production suited to local conditions (Wu, 1997; Lin and Zhang, 1999).

To increase farmers' incomes and to meet food security goals, the government raised procurement prices for grain by $40 \%$ in 1994 and by another $42 \%$ in 1996. As a result, agricultural production expanded rapidly, and the gap between procurement and market prices narrowed. In 1997, market prices fell below procurement prices following two consecutive bumper crops, and in response the government launched a price support policy to protect the interest of grain producers (Fan et al., 2002; Brümmer et al., 2006).

The fifth period (1998-2003) can be summarized as a transition period integrating rural development with overall economic reforms. Facing a series of problems in the grain procurement and marketing system, including a heavy financial burden because of excessively increased grain stocks and the huge debt of state-owned grain enterprises, the government implemented a new round of grain procurement and marketing reform, the so-called 'three policies and one reform' in 1998 (Li, 2005). The three policies procured farmers' surpluses to the largest extent at subsidized prices, correlated market prices and procurement prices of state-owned grain enterprises (SGEs), and centralized the state grain purchase fund for grain procurement. The one reform consisted of an acceleration in the reform of the state-owned grain enterprises. However, problems arose from the contemporaneous official announcement that only state-owned grain enterprises were allowed to procure grain from farmers, prohibiting private dealers from entering the market. This was to some extent 
a reverse to the government's monopolistic control of the grain market. There were also some problems related to the implementation of subsidized prices for grain. The SGEs were expected to undertake state procurement at subsidized prices and to operate as a commercial enterprise marketing grains at a profit. This double role of the SGEs led to inconsistency in the goals of state procurement in that it sought to both increase profit and to support income. Another problem was the lack of funds for implementing these policies because of budgetary constraints in many major grain-producing regions (OECD, 2005). During this period, the government continued to adjust the previous grain reform policies, and in 2001 the quota procurement system was finally eliminated and a free grain market was introduced in major consuming regions. In 2004, the free grain market spread to most of the regions in China, indicating an accomplishment of the marketization reform of grains (see Li, 2005).

Faced with a growing income gap between urban and rural areas, the government began to adopt policies to raise farmers' income nationwide with a fundamental shift from taxing agriculture to supporting it. A series of policy measures have been implemented to support agricultural producers, including: input subsidies for farmers to purchase improved seed for wheat, corn, rice and soybeans starting in 2002; direct payments to farmers engaged in grain production as a trial in 2002, and later nationwide in 2004; and an agricultural tax reform as a trial in 2000 , and later phased in across rural China starting in 2004. At the end of 2005, the government formally announced that it would fully abolish agricultural tax starting at the beginning of 2006 , a tax that had been implemented 
for 2600 years (see OECD, 2005, for more details).

Between 2004 and 2008, with five consecutive No. 1 Documents ${ }^{3}$ focusing on rural areas and particularly on issues related to agriculture, farmers, and the countryside (the so-called three nongs), China's approach to rural policy has evolved towards a comprehensive framework which aims at addressing questions of rural social welfare and income distribution. The major policy directives concentrate on increasing farmers' income, reducing the rural-urban gap, raising agricultural production capacities, maintaining food security, improving environmental sustainability, and integrating the economic and social development of urban and rural areas (see OECD, 2009b, for more details). In line with these documents, the government set up a series of price and income support policies. From 2004 on, a liberalized pricing system has been applied to all agricultural commodities except tobacco; since then, eligible firms have been allowed to buy and sell grains on the open market where grain prices were largely liberalised. Minimum prices for grains, which are set every year by the National Development and Reform Commission (NDRC) in consultation with other governmental institutions, were first announced in 2004 for early indica rice and japonica rice, and then extended to include wheat in 2006. With regard to the aim of supporting grain production and increasing the income of grain producers, direct payments were implemented at the national level in 2004, which are based on current area sown for rice, wheat, or corn, and are financed from the National Grain Risk Fund.

\footnotetext{
${ }^{3}$ No. 1 Documents are the top priority documents issued jointly at the beginning of each year by the Central Committee of the Communist Party and the State Council. They are the first major policy directives of the year and give policy suggestions for the National People's Congress (NPC) (OECD, 2009b, p. 127).
} 
In addition, the government introduced a subsidy for reproductive sows which started in 2007 to encourage pig production. At the same time, the government has continued and expanded its policies on input subsidies. Comprehensive subsidy on agricultural inputs was introduced in 2006 to compensate farmers in response to an increase of agricultural inputs prices such as fertilizers, pesticides, plastic films and diesel. The amount of subsidies for improved quality seeds continued to increase, with subsidies for rapeseeds and cotton added in 2007. Since 2004, the government has provided a subsidy for the purchase of agricultural machinery, which is available to individual farmers as well as to so-called specialised households and agricultural machine service delivery organisations. The subsidy has been used primarily to target the mechanization of wheat harvesting and rice planting, but was extended in 2007 by way of trials to support the mechanization of corn harvesting. Since food security is still one of the major concerns for the government, the conversion of farmland for non-agricultural use is strictly controlled. The Property Law of the People's Republic of China, which went into effect on October 1, 2007, stipulates equal protection of state, collective, and private property rights, and further formalizes farmers' land use rights .

\subsubsection{Empirical results on TFP change and policy re- form impacts}

Numerous authors interested in China's dramatic agricultural development since the reform have made efforts to explain changes in productiv- 
ity and to explore the growth sources behind it. Lin (1992) applies the production function approach proposed by Griliches (1963) to evaluate the effects of the various components of reforms on agricultural growth. He reports that the productivity change resulting from various reforms made up 48.64 percent of the output growth, and the dominant source of output growth in the 1978-1984 period was the change from the production team system to HRS. Although the changes in market prices and state procurement prices in the 1978-1984 period did not affect the total factor productivity, his results indicate that the substantial increase in the state procurement price had a significant impact on output growth, contributing 15.98 percent of the growth. He explains the slowdown in output growth in the second phase as the result of the completion of HRS reform between 1983 and 1984 and the sharp drop in the state procurement prices relative to input prices.

Using the Törnqvist-Theil index approach, Fan (1997) estimates that agricultural production increased by more than 6.6 percent per annum and productivity by 5.1 percent per annum during the first stage of the reforms. From 1985 to 1995, agricultural production and productivity continued to rise rapidly with growth rates of 5.6 percent and 3.9 percent per annum respectively, although at a lower pace than during the first phase of the reforms. Fan (1999) applies a frontier shadow cost function approach to the case of rice production in the Jiangsu province using aggregated cell means of the prefectural household data. He presents measures of technical and allocative efficiency as well as the rate of technical change from 1980 to 1993 . The results show that technical efficiency 
improved substantially in the first stage of the reforms (with an annual growth rate of $8.5 \%$ ), while improvement of both technical and allocative efficiency stagnated after that. The rate of technical change continued to increase over the whole study period, which the author explains as a result of long-term government investment in technology and rural infrastructure. One particularly interesting finding is that technical efficiency has relatively small regional variations in contrast to allocative efficiency.

Lambert and Parker (1998) use a distance function measure of productivity change and obtain a sequence of technical change, technical efficiency, and multifactor productivity (MFP) indices on the provincial level for the period from 1979 to 1995 . The results show outward shifts in the production possibilities set over this period. They furthermore demonstrate that most of the recorded changes in MFP for the most progressive provinces are attributable to shifts in the production possibilities frontier, while the effect of technical efficiency change is limited. Longitudinally, the highest rates of improvement in MFP are found in the period from 1979 to 1984, as the process of decollectivization picked up speed, as well as in the three years after reform accelerated in 1992 as part of the goal of creating the Socialist Market Economy. However, these results are not unambiguous, as MFP indices of all provinces do not all move in the same direction.

Brümmer et al. (2006) also apply a distance function approach using individual farm household data in the Zhejiang province from 1986 to 2000. Based on estimates in a stochastic frontier framework, they find the highest rate of TFP growth in the period from 1985 to 1989 (i.e., the second policy reform phase). Main factors are large improvements in technical 
efficieny and a moderate rate of technical progress. When entering the 1990 s, the increase in factor productivity slows down and technical efficiency decreases. The authors argue that the market-oriented reforms of the mid-80s continued to exert a positive influence on technical efficiency but that the incompleteness of the reforms led to allocative distortions between the agricultural subsectors, which hampered improvements in terms of allocative efficiency. The authors suggest that input quality problems might be partially responsible for the slowdown of TFP growth and technical efficiency in the 1990s. For example, provision of extension services and land quality might have deteriorated. Another factor might be related to institutional inefficiencies, in that land property rights were extensively redistributed in the 1990s. Besides this, the uncertainty in land tenure weakens farmers' investment incentives in land. Furthermore, the outflow of educated and younger farmers from agriculture could also have a negative impact on the development in technical efficiency.

Using a sequential data envelopment analysis (DEA) approach, Chen et al. (2008) calculate the output-oriented Malmquist productivity indexes and their decomposition based on a panel dataset of 29 provinces in China over the period 1990-2003. Their results indicate that the national average TFP grew at an annual rate of $1.5 \%$ during the sample period and that the major source of productivity growth was technical progress, while the performance in terms of the efficiency has deteriorated over the entire period. And the comparisons across the provinces show that the regional disparities in productivity growth have worsened over time. 


\subsection{Analytical framework}

The productivity of a production unit is defined as 'the ratio of the output(s) that it produces to the input(s) that it uses' (Coelli et al., 1998, p.2). 'Productivity change occurs when an index of outputs changes at a different rate than an index of inputs does' (Kumbhakar and Lovell, 2003, p.279). Initially, the shifts in production technology (neutral technical change) were regarded as the only source of productivity change; later, the biases of technical change and the structure of the technology (scale economies) were also incorporated. Finally, the efficiency change was added, as its omission will lead to an overstatement of the unexplained residual as well as to an erroneous allocation of productivity change to its included sources (Kumbhakar and Lovell, 2003).

In our case, total factor productivity (TFP) is decomposed into three components: technical change, technical efficiency change, and a scale effect. To obtain estimates of productivity change and its components, a stochastic frontier analysis (SFA) approach is applied. Aigner et al. (1977) and Meeusen and Broeck (1977) independently proposed the SFA models. A number of comprehensive reviews of literature on stochastic frontier estimation are available, including Førsund et al. (1980), Schmidt (1985), Bauer (1990), Greene (1993) and Murillo-Zamorano (2004). The production frontier has an error term with two components, one for random effects beyond the control of the producer (weather, etc.) and another for technical inefficiency, which is under the firm's control. Specifically, the stochastic production frontier is written as 


$$
\ln \left(y_{i t}\right)=f\left(x_{i t}, t ; \beta\right)+v_{i t}-u_{i t}, \quad i=1,2, \ldots, t=1,2, \ldots,
$$

where $y_{i t}$ is the output of the $i$-th firm in the $t$-th year; $x_{i t}$ denotes a $(1 \times K)$ vector of inputs; $f($.$) is a suitable functional form (e.g., translog); t$ is a linear time trend representing technical change; $\beta$ is a vector of unknown parameters to be estimated; the $v_{i t} s$ are random errors, assumed to be i.i.d. and have $N\left(0, \sigma_{v}^{2}\right)$-distribution, independent of the $u_{i t} s$; and the $u_{i t} s$ are the technical inefficiency effects. The rate of technical efficiency change is calculated as

$$
T E \Delta=-\frac{\partial u}{\partial t}
$$

The rate of technical change can be calculated directly from the estimated parameters, that is

$$
T \Delta=\frac{\partial f(x, t ; \beta)}{\partial t}
$$

According to Kumbhakar and Lovell (2003, p.283), a conventional Divisia index of productivity change is defined in the scalar output case as the difference between the rate of change of output and the rate of change of an input quantity index, and so

$$
T \dot{F} P=\dot{y}-\dot{X}=\dot{y}-\sum_{n} S_{n} \dot{x}_{n}
$$

where a dot over a variable indicates its rate of change $[e . g ., \dot{y}=(1 / y)(d y / d t)=$ $d \ln y / d t], S_{n}=w_{n} x_{n} / E$ is the observed expenditure share of input $x_{n}$, $E=\sum_{n} w_{n} x_{n}$ is total expenditure, and $w=\left(w_{1}, \ldots, w_{N}\right)>0$ is an in- 
put price vector. Hence, after some transformations, productivity change can be decomposed as

$$
T \dot{F} P=T \Delta+(\varepsilon-1) \cdot \sum_{n}\left(\frac{\varepsilon_{n}}{\varepsilon}\right) \dot{x}_{n}+\sum_{n}\left[\left(\frac{\varepsilon_{n}}{\varepsilon}\right)-S_{n}\right] \dot{x}_{n}+T E \Delta,
$$

where $\varepsilon_{n}=\varepsilon_{n}(x, t ; \beta)=x_{n} f_{n}(x, t ; \beta) / f(x, t ; \beta), n=1, \ldots, N$, are elasticities of output with respect to each of the inputs. The scale elasticity $\varepsilon=\varepsilon(x, t ; \beta)=\sum_{n} \varepsilon_{n}(x, t ; \beta) \gtreqless 1$ provides a primal measure of returns to scale characterizing the production frontier. The relationship in the equation (2.5) decomposes productivity change into a technical change component $[T \Delta]$, a scale component $\left[(\varepsilon-1) \cdot \sum_{n}\left(\frac{\varepsilon_{n}}{\varepsilon}\right) \dot{x}_{n}\right]$, a technical efficiency change component $[T E \Delta]$, and an allocative inefficiency component $\left[\sum_{n}\left[\left(\frac{\varepsilon_{n}}{\varepsilon}\right)-S_{n}\right] \dot{x}_{n}\right]$.

In our case, as input price information or expenditure share of respective input factors are unavailable, $S_{n}$ in the allocative inefficiency component $\left[\sum_{n}\left[\left(\frac{\varepsilon_{n}}{\varepsilon}\right)-S_{n}\right] \dot{x}_{n}\right]$ is not attainable, and the allocative inefficiency component cannot be calculated empirically. An analysis of the development of allocative inefficiency over time would be an interesting exercise, but it is effectively prevented by the large role of centralized planning in the early phase of our sample. With central planning, the available 'market' prices do not adequately reflect economic scarcities, rendering the observed prices unusable for the evaluation of allocative inefficiency. At the same time, the degree of allocative inefficiency is expected to decrease with pro-liberalization reforms. In addition, not only the short-run direction of reforms but also the medium-term stability is likely to improve 
allocative efficiency. Thus, in this study we assume that $S_{n}=\left(\varepsilon_{n} / \varepsilon\right) \forall n$ and the decomposition in equation (2.5) can be simplified to

$$
T \dot{F} P=T \Delta+(\varepsilon-1) \cdot \sum_{n}\left(\frac{\varepsilon_{n}}{\varepsilon}\right) \dot{x}_{n}+T E \Delta .
$$

\subsection{Data and empirical specification}

\subsubsection{Data description}

The data series used for this empirical analysis are drawn from the "China: government expenditure, growth, poverty, and infrastructure, 1952-2001" datasets (2004), ${ }^{4}$ the China Statistical Yearbook (NBSC, various years), the China Rural Statistical Yearbook (NBSC, various years), and the China Education Expenditure Statistical Yearbook (NBSC, various years). The dataset includes agricultural output and the conventional input series of 28 provinces for the period of reform in Mainland China from 1979 to $2008 .{ }^{5}$ In addition to this, a series of exogenous variables are incorporated that might be considered determinants of technical efficiency. Table

\footnotetext{
${ }^{4}$ We have benefited from the dataset provided by the International Food Policy Research Institute (IFPRI). The "China: Government Expenditure, Growth, Poverty, and Infrastructure, 1952-2001" dataset contains provincial-level data was compiled by the International Food Policy Research Institute. The data were collected from various sources such as China Statistical Yearbook (SSB, various years), China Rural Statistical Yearbook (SSB, various years), China Fixed Asset Investment Yearbook (various years), China Education Expenditure Statistical Yearbook (SSB, various years), Khan (1997), Fan (1997), World Bank (2000), Chinese Agricultural Science and Technology (1949-1989), China Transportation Yearbook (various years), as well as authors' estimations (Fan et al., 2002).

${ }^{5}$ Tibet is not included in the dataset because of the lack of data. Hainan and Chongqing obtained their provincial status in 1988 and 1997, respectively. The statistical data are still incorporated in their original provinces (Guangdong and Sichuan, respectively) for the reason of consistency.
} 
2.1 gives an overview of the data characteristics based on the six reform phases mentioned above.

Table 2.1: Descriptive statistics of the sample

\begin{tabular}{|c|c|c|c|c|}
\hline & Mean & Std.Dev. & Min & Max \\
\hline \multicolumn{5}{|c|}{ Whole Sample Period $(1979-2008, \mathrm{n}=840)$} \\
\hline Output & 187.02 & 175.67 & 6.18 & 1174.02 \\
\hline Labor & 1119.77 & 892.47 & 47.79 & 4333.00 \\
\hline Land & 5357.33 & 3443.01 & 295.00 & 16708.03 \\
\hline Fertilizer & 113.44 & 103.59 & 3.00 & 601.70 \\
\hline Machinery & 1886.41 & 2142.65 & 90.30 & 14081.63 \\
\hline \multicolumn{5}{|c|}{ Phase I $(1979-1984, \mathrm{n}=168)$} \\
\hline Output & 81.31 & 58.40 & 6.18 & 257.79 \\
\hline Labor & 1078.96 & 871.61 & 91.70 & 3871.20 \\
\hline Land & 5188.19 & 3263.95 & 502.00 & 12173.00 \\
\hline Fertilizer & 51.50 & 42.09 & 3.10 & 189.50 \\
\hline Machinery & 791.29 & 560.44 & 90.30 & 2866.10 \\
\hline \multicolumn{5}{|c|}{ Phase II $(1985-1989, \mathrm{n}=140)$} \\
\hline Output & 113.50 & 81.51 & 10.35 & 318.90 \\
\hline Labor & 1102.49 & 902.74 & 76.20 & 4156.70 \\
\hline Land & 5165.41 & 3331.04 & 500.47 & 12295.67 \\
\hline Fertilizer & 72.79 & 56.10 & 3.00 & 227.50 \\
\hline Machinery & 1196.37 & 891.81 & 119.70 & 4302.82 \\
\hline \multicolumn{5}{|c|}{ Phase III $(1990-1993, \mathrm{n}=112)$} \\
\hline Output & 142.78 & 100.59 & 12.10 & 440.43 \\
\hline
\end{tabular}


Descriptive statistics of the sample (continued)

\begin{tabular}{lrrrr}
\hline & Mean & Std.Dev. & Min & Max \\
\hline Labor & 1200.64 & 979.26 & 63.00 & 4333.00 \\
Land & 5302.11 & 3364.55 & 543.47 & 12752.10 \\
Fertilizer & 102.32 & 77.36 & 5.30 & 355.00 \\
Machinery & 1410.03 & 1041.95 & 170.17 & 4717.46 \\
Phase IV (1994-1997, $\mathrm{n}=112)$ & & & \\
Output & 197.35 & 148.16 & 13.35 & 683.26 \\
Labor & 1155.06 & 921.43 & 62.70 & 4023.80 \\
Land & 5421.31 & 3497.70 & 535.80 & 16708.03 \\
Fertilizer & 131.37 & 98.99 & 6.10 & 386.70 \\
Machinery & 1798.54 & 1531.26 & 211.44 & 7796.91 \\
Phase V (1998-2003, $\mathrm{n}=168)$ & & & \\
Output & 250.80 & 182.25 & 14.99 & 823.10 \\
Labor & 1150.62 & 903.78 & 59.30 & 3755.60 \\
Land & 175.04 & 134.05 & 6.60 & 601.70 \\
Fertilizer & 150.86 & 116.71 & 6.90 & 468.80 \\
Machinery & 2570.38 & 2499.51 & 153.20 & 11342.45 \\
Phase VI (2004-2008, $\mathrm{n}=140)$ & & & \\
Output & 337.97 & 248.07 & 30.80 & 1174.02 \\
Labor & 1056.04 & 800.63 & 47.79 & 3235.00 \\
Land & 5532.95 & 3672.19 & 295.00 & 14185.64 \\
Fertilizer & & & & \\
\hline
\end{tabular}


Note: units of the above variables are 100 millions of 1980 China Yuan (constant price) for "Output", 10000 people for "Labor", 1000 hectares for "Land", 10000 tons for "Fertilizer" and 10000 horsepower for "Machinery", respectively.

Agricultural output values for all the years are calculated at constant 1980 prices. ${ }^{6}$ Inputs consist of four conventional categories: land, labor, capital, and fertilizer. Land is measured as sown area for all crops in each province. The amount of agricultural labor force is chosen to indicate the labor input of each province. Machinery use is selected as a proxy for capital input. Fertilizer use is measured in pure nutrients. ${ }^{7}$ In Figure 2.1, we have plotted the mean values of the output and the four inputs for each year in the sample period, with vertical dashed lines separating the six policy reform phases. Agricultural output continuously increased during the whole period, indicating an overall growth in China's agricultural production since the start of the reforms. Agricultural labor has remained almost unchanged but showed a trend of decrease over the last three phases. This might coincide with the government's policy of encouraging more rural labor mobility in recent years. Variation in sown area is negligible for the whole period, which reflects the government's efforts on the policy aim of food security. Both fertilizer use and machinery use increased steadily, indicating the strong development of China's

\footnotetext{
${ }^{6}$ Agriculture consists of cropping, forestry, animal husbandry and fishery in China's statistics.

${ }^{7}$ In China rural statistical yearbook, chemical fertilizer use is measured as the actual quantity of chemical fertilizer used for agricultural production, including nitrogen, phosphate, potash and compound fertilizer. The magnitude of Fertilizer use is calculated by the method that using pure nutrients, that is, the actual quantity of chemical fertilizer multiplying the proportion of nitrogen, phosphorus pentoxide, and potassium hydroxide in them. The formula is: Discounted scalar physical quantity = actual quantity $\times$ percentage of the content in that fertilizer.
} 


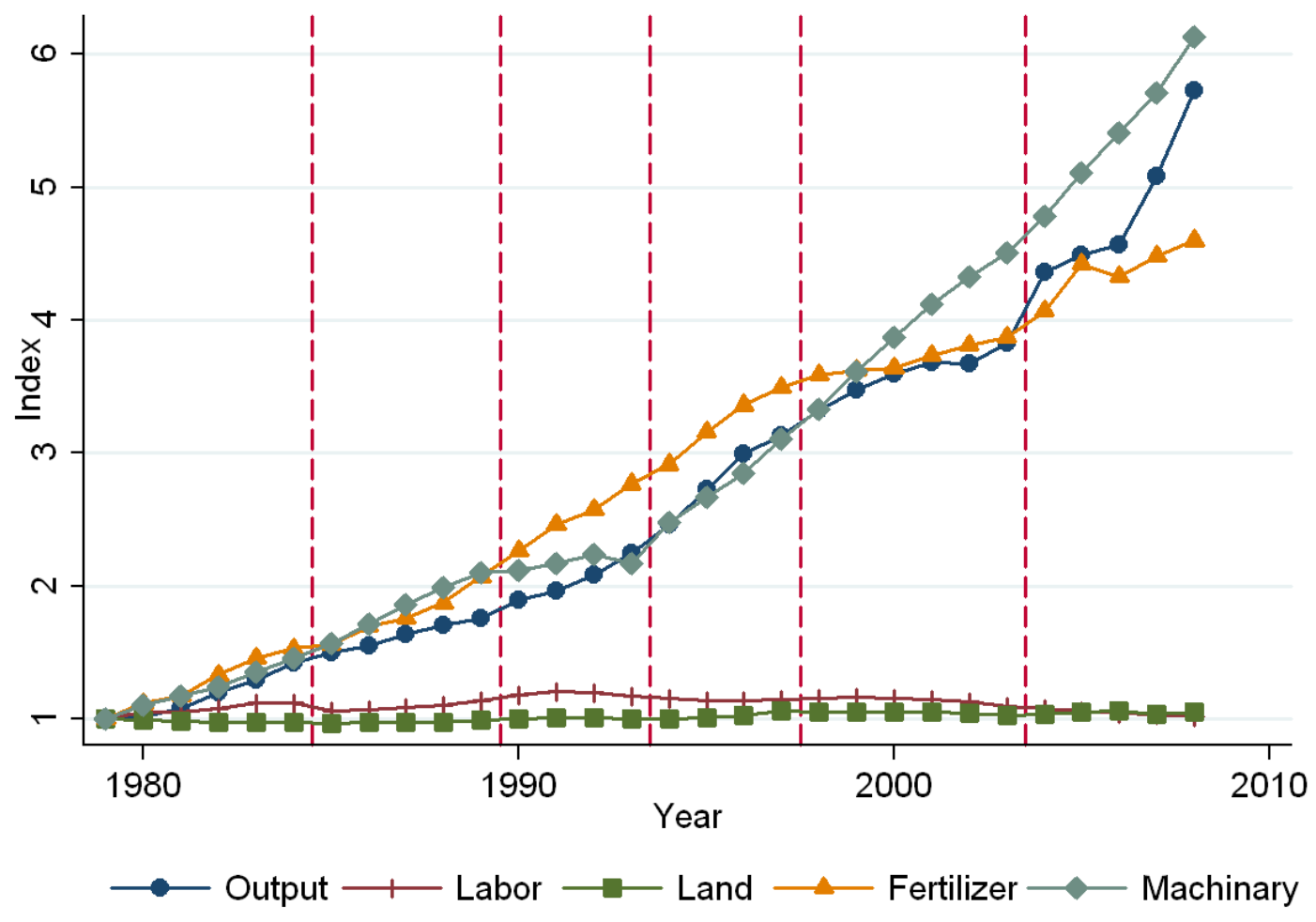

Figure 2.1: Output and inputs in the whole sample period Note: The mean value of the variables for each year has been converted to indices with that of year 1979 as a reference equal to one.

Source: Own figure. 
agricultural production.

\subsubsection{Translog specification of the production fron- tier}

For our study, a translog specification of the production frontier is used. The specified stochastic production frontier model is depicted as follows

$$
\begin{aligned}
\ln \left(Y_{i t}\right) & =\beta_{0}+\beta_{L} \ln \left(L_{i t}\right)+\beta_{A} \ln \left(A_{i t}\right)+\beta_{K} \ln \left(K_{i t}\right)+\beta_{F} \ln \left(F_{i t}\right) \\
& +\frac{1}{2}\left\{\beta_{L L}\left[\ln \left(L_{i t}\right)\right]^{2}+\beta_{A A}\left[\ln \left(A_{i t}\right)\right]^{2}+\beta_{K K}\left[\ln \left(K_{i t}\right)\right]^{2}+\beta_{F F}\left[\ln \left(F_{i t}\right)\right]^{2}\right\} \\
& +\beta_{L A} \ln \left(L_{i t}\right) \ln \left(A_{i t}\right)+\beta_{L K} \ln \left(L_{i t}\right) \ln \left(K_{i t}\right)+\beta_{L F} \ln \left(L_{i t}\right) \ln \left(F_{i t}\right) \\
& +\beta_{A K} \ln \left(A_{i t}\right) \ln \left(K_{i t}\right)+\beta_{A F} \ln \left(A_{i t}\right) \ln \left(F_{i t}\right)+\beta_{K F} \ln \left(K_{i t}\right) \ln \left(F_{i t}\right) \\
& +\beta_{L t} \ln \left(L_{i t}\right) t+\beta_{A t} \ln \left(A_{i t}\right) t+\beta_{K t} \ln \left(K_{i t}\right) t+\beta_{F t} \ln \left(F_{i t}\right) t \\
& +\beta_{t} t+\frac{1}{2} \beta_{t t} t^{2}+v_{i t}-u_{i t} \\
& i=1,2, \ldots, N, t=1,2, \ldots, T,
\end{aligned}
$$

where $Y_{i t}=$ agricultural output for the $i$-th province in the $t$-th year; $L_{i t}=$ land; $A_{i t}=$ labor; $K_{i t}=$ capital; $F_{i t}=$ fertilizer; $t=$ a linear time trend; the $\beta \mathbf{s}$ are unknown parameters to be estimated; the $v_{i t}$ are random errors assumed to be i.i.d. $N\left(0, \sigma_{v}^{2}\right)$, and independent of the $u_{i t}$. The error terms $u_{i t}$ are non-negative random variables that account for technical inefficiency in production, obtained by truncating (at zero from below) random variables from normal distributions with the mean $m_{i t}$ and variance $\sigma_{u}^{2}$, where 


$$
m_{i t}=\theta_{0}+\sum_{j=1}^{8} \delta_{j} Z_{i t}+\sum_{j=1}^{5} \theta_{j}^{P} P_{j}+\sum_{j=1}^{5} \theta_{j}^{R} R_{j}+\sum_{j=1}^{2} \theta_{j}^{S} S_{j} .
$$

$Z_{i t}$ is a vector of exogenous variables used to explain variation in technical efficiency. ${ }^{8}$ Based on previous empirical research results and the availability of data, our final choices are: rural electricity consumption (elec), length of roads (road), rural education expenditures (redue), the share of the rural labor force with a primary school education (primary), a middle school education (middle), a high school education (high), a technical secondary school education (tech), and a college education (college), respectively, where the share of the illiterate rural population is used as a reference. In addition, three categories of dummy variables are introduced to capture the effects of policy reform in the last three decades and the impact of different regional development levels. Specifically, $P_{j} \mathrm{~s}$ reprensent aggregate reform policy effects in different phases, with the first phase as a reference period. Two dummy variables $\left(S_{j}\right)$ are incorporated to identify specific policy effects: the adoption of the voluntary procurement contract for grain production in 1985, which became mandatory again in 1986 to ensure food security; and the discontinuation of agricultural tax starting in 2006, which is believed to be an important milestone in China's rural development. $R_{j}$ s are five regional dummy variables with the regional group of the three municipalities as a reference. ${ }^{9}$ Con-

\footnotetext{
${ }^{8}$ Four broad categories of variables usually used to explain differences in technical efficiency: the development of infrastructure, the quality of management, the financial conditions, and foreign competition (see Fried et al., 1993).

${ }^{9}$ We adopt the classification of regional groups for China's provinces, municipalities and autonomous regions developed by Territorial Development Service, OECD (2001), which takes account not only of geographic location but also of the economic characteristics shared by certain provinces.
} 
cerning our dataset, the three municipalities are Beijing, Tianjin, and Shanghai; the six coast provinces are Hebei, Jiangsu, Zhejiang, Fujian, Shandong, and Guangdong; the three north-eastern provinces are Heilongiiang, Jilin, and Liaoning; the six center provinces are Shanxi, Anhui, Jiangxi, Henan, Hubei, and Hunan; the six north-western provinces are Inner Mongolia, Shaanxi, Gansu, Qinghai, Ningxia, and Xinjiang; and the four south-western provinces are Sichuan, Guizhou, Yunnan, and Guangxi. $\delta_{j}$ s and $\theta_{j}$ s are unknown parameters to be estimated.

The variables elec, road, and redue are used to measure the impact of the development of physical infrastructure. Improvements in rural infrastructure are expected to increase technical efficiency. The variables regarding the share of the rural labor force with different educational levels are used to capture the quality of the labor force. Since the share of the illiterate rural labor force does not enter the function and is used as an implicit reference, this vector of educational level variables is assumed to be positively related to technical efficiency. The five policy reform dummy variables and the two specific policy dummy variables represent the effects of institutional arrangements that characterize different policy reform phases and major economic events. Taking into account the difference in the stages of development in various provinces, the five regional dummy variables are included to distinguish the effect of the institutional environment that each regional group presents. The impact of the three categories of dummy variables on technical efficiency depends on empirical analysis, and we will discuss it in detail in the following section. In order to avoid numerical difficulties in the maximum likeli- 
hood estimations and to facilitate the interpretation ${ }^{10}$ of the parameter estimates, the output and the four inputs variables are divided by their respective sample means and the time trend variable is scaled to have a mean of zero. ${ }^{11}$

\subsection{Empirical results and discussion}

\subsubsection{Description of the parameter estimates and hy- potheses tests}

The results of estimated parameters are presented in Table 2.2. It seems that the specified translog production frontier model is acceptable given the large share of significant parameters.

Several hypotheses tests have been conducted, and the results are shown in the lower part of Table 2.2. The first one is that there are no technical inefficiency effects in the model $\left(H_{0}: \gamma=\delta_{j}=\theta_{j}=0 ; H_{1}: \gamma>0\right.$ and/or at least one of the $\theta_{j}$ and $\delta_{j}$ are not equal to zero). Under $H_{0}$, the generalized likelihood-ratio statistic is asymptotically distributed as a mixture of chi-square distributions, namely $\frac{1}{2} \chi_{0}^{2}+\frac{1}{2} \chi_{1}^{2}$ (Coelli, 1995). In our case, the critical value ( $\alpha=0.05, d f=22$ ) is 33.33 (see Kodde and Palm, 1986, Table 1). The calculated statistic value is 779.86 , which is greater than

\footnotetext{
${ }^{10}$ At the sample mean, the transformed variables after taking logarithms take the value zero. Hence, in the calculations of the elasticities, those terms involving the inputs for each observation vanish so that the first-order coefficients $\beta_{i}, \mathrm{i}=\mathrm{L}, \mathrm{A}, \mathrm{K}, \mathrm{F}$, can be interpreted as elasticities at the sample mean.

${ }^{11}$ The results are generated using Ox version 6.10(see Doornik, 2007).
} 
Table 2.2: Parameter estimates of the stochastic production frontier

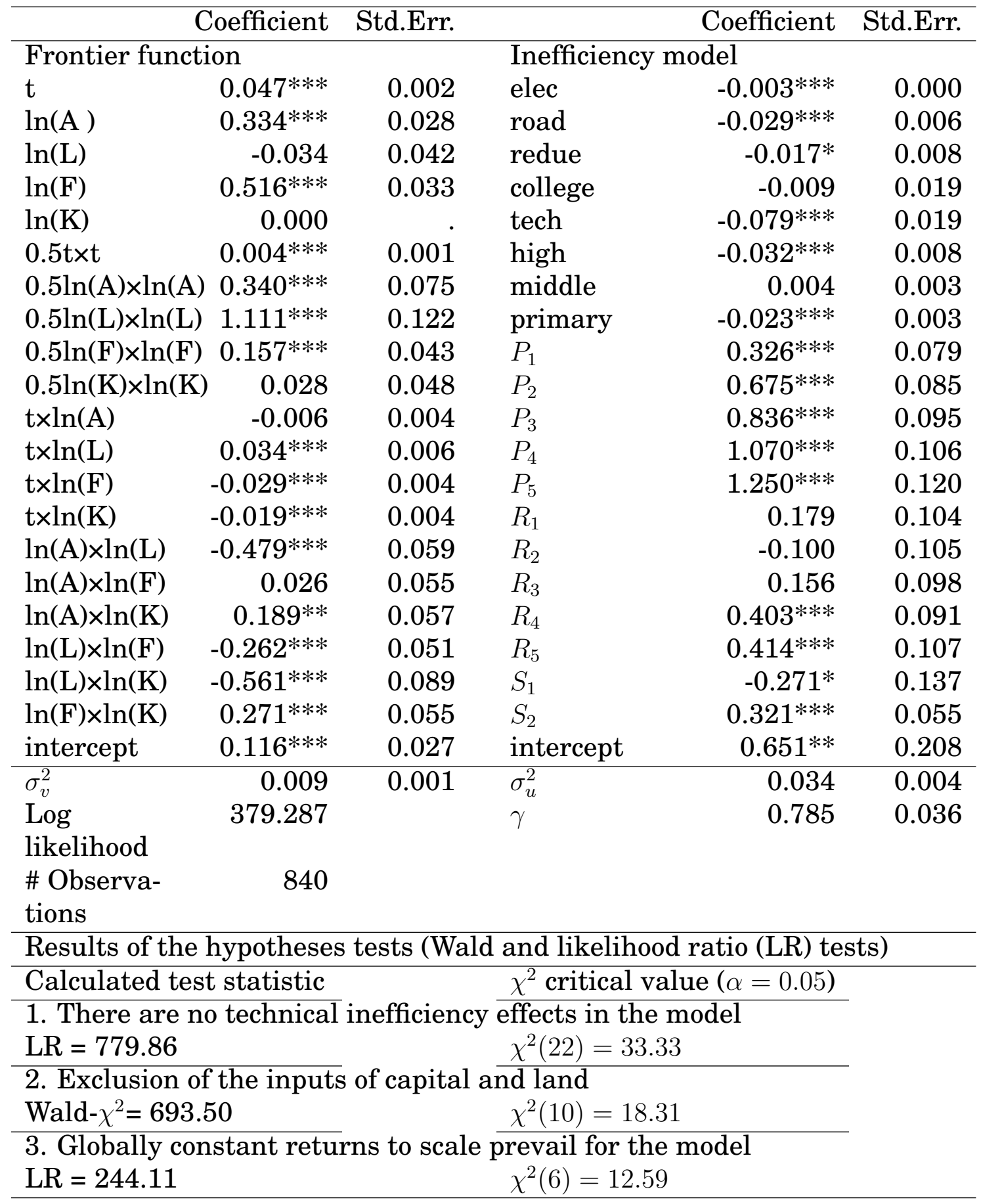

Note: $* \mathrm{p}<0.05, * * \mathrm{p}<0.01, * * * \mathrm{p}<0.001$ 
the critical value. This indicates that the specified model, which incorporates the technical inefficiency component, is appropriate. The value of $\gamma(0.785)$ implies that, on average, $57.12 \%$ of the total variance is due to the variance of the technical inefficiency term. ${ }^{12}$

The coefficients of $\ln (\mathrm{L})$ and $\ln (\mathrm{K})$, which present the respective output elasticity of these two inputs at the sample mean, are not significantly different from zero. We have therefore done the Wald test to see whether the inputs of land and capital could be left out of the model without significantly reducing the fit of the model. The test statistic of 693.50 exceeds the critical value of $18.31(\alpha=0.05, d f=10)$, which indicates that these variables should be included in the model.

Another hypothesis we are interested in is whether the production frontier exhibits the property of globally constant returns to scale (CRTS). As mentioned above, the TFP change in our case is decomposed into a technical change component, a scale component, and a technical efficiency change component. If globally constant returns to scale prevail, the scale effect drops out, and it is not necessary to calculate this component. The calculated $\chi^{2}$ test statistic is 244.11 , which is highly significant compared with the critical value of 12.59 ( $\alpha=0.05, d f=6)$, so we can reject the null hypothesis of globally CRTS.

Four inputs and time trend variables have been normalized by their respective sample means in our specified translog model so that, on average, the coefficients of $\ln (\mathrm{A}), \ln (\mathrm{L}), \ln (\mathrm{F})$ and $\ln (\mathrm{K})$ show us the elasticity

\footnotetext{
${ }^{12}$ The variance of $u_{i t}$ is equal to $[(\pi-2) / \pi] \sigma_{u}^{2}$ not $\sigma_{u}^{2}$, so the relative contribution of the inefficiency effect to the total variance term is $\gamma /[\gamma+(1-\gamma) \pi /(\pi-2)]$ (Coelli et al., 1998).
} 
of output with respect to each of the inputs at the sample mean and $\beta_{t}$ denotes the average annual growth rate of technical change in the whole research period. Fertilizer use is the most important input for agricultural production in our model. A one percent increase in fertilizer use will lead to a 0.516 percent increase in output. In addition, labor input also contributes $33.4 \%$ to agricultural output growth. Both for land and capital, the first-order coefficients are not significantly different from zero, i.e., they do not affect output significantly at the sample mean. However, variable exclusion tests show that the exclusion of these variables is rejected. The sum of $\beta_{A}, \beta_{L}, \beta_{F}$ and $\beta_{K}$ presents a measure of the scale elasticity of roughly 0.82 at the sample mean, indicating decreasing returns to scale. The value of $\beta_{t}$ shows an average annual growth rate of technical change at $4.7 \%$, which is a sign of good improvement in terms of technology over the last three decades.

In our model, 20 variables are included to explain the variation in technical inefficiency (see the right part of Table 2.2). The coefficients of rural electricity consumption (elec), length of road (road), and rural education expenditures (redue) are all significantly negative, i.e., they positively affect technical efficiency, indicating the importance of infrastructure development. Three of the five education-related variables (tech, high, and primary) are significantly positively related to technical efficiency, confirming the a priori expectation of increasing technical efficiency with improved education. The coefficients of five policy reform dummy variables $\left(P_{j} \mathrm{~s}\right)$ are all significantly positive. The results show that, compared with the implicit reference of the first phase, the reform policies in the 
following phases have negative effects on technical efficiency. Furthermore, judged by the value of these five coefficients, the negative effects have been increasing with the ongoing reforms, confirming the downward trend of technical efficiency level (see Figure 2.2). Among the coefficients of the five regional dummy variables $\left(R_{j} \mathrm{~s}\right)$, only the parameters for northwestern $\left(R_{4}\right)$ and south-western provinces $\left(R_{5}\right)$ are significant. The positive value of coefficients indicate the significantly negative regional effects on technical efficiency for these two western regions, compared with the reference region of the three municipalities. The two specific policy dummy variables $\left(S_{j}\right)$ are both significant. The negative value of $S_{1}$ identifies the positive effects of the policy of adopting the voluntary procurement contract for grain production in 1985. In contrast, the policy of the discontinuation of agricultural tax starting in $2006\left(S_{2}\right)$ had negative effects on technical efficiency. The main aim of this policy design and the other corresponding policies was to increase farmers' income and to eliminate the rural-urban divide in a social welfare concern. So our results show that, besides this type of policy design, reform polices focusing on the input factor market such as the reform in the household registration system (hukou system) and the reform related to land rights, just like the functioning of HRS in the first phase, need to be introduced or furthered in order to improve technical efficiency.

\subsubsection{Technical efficiency}

After the estimation, the average technical efficiency for each year is shown in Figure 2.2 at the national level and for each of the six regions. 


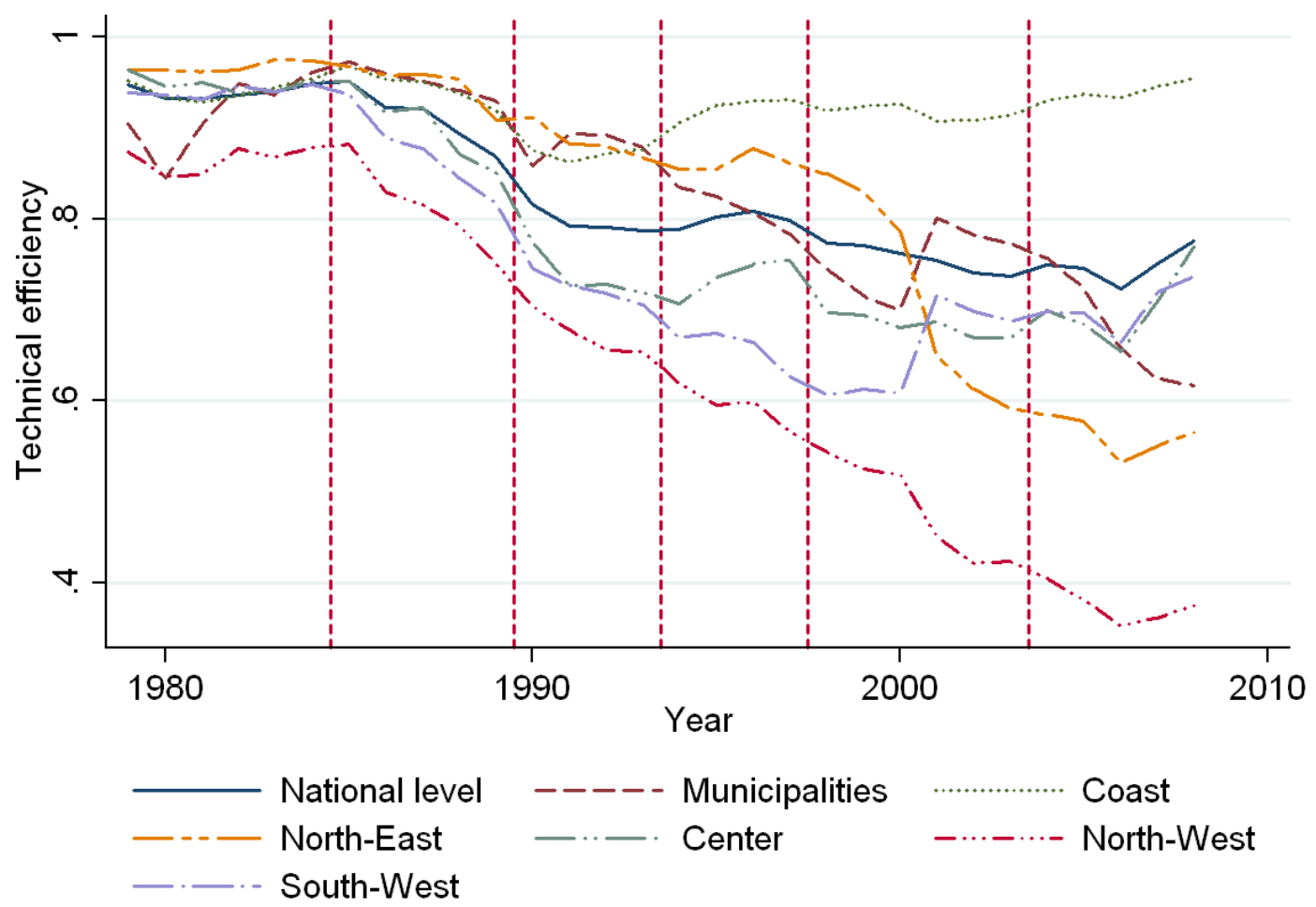

Figure 2.2: Average yearly degree of technical efficiency by regions, 19792008

Note: The weighted mean values of technical efficiency for each year have been calculated with each province's contribution of agricultural output as weight. Source: Own figure. 
The vertical dashed lines separate the six policy reform phases. At the national average (the solid line), technical efficiency scores kept a high level of around 0.94 during the first phase. After reaching the peak value of 0.95 in 1985, technical efficiency dropped substantially in the second phase. The trend of deterioration was stopped at the beginning of 1990s, and the scores of technical efficiency have been relatively steady around 0.80 for the third and the fourth phases. Starting at the beginning of the fifth phase, technical efficiency decreased again slowly. After reaching its lowest value of 0.72 in 2006 , technical efficiency increased continuously in 2007 and 2008.

Relating these observed trends to agricultural policy reforms, the good performance of technical efficiency in the first phase could be attributed largely to the decentralization of the agricultural production system and to the reforms of the agricultural procurement system, especially the implementation of HRS. This institutional arrangement greatly motivated agricultural production from farm households. The second phase was designed to further liberalize the country's agricultural pricing and marketing systems, and at the same time the government wanted to retain the level of grain production in order to ensure food security. These multifaceted concerns often led to contradictory and inconsistent policy implementation. One example is the adoption of the voluntary procurement contract for grain production in 1985, which became mandatory again in 1986 in order to ensure food security. Meanwhile, input prices increased much faster than the government's output procurement prices, raising production costs. All of these factors led to the deterioration of technical 
efficiency in the second phase. During the third and fourth phases, the government continued with the reforms of the procurement and marketing systems and raised procurement prices for grain enormously to increase farmers' incomes and to meet food security goals. As a result, the decrease in technical efficiency stopped and the scores remained around 0.8 for these two phases. In response to the huge rural-urban divide, ${ }^{13}$ the government started to integrate rural development into its overall economic reforms starting at the beginning of the fifth phase. A series of rurally-targeted policies were implemented to increase farmers' income and to facilitate rural development (see section 2.2.1). In terms of their impact on technical efficiency, these policies initially do not seem to have substantial effects. However, the two consecutive increases in the technical efficiency scores at the end of the sample period is a sign that technical efficiency is again improving gradually.

The performance of technical efficiency for the six regional groups is also shown in Figure 2.2. The trend of divergence is obvious in the whole sample period. Technical efficiency for the coast provinces has remained high during all of the reform phases except for a small drop in the third phase, which could reflect the impact of some local governments' policies of liberalizing both procurement and retail prices in local grain markets. The performance of technical efficiency for the north-western provinces is quite poor, and the gap between it and other regions is increasing as reforms continue to be implemented. The average score dropped from

\footnotetext{
${ }^{13}$ Per capita income in urban areas was 1.85 times that in rural areas in the mid$1980 \mathrm{~s}$, but by 2003 and 2004 the ratio had risen to 3.2, the highest over the whole reform period (OECD, 2005).
} 
around 0.87 in the first phase to less than 0.38 in the sixth phase. Another region to which our attention has been drawn is the north-eastern provinces. Its level of technical efficiency was very high among the six regions in the first four phases. But its score decreased substantially by 0.27 in the fifth phase, and it now ranks second to last in the six regions. The performance of the other three regional groups are relatively consistent with that on the national average level.

\subsubsection{TFP change and its decomposition}

According to our analytical framework, TFP change is decomposed into three components: technical change, a scale component, and technical efficiency change. Indices of these three components and TFP change have been calculated and converted into cumulative (chained) indices, which are reported in Table 2.3 and plotted in Figure 2.3 with vertical dashed lines separating the six policy reform phases. We observe that the indices of technical efficiency change are greater than 0.9 for the entire decade of the $1980 \mathrm{~s}$, but the situation deteriorates consecutively in the following four phases, with a decline in technical efficiency of $18.5 \%$ during the sample period (1979-2008). On the contrary, technical change performs quite well throughout the whole period, increasing steadily and reaching a dramatic improvement of $360.5 \%$ over the 30 -year period. Although the hypothesis of globally CRTS does not hold, the total scale effects seem to contribute in only a very limited manner to TFP change. The trend has developed similarly to that of technical efficiency change. A slight decline of $3.6 \%$ over the whole period indicates that the prevailing agricultural 
Table 2.3: TFP change and its decomposition, 1979-2008

\begin{tabular}{lrrrr}
\hline Year & TE change & Technical change & Scale effect & TFP change \\
\hline 1979 & 1.000 & 1.000 & 1.000 & 1.000 \\
1980 & 0.985 & 1.037 & 1.002 & 1.023 \\
1981 & 0.985 & 1.074 & 1.004 & 1.063 \\
1982 & 0.990 & 1.114 & 1.005 & 1.109 \\
1983 & 0.994 & 1.154 & 1.004 & 1.152 \\
1984 & 1.003 & 1.197 & 1.003 & 1.205 \\
1985 & 1.006 & 1.241 & 1.003 & 1.253 \\
1986 & 0.976 & 1.292 & 1.004 & 1.265 \\
1987 & 0.973 & 1.343 & 1.002 & 1.306 \\
1988 & 0.946 & 1.402 & 1.001 & 1.323 \\
1989 & 0.919 & 1.461 & 0.995 & 1.326 \\
1990 & 0.862 & 1.534 & 0.986 & 1.295 \\
1991 & 0.837 & 1.603 & 0.979 & 1.301 \\
1992 & 0.836 & 1.680 & 0.974 & 1.348 \\
1993 & 0.832 & 1.758 & 0.970 & 1.393 \\
1994 & 0.833 & 1.838 & 0.967 & 1.437 \\
1995 & 0.847 & 1.919 & 0.962 & 1.506 \\
1996 & 0.853 & 2.029 & 0.955 & 1.589 \\
1997 & 0.843 & 2.144 & 0.948 & 1.636 \\
1998 & 0.816 & 2.267 & 0.944 & 1.655 \\
1999 & 0.814 & 2.393 & 0.944 & 1.733 \\
2000 & 0.805 & 2.537 & 0.943 & 1.804 \\
2001 & 0.795 & 2.748 & 0.946 & 1.937 \\
2002 & 0.780 & 2.938 & 0.947 & 2.015 \\
2003 & 0.777 & 3.170 & 0.950 & 2.155 \\
2004 & 0.789 & 3.382 & 0.951 & 2.316 \\
2005 & 0.785 & 3.636 & 0.953 & 2.458 \\
2006 & 0.761 & 3.921 & 0.959 & 2.547 \\
2007 & 0.789 & 4.258 & 0.961 & 2.868 \\
2008 & 0.815 & 4.605 & 0.964 & 3.220 \\
\hline Average annual growth rate $(\%)$ & & & \\
Phase I & 0.060 & 3.662 & 0.060 & 3.800 \\
Phase II & -2.236 & 4.164 & -0.200 & 1.426 \\
Phase III & -1.174 & 4.648 & -0.544 & 2.461 \\
Phase IV & 0.399 & 5.267 & -0.659 & 4.418 \\
Phase V & -0.975 & 6.935 & 0.127 & 5.422 \\
Phase VI & 0.814 & 8.022 & 0.340 & 8.587 \\
$1979-$ & -0.703 & 5.407 & -0.126 & 4.115 \\
2008 & & & & \\
\hline & & & & \\
& & & &
\end{tabular}

Note: The weighted mean values of TFP change and its decomposition for each year have been calculated with each province's contribution of agricultral output as weight. 


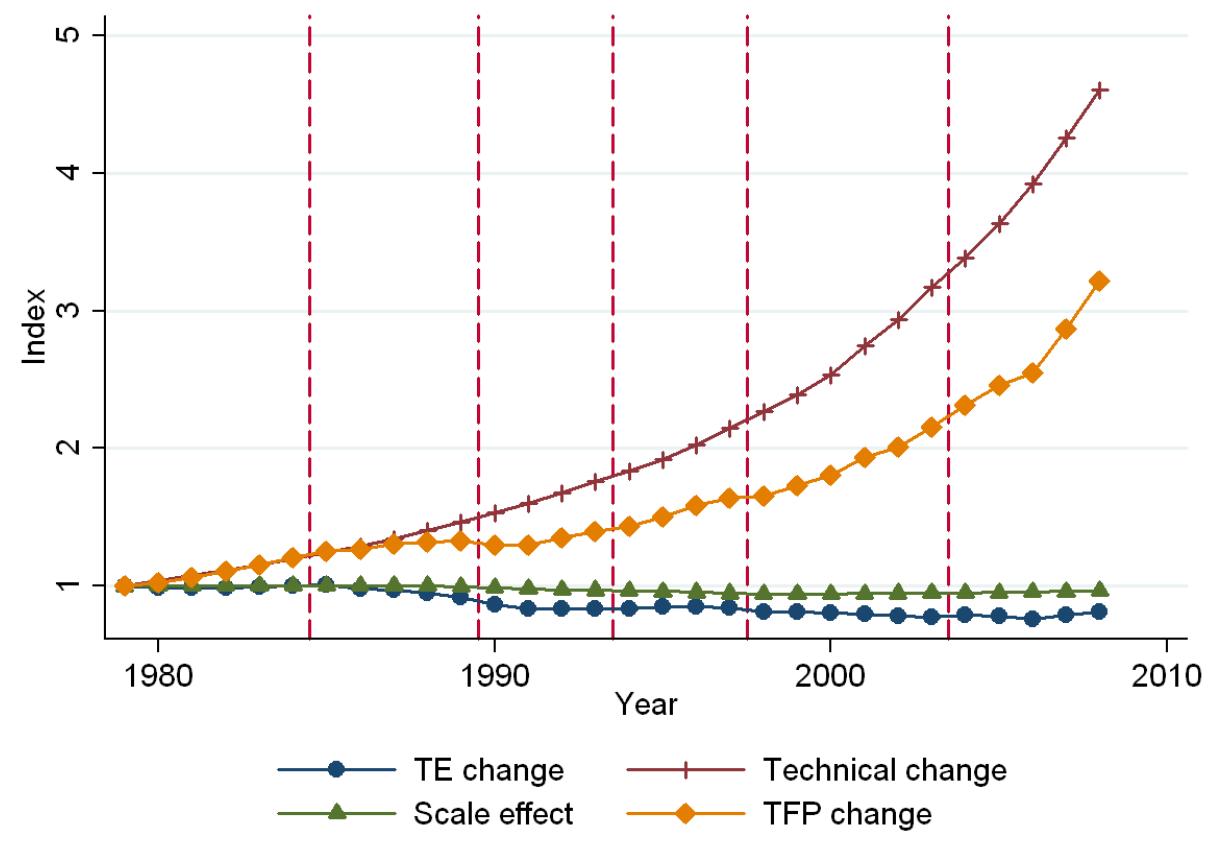

Figure 2.3: TFP change and its decomposition on the national average, 1979-2008

Source: Own figure. 

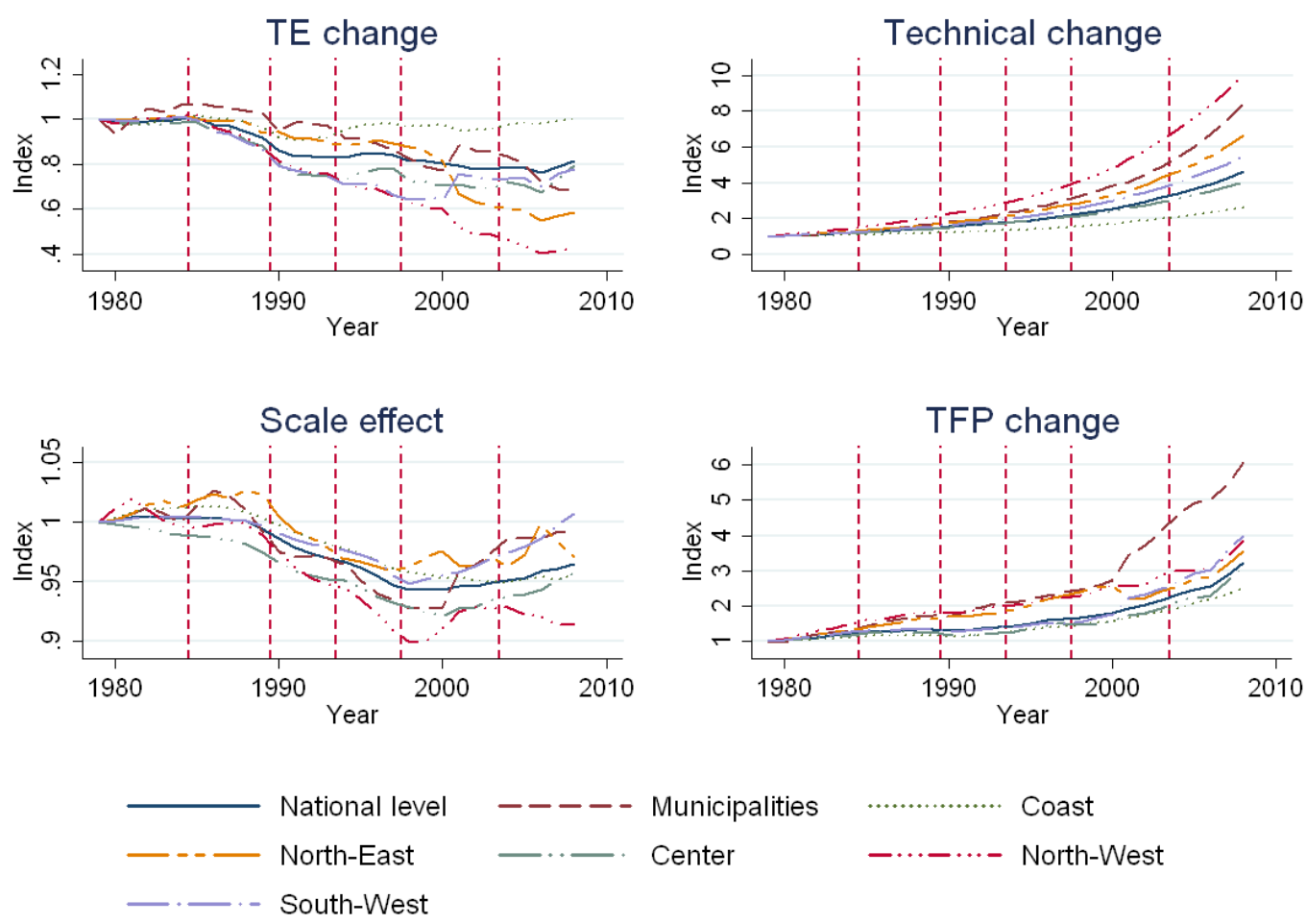

Figure 2.4: TFP change and its decomposition by regions, 1979-2008 Source: Own figure.

production structure has a negative effect on TFP change in China. When these three components are combined together, we observe a net cumulated increase of $222 \%$ in TFP over the sample period.

To view and compare the trend of changes for different regional groups, we have presented TFP change and its decomposition in the respective regions in Figure 2.4. Since the cumulative indices are calculated in this study, technical efficiency change in Figure 2.4 presents the same information that technical efficiency does in Figure 2.2. The patterns of the development of technical change are consistent for the six regional groups with the only difference being the rate of increase. It is interesting to 
see that the rank of performance in terms of technical change for the six regional groups is almost the opposite to that of technical efficiency change. Unlike its poor performance in technical efficiency change, the north-western provinces rank first in technical change, equivalent to a tenfold increase in the TC index over the last three decades. Similarly, the performance of technical change for the three municipalities and the north-eastern provinces are quite good in contrast with their poor performance in terms of technical efficiency change. Although it increases by $163 \%$ over the whole sample period, technical change for the coast provinces still comes in last among the six regional groups. The trend of the scale effects for the six regional groups looks similar, too. Even though the scale effects are small, the decreasing trend stopped at the end of the fourth phase and started to increase slowly over the last two phases. The trends in technical change dominated the development of the TFP index. The gap between the three municipalities and the other five regional groups increased substantially, which is mainly due to the contribution of scale effects for the three municipalities.

The average annual growth rate of TFP change and its components with respect to the six phases of the reform are further disaggregated in Table 2.3. We can see that the indices of average annual growth rate for technical efficiency change are consistent with what we have discussed in section 2.5.2. The indices of average annual growth rate for technical change develop more steadily than the technical efficiency change indices. The annual growth rate of technical change increases greatly from the first phase (3.66\%) until the last phase (8.02\%). This development 
reflects the success of the government's long-term efforts on investment in agricultural technology and rural infrastructure. The indices of the average annual growth rate for the scale effects have fluctuated during the sample period, and the value is positive for the last two phases. The indices of the average annual growth rate for TFP change have kept pace with that of technical change over the whole period except for the second and third phases, where the achievements of technical change are largely offset by the poor performance in terms of technical efficiency change.

\subsubsection{Analysis of annual average growth rate across regions}

In this section, we would like to compare the performance of TFP change and its decomposition for each province within the six regional groups. The annual average growth rate of TFP change and its three components with respect to 28 provinces, municipalities, or autonomous regions ${ }^{14}$ for the whole reform period have been calculated and presented in Table 2.4. For the purpose of comparison, the rankings of these 28 provinces with respect to annual average TFP change and its decomposition are also shown in parentheses after each value of the growth rate in Table 2.4.

The annual average growth rate of technical efficiency change for the 28 provinces are in accordance with the regional performance of technical efficiency discussed in section 2.5.2. Only six out of 28 provinces have

\footnotetext{
${ }^{14}$ For simplicity, the term 'provinces' is used to refer to provinces, municipalities, or autonomous regions in the following discussion.
} 
Table 2.4: Annual average growth rate of TFP change and its components across regions, $1979-2008(\%)$

\begin{tabular}{|c|c|c|c|c|c|c|c|c|}
\hline \multirow{2}{*}{$\begin{array}{l}\text { Region } \\
\text { Municipalities }\end{array}$} & \multicolumn{2}{|c|}{ TE change } & \multicolumn{2}{|c|}{$\begin{array}{l}\text { Technical } \\
\text { change }\end{array}$} & \multicolumn{2}{|c|}{ Scale effect } & \multicolumn{2}{|c|}{ TFP change } \\
\hline & & & & & & & & \\
\hline Beijing & -1.911 & (15) & 6.901 & (11) & -0.086 & (12) & 4.768 & (10) \\
\hline Tianjin & -3.860 & (27) & 7.863 & (9) & -1.116 & (28) & 2.543 & (24) \\
\hline Shanghai & -0.352 & (8) & 7.934 & (8) & 0.358 & (3) & 7.940 & (1) \\
\hline \multicolumn{9}{|l|}{ Coast } \\
\hline Hebei & 0.063 & (4) & 3.011 & (26) & -0.642 & (26) & 2.414 & (26) \\
\hline Jiangsu & 0.090 & (3) & 2.973 & (27) & 0.137 & (8) & 3.207 & (22) \\
\hline Zhejiang & 0.020 & (6) & 4.586 & (22) & 0.164 & (6) & 4.779 & (9) \\
\hline Fujian & -1.143 & (12) & 5.019 & (18) & 0.049 & (10) & 3.869 & (15) \\
\hline Shandong & 0.157 & (1) & 1.973 & (28) & -0.272 & (18) & 1.855 & (27) \\
\hline Guangdong & 0.107 & (2) & 3.751 & (24) & -0.263 & (17) & 3.588 & (18) \\
\hline \multicolumn{9}{|l|}{ North-East } \\
\hline Liaoning & -0.869 & (10) & 4.942 & (19) & -0.234 & (16) & 3.787 & (16) \\
\hline Jilin & -2.425 & (16) & 6.663 & (12) & -0.414 & (22) & 3.645 & (17) \\
\hline Heilongjiang & -2.566 & (19) & 7.972 & (6) & 0.216 & (4) & 5.428 & (7) \\
\hline \multicolumn{9}{|l|}{ Centre } \\
\hline Shanxi & -2.957 & (25) & 6.074 & (15) & -0.459 & (24) & 2.464 & (25) \\
\hline Anhui & -0.873 & (11) & 4.486 & (23) & -0.154 & (14) & 3.414 & (20) \\
\hline Jiangxi & -1.329 & (14) & 6.962 & (10) & 0.527 & (1) & 6.097 & (4) \\
\hline Henan & -1.204 & (13) & 3.360 & (25) & -0.602 & (25) & 1.502 & (28) \\
\hline Hubei & -0.489 & (9) & 4.930 & (21) & -0.145 & (13) & 4.265 & (13) \\
\hline Hunan & -0.166 & (7) & 4.939 & (20) & -0.070 & (11) & 4.691 & (12) \\
\hline \multicolumn{9}{|c|}{ 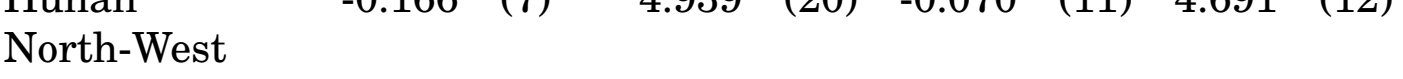 } \\
\hline Inner Mongolia & -2.751 & (22) & 9.026 & (3) & -0.279 & (19) & 5.731 & (5) \\
\hline Shaanxi & -2.665 & (20) & 6.402 & (14) & -0.311 & (20) & 3.244 & (21) \\
\hline Gansu & -2.842 & (23) & 8.039 & (5) & -0.198 & (15) & 4.761 & (11) \\
\hline Qinghai & -4.129 & (28) & 11.023 & (1) & 0.148 & (7) & 6.597 & (2) \\
\hline Ningxia & -3.693 & (26) & 9.436 & (2) & 0.079 & (9) & 5.477 & (6) \\
\hline Xinjiang & -2.881 & (24) & 7.969 & (7) & -0.705 & (27) & 4.119 & (14) \\
\hline \multicolumn{9}{|l|}{ South-West } \\
\hline Guangxi & -2.471 & (18) & 5.715 & (16) & -0.399 & (21) & 2.691 & (23) \\
\hline Sichuan & 0.041 & (5) & 5.116 & (17) & 0.165 & (5) & 5.332 & (8) \\
\hline Guizhou & -2.683 & (21) & 8.611 & (4) & 0.456 & (2) & 6.179 & (3) \\
\hline Yunnan & -2.443 & (17) & 6.608 & (13) & -0.436 & (23) & 3.550 & (19) \\
\hline
\end{tabular}


experienced positive growth rate during the sample period. Five of them belong to the coast province group. Although Fujian has a negative value, its ranking is relatively high (12) among the 28 provinces. In contrast, the performance of four south-western provinces and six north-western provinces are very poor with the single exception of Sichuan. A large amount of variation is observed for the municipality group, where Beijing, Tianjin, and Shanghai rank 15th, 27th and 8th respectively. Hence, the classification of the regional groups, with the exception of the municipality group, is roughly consistent in terms of the performance of techical efficiency change. The obvious gap between the western provinces and the other regions implies that the government should take measures to improve their technical efficiency in order to catch up with the production frontier.

The annual average growth rate of technical change for the 28 provinces again looks similar to the technical change pattern observed at the regional level (see Figure 2.4). All provinces have experienced significant technological progress albeit to a different extent. The six north-western provinces and the six coast provinces have exchanged their positions in comparison with their performance in terms of technical efficiency change. For instance, Qinghai ranks first in technical change and last in technical efficiency change, whereas Shandong does the opposite. Since the coast provinces and the center provinces have already had a relatively high level of agricultural production, the impressive performance of western provinces is not unexpected. The development of technical change for all provinces is also a result of the goverment's long-term support in agricul- 
tural R\&D.

In contrast to the performance of technical efficiency change and technical change, the pattern of the annual average growth rate of the scale effects for the 28 provinces does not show any regional differences. Ten

provinces have positive growth rates and are dispersed throughout all of the six regional groups. The fact that almost two-thirds of the provinces have experienced negative growth rates in the scale effects suggests there is still room for the structural adjustment of agricultural production.

The performance of the annual average growth rate of TFP change for the 28 provinces is dominated by that of technical change. At the same time, because of the existence of the opposite effect of technical efficiency change for most of provinces, the variation of growth rate of TFP change among the 28 provinces is not as great as that of technical change. The value of the growth rate ranged from $7.94 \%$ for Shanghai to $1.50 \%$ for Henan.

\subsection{Summary}

In this chapter, we estimate productivity change in China's agriculture and decompose the observed TFP growth in order to evaluate the effects of the government's policy reform on agricultural production over the last three decades. Total factor productivity (TFP) change is decomposed into three components: technical efficiency change, technical change, and scale effect. A translog production frontier model is applied to calculate 
indices of TFP change and its three components, with a specific focus on explaining the variation in technical efficiency. We then evaluate and discuss the impacts of the government's policy reform on the changes in productivity and efficiency during China's rural reform period, which can be roughly divided into six phases from 1979 to 2008 .

Our results show that the best performance in terms of technical efficiency is exhibited in the first phase (1979-1984). After reaching the peak value of 0.95 in 1985, technical efficiency deteriorated substantially during the second phase and remained at a lower level of about 0.80 for the third and fourth phases. In the last two phases, technical efficiency initially continued to decrease but, after reaching its lowest value of 0.72 in 2006, it increased again in 2007 and 2008. Connecting the performance of technical efficiency with the government's agricultural policy in different reform phases, we argue that the implementation of a new institutional arrangement aiming at input factor market reform has contributed to the high level of technical efficiency. A good example of this is the implementation of HRS in the first phase. HRS liberalized the rural labor force and other production endowments, which greatly motivated agricultural production. After the first phase, reform policies were mainly designed to solve pricing and marketing problems without including further reform of input markets. The effects of these policies have been illustrated by poor performance of technical efficiency in the following phases. Hence, in addition to the series of policy designs concerning rural social welfare that aim to increase farmers' income and to eliminate the rural-urban divide, reform polices focusing on input factor market reform, such as the 
reform in household registration system (hukou) and the reform related to land rights, need to be introduced or furthered in order to improve technical efficiency.

From the analysis of TFP change and its decomposition, we find that the impressive improvement of TFP change (222\%) over the last three decades is dominated by the good performance of technical change (360.5\%). At the same time, both technical efficiency change (-18.5\%) and the scale effects (-3.6\%) have worked against the improvement in TFP change. In the comparisons of regions and among provinces, we observe an obvious trend of dispersion in technical efficiency change. The ever-growing gap between the western provinces and the other regions suggests that agricultural production for the western regional groups was not able to gradually catch up with the production frontier, and therefore more preferential policies should be carried out in these regions to improve their technical efficiency. The dramatic performance of technical change for all provinces has reflected the success of the government's long-term efforts on investment in agricultural technology and rural infrastructure. An interesting finding is that the rank of performance in terms of technical change for the six regional groups is almost the exact opposite to that of technical efficiency change. Based on the fact that the coast provinces and the center provinces have already experienced a relatively high level of agricultural production, the impressive performance of the western provinces is not unexpected. In contrast to technical efficiency change and technical change, the pattern of the annual average growth rate of the scale effects for the 28 provinces does not show any regional differences. Ten 
provinces have positive growth rates and are dispersed throughout all of the six regional groups. The fact that almost two-thirds of the provinces have experienced negative growth rates in the scale effects suggests that there is still room for the structural adjustment of agricultural production.

Some limitations of our study arise from the quality of the available data, the unavailability of important data series, and the overall aggregate nature of the dataset. In aggregating the total agricultural output, using constant prices as weights may be not appropriate, when considering that the changes of relative output prices in China over time and across regions always leads to a biased estimate of the growth rate. Based on the question of accuracies in the livestock and fishery output in China's official statistics, Fan and Zhang (2002) constructs a Törnqvist-Theil index using adjusted livestock and fishery output data and gets the result that official output data tends to understate the regional development gap. As for the choice of appropriate input proxies, the exclusion of the quantity of manurial fertilizer in pure nutrients as a proxy for fertilizer use and numbers of draft animals for capital because of missing data for several of the years examined are especially problematic. The last limitation is related to the aggregate character of the dataset used in our study. A production frontier is usually considered to be well-developed if using a more disaggregate, farm-level data set, whereas an average provincial-level data set is applied in our study. Since our results are consistent with that of most other authors, our findings can still be considered robust. For future research, this study could be refined and furthered with reconstructing 
aggregate agricultural output indices, choosing suitable proxies for agricultural capital input, and using disaggregated farm household level data set. Further research should focus on the estimation of impacts of factor market reform policies on technical efficiency and productivity change, and hence the rural income. 


\section{Chapter 3}

\section{The impact of land}

\section{reallocation on technical}

\section{efficiency}

The main contents of this chapter are based on the article "The impact of land reallocation on technical efficiency : evidence from China", and this article is a cooperation with Xiaobing Wang, Thomas Glauben, and Bernhard Brümmer. It has been accepted for publication in the journal Agricultural Economics. It appears in print for issue 42(4), July 2011. 


\subsection{Introduction}

URAL reform in transition economies, such as China, Vietnam, the
former Soviet Union, and Eastern Europe, involves substantial changes in land institutions (e.g., Lerman et al., 2004). Induced by the preexisting diversity and dimensions of land institutions, political pressure toward land reform has widely differed across the countries and has also fluctuated over time within countries. The success in the development of Chinese agricultural production has been acknowledged to a series of radical land reforms (Fan, 1991; Lin, 1992; Huang and Rozelle, 1995). The core of these reforms is the coexistence of land ownership remaining at the village level and land use rights being vested in households. This characteristic, on the one hand, motivates farmers to invest in land. On the other hand, the rural households still face the potential risk of land allocation, reallocation, and adjustment as deemed fit by the local officials, typically at the village level. The initial duration of the land allocation was 15 years, but it was extended in 1993 to another 30 years after the expiration of the land contract between farmers and the local government. ${ }^{1}$

In the Chinese land tenure system, farmland is allocated equally based on household size, household labor supply, or both. However, household demographics or labor composition constantly change as a result of births and deaths, aging, marriage, family separation, etc. Cultivated land per

\footnotetext{
${ }^{1}$ The starting point of the initial land tenure differs significantly across provinces and even counties in the same province due to differences in the process of introducing the household responsibility system (HRS).
} 
capita, which was already relatively limited, has declined further due to population growth, urbanization, and industrialization over time. This decline in per capita arable area was exacerbated by problems of land degradation. Furthermore, although China has codified a robust framework for the protection of land rights, such as the Land Management Law (1998), the Land Contracting Law (2003), and the Property Law (2007), knowledge and practical implementation of these rights are still lagging behind in rural areas (Tan et al., 2008; Jin and Deininger, 2009). The top-down changes to legal and political structures did not solve China's continued struggles with unrest resulting from the appropriation of land by developers and local officials (Kung, 2002). Farmers in many areas are still being forced to relocate by local officials, often illegally, and local cadres still retain large amounts of money intended to be distributed to farmers as compensation for any public-interest land seizures.

The issues related to land reallocation have received special attention by economists and policy makers. Some of the existing literature focused on land reallocation policies associated with the land tenure system and the effects these policies have on land security (Liu et al., 1998; Brandt et al., 2002; Tan et al., 2006). Liu et al. (1998) used village-level data to analyze the frequency of land reallocation and its difference across villages. Brandt et al. (2002) concluded that land tenure security is influenced by land reallocation through the frequency and the extent to which households have been targeted. Tan et al. (2006) used land reallocation as one subgroup of independent variables to find the determinants of land fragmentation and, in turn, its effects on agricultural productivity. 
In addition, some authors explored the impacts of land reallocation on investment and other factor markets such as the land rental market. $\mathrm{Li}$ et al. (1998) and Jacoby et al. (2002)concluded that land insecurity, which arose from the frequency of land reallocation, dampened farmer incentive to invest in the land, especially via the use of organic fertilizers to improve the soil fertility. Kung (2002) identified a positive relationship between the size of the reallocated land and the demand of land rented; hence, land reallocation was found to serve as a complement of the land rental market in improving the allocation of land.

Other studies aimed to improve understanding of the determinants and extent of land reallocation at different levels because it is well observed that land has been reallocated or adjusted during the legal contract period of 15 and even 30 years later. Kung (2000) found that the incidence of land reallocation has been significantly influenced by the land endowment, off-farm income opportunities, as well as population growth rate of the village. This conclusion is consistent with the finding of Yao (2000b), who provided evidence on the interaction of land reallocation, in magnitude and frequency, with income levels and the endowment of local land resources. Brandt et al. (2002) concluded that the scope and duration of the dependence of land reallocation is sensitive to the availability of off-farm employment. These studies used either village level data (Kung, 2000; Yao, 2000b) or household level data (Brandt et al., 2002) to elaborate the relationship between land reallocation and its determinants. Because the data set used in our study contains both village level and household level information, it provides us with an opportunity to simul- 
taneously study land reallocation at the farm household level, as well as the potentially important factors at the village level.

A successful transition process in agriculture requires inter alia improvements in productivity and in efficiency, as well as functioning input markets in order to make full use of scarce resources (Swinnen and Rozelle, 2006). Given that Chinese agricultural production is still largely based on household-level production with a low land/labor ratio, and that rural households are heavily dependent on land as the main income source, the frequency and scope of land reallocation affects how the land is used. In this sense, land reallocation, which usually takes places independently from the consent of the farm household, can be expected to lead to a variation in productivity and efficiency in several dimensions. On the one hand, frequent land reallocation and adjustment dampen the incentive of household investment on land, as well as the efficiency of organizing the farm structure in the long-run. On the other hand, land reallocation and adjustment, which is a common means of shifting land between households, is a potential instrument to achieve efficient allocation of land resources. To date, few studies have provided an empirical analysis of the impacts of land reallocation on the efficiency and output of agricultural production in China.

The overall goal of this chapter is to contribute to the ongoing assessment of land reallocation. Special attention is given to its effects on the efficiency and output of agricultural production across the provinces with very different resource endowments and technology levels. It is specifically based on a panel data set of household and village surveys con- 
ducted in three provinces by the Ministry of Agriculture from 1995 to 2002. We first give a descriptive overview of the extent to which land reallocation occurs in rural China. Second, an instrumental-variables (IV) estimation of a fixed-effects model is implemented to identify the main determinants of land reallocation in rural China. Finally, we use a stochastic frontier production function to examine how land reallocation influences technical efficiency and production of individual farms.

The rest of the chapter is organized as follows. Section 3.2 presents the conceptual framework and econometric model. Section 3.3 describes the incidence of land reallocation at the village level and presents the descriptive statistics of the variables used in empirical estimations. Section 3.4 presents the empirical results. The final section concludes.

\subsection{Conceptual framework and econometric model}

\subsubsection{Conceptual framework}

Land reallocation is common in rural China, and motivations for the reallocation differ among provinces and villages within a province (Brandt et al., 2002). The occurrence of land reallocation for our research consists of the following: first, the second round of land allocation connected to the extension of land contracts for another 30 years at the end of the 1990s; second, village cadres periodically taking back and redistributing 
farm land, due to a demographic change in the household based on egalitarian rule; and third, the expropriation of land either for non-farming purposes or collective production and the corresponding compensation of land afterward. The existing literature concerning the determinants of land reallocation shows that the frequency and scope of land reallocation is affected by the demographic change in the village; differential access to off-farm and self-employment opportunities; income level of the village; change of land endowment in the village, such as land per capita; and the functioning of the land rental market (Yao, 2000b; Tan et al., 2006). In addition, farm and household characteristics, such as the demographic change of the household, might affect land reallocation.

Among these factors affecting land reallocation, we focus in particular on the following questions because of their important implications for future policy reforms. First, does demographic change play a crucial role in land reallocation? The framework of household responsibility system (HRS) contains two general principles related to land allocation: equal access to land and 15 year (extended to 30 years in the second round of land allocation) duration of land contract. With demographic change ongoing in the village, village leaders are under the pressure of land reallocation for egalitarian reason. If village leaders decide to reallocate without much regard to the land contract, which is common in most villages, the scope of the reallocation could be either village-wide or restricted to a selected number of farm households within the village. The latter form is more frequently documented in the literature (Kung, 2000; Brandt et al., 2002). Even though the 1998 Land Management Law constrains land re- 
allocation to cases of demographic changes at the household level, some villages seem not to strictly follow this rule. Hence, variables indexing both village level and household demographic change will be introduced in our model to capture their impact on land reallocation.

Second, are land rental markets a substitute for or a complement of land reallocation? Brandt et al. (2002) argue that administrative reallocations are a substitute for the exchange of land that would occur if households rented land to each other because farm rental markets are incomplete or relatively thin. In contrast, Kung (2002) identifies a positive relationship between the size of the reallocated land and the demand of land rented, which implies that land reallocation is a complement of the land rental market. He suggests that the local off-farm economy is developing so rapidly that the mere reallocation of land via administrative means is insufficient to cope with the structural transformation of the economy.

Third, how does central government policy affect the determinants and impacts of reallocation? For instance, the Land Management Law (1998) and the Land Contracting Law (2003) both attempt to increase land tenure security for farm households and strengthen their rights to land. The forces behind the implementation of these policy arrangements in practice are also an area of our research interest. Thus, in our empirical work, we have assumed that social and economic development of the villages, household and farm characteristics, and relevant policy effects determine the incidence of land reallocation.

There are quite a few studies that evaluate the productivity and technical efficiency of Chinese agricultural production (Lin, 1992; Huang and 


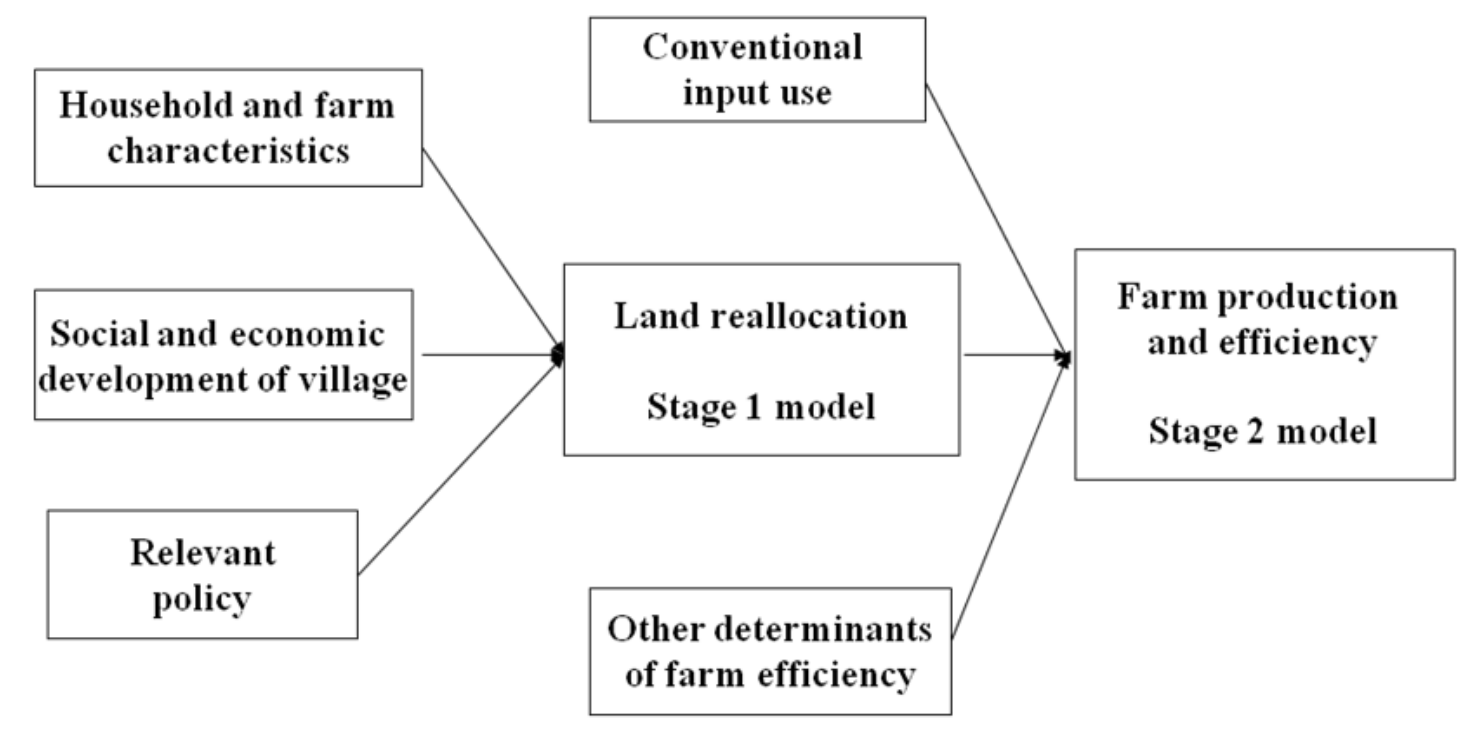

Figure 3.1: Assumed relationships in the two stages model

Source: Own figure.

Rozelle, 1995; Brümmer et al., 2006). To the best of our knowledge, however, few of them have empirically assessed the influence of land reallocation on the productivity and technical efficiency in China or even in other transition countries. In this study, conventional physical inputs, including cultivated land; labor; capital; expense on intermediate inputs, such as fertilizer, seed, etc.; and the predicted value of land reallocation attained from the stage 1 model, associated with other control variables, are used to estimate the stochastic frontier production function and the calculation of farm technical efficiency. The hypothesized relationships are shown in Figure 3.1 .

The three provinces in our study are characterized by differences in resource endowments and in levels of economic development. Hence, it is interesting to compare the determinants of land reallocation across the 
provinces and, in particular, the effects of the land rental market. Although land leasing has been legally sanctioned and encouraged by the government, the extent of progress of the land rental market is different across China. However, whether it complements or substitutes for administrative land reallocation is an empirical question to explore, when regional characteristics are taken into account. The conceptual framework indicates that administrative land reallocation influences household agricultural production, not vice versa, because in most Chinese villages, the frequency and magnitude of land reallocation is determined by village leaders and the influence of an individual farm is limited. The impacts of administrative land reallocation on technical efficiency need elaborate inspection. On the one hand, if frequent reallocation of land is detrimental to output by dampening the incentive of farmers in production, future reforms should be oriented to guarantee land security. On the other hand, land reallocation could also optimize the allocation of land resources because of incomplete development of the land rental market in some regions. Thus, the direction and magnitude of the impact of land reallocation on production and efficiency should be determined based on an empirical analysis.

\subsubsection{Econometric model}

According to the conceptual framework listed in Figure 3.1, we apply the following two-stage model to analyze the determinants of land reallocation and its impact on farm production in rural China. 
Stage 1: Fixed-effects model $^{2}$ with instrumental variables (IV) estimation

$$
\begin{gathered}
Y_{i t}=\alpha Z_{i t}+\theta L_{i t}+c_{i}+\varepsilon_{i t} \\
\operatorname{Cov}\left(L_{i t}, \varepsilon_{i t}\right) \neq 0 \\
\operatorname{Cov}\left(I_{i t}, \varepsilon_{i t}\right)=0 \\
\operatorname{Cov}\left(L_{i t}, I_{i t}\right) \neq 0
\end{gathered}
$$

In Equation (3.1), $Y_{i t}$ is a proxy for land reallocation for household $i$ at time $t$ as shown. $Z_{i t}$ is a vector of exogenous variables that describe the social and economic development of a village, the household and farm characteristics, and relevant state policy variables. $L_{i t}$ represents potentially endogenous variables that might be correlated with $\varepsilon_{i t} \sim \mathrm{N}\left(0, \sigma_{\varepsilon}\right)$, the random error term in Equation (3.1). $I_{i t}$ are excluded instrumental variables that do not appear as regressors in Equation (3.1), are uncorrelated with $\varepsilon_{i t}$ in Equation (3.3), and possibly correlated with $L_{i t}$ in Equation (3.4). $\alpha$ and $\theta$ are the associated vectors of the parameters to be es-

\footnotetext{
${ }^{2}$ The Breusch-Pagan test and the Hausman test are used to compare random-effects and fixed-effects specifications. The resulting Chi-squared statistic strongly rejects the random effects model at the $1 \%$ significance level, suggesting that the unobserved factors are correlated with the explanatory variables in the estimations.
} 
timated. $c_{i}$ represents the unobserved time-invariant household effects. ${ }^{3}$ All estimations are carried out with Stata (Version 10.0), using clusterrobust estimates of the variance-covariance matrices (Schaffer, 2007).

\section{Stage 2: Normal/Half-normal Stochastic Frontier Production}

$$
\begin{gathered}
Q_{i t}=f\left(X_{i t}, T ; \beta\right)+v_{i t}-u_{i t} \\
u_{i t} \sim \mathrm{N}^{+}\left(0, \sigma_{u_{i t}}\right)=\mathrm{N}^{+}\left(0, \sigma_{u} e^{r J_{i t}}\right)
\end{gathered}
$$

Where $Q_{i t}$ represents the value of aggregated farming ${ }^{4}$ output for farm $i$ in year $t, f\left(X_{i t} ; \beta\right)$ is a suitable production function form (a translog specification in our study), $X_{i t}$ is the vector of conventional inputs, $T$ is a linear time trend to capture technological progress, $\operatorname{and} \beta$ is the associated vector of technology parameters to be estimated. $v_{i t}$ is a random error term assumed to be i.i.d. $\mathrm{N}\left(0, \sigma_{v}\right)$. The error terms $u_{i t}$ are nonnegative random variables that account for technical inefficiency in production. They are half-normally distributed with the location parameter $\mu$ set equal to zero, and parameter $\sigma_{u_{i t}}^{2}$ to be estimated. This error term $u_{i t}$ is allowed to be heteroscedastic by introducing a multiplicative relationship between the variables $J_{i t}$ responsible for heteroscedasticity and the common distribution parameter $\sigma_{u}$ (Equation (3.6)). $J_{i t}$ can be interpreted as a vector of variables used to explain variation in technical inefficiency. In particu-

\footnotetext{
${ }^{3}$ These effects include location of the household and farm, the quality level of farm land, etc.

${ }^{4}$ Farming output includes (1) grain crops, cash crops, and other crops; (2) fruits, silkworm cocoon, tea, crude drugs, and vegetables.
} 
lar, we also include the predicted value of the change in arable land (due to land reallocation) from stage 1 of the model. $\gamma$ is the associated parameter vector of the determinants of technical inefficiency that is to be estimated.

\subsection{The incidence of land reallocation and data description}

The database used in this study is drawn from a fixed-point survey data series across Zhejiang, Hubei, and Yunnan provinces conducted annually by Research Center for Rural Economy (RCRE), China. The three provinces were chosen to reflect the diversity of China's agricultural production. Zhejiang province is one of the richest Chinese provinces in the East, Hubei province represents the central middle-income region, and Yunnan province belongs to West China and is one of the poorest regions in the country. ${ }^{5}$ The sample collection proceeds in a stratified way for the village data. After that, the household data of the respective villages are randomly selected. Initially, every county is stratified by annual net income per capita into upper, middle, and lower groups (Benjamin et al., 2005). Representative villages in each group are then chosen according to geographic (plain, hilly, or mountainous area), location (city, suburb, or not), and economic characteristics. We use individual household data

\footnotetext{
${ }^{5}$ Per capita Gross Regional Product in 2004 amounts to 23,942 RMB, 10,500 RMB and 6,733 RMB, respectively (NBSC, 2006).
} 
and the associated village data covering the period from 1995 to $2002 .^{6}$ The data constitute a balanced panel at the village level, with nine villages in Zhejiang, fifteen villages in Hubei, and five villages in Yunnan. At the household level, the data set is unbalanced; on average, there are 204 households per year in Zhejiang, 606 in Hubei, and 283 in Yunnan in the data set. The individual household data contains detailed information on agricultural production operations and farm features, as well as personal and household characteristics. The village data reflects the village's characteristics and its social and economic development.

Table 3.1 presents the summary statistics on land reallocation and land rental markets over the sample period. Land reallocation is quantitatively measured as area of changed arable land of the farm household due to land reallocation within a year. We illustrate the distribution of the reallocation at the village level over time, and the number of villages with respect to their aggregate land reallocation in three categories over the sample period is counted here. The result shows roughly half of the village observations have experienced significant loss of arable land during land reallocation. It at least certifies a decrease of arable land at the village level. Sample mean values for the three provinces are reported here; summary statistics by year did not reveal any obvious trend. In general, land reallocation or adjustment occurred in almost all the sampled villages more than once in the period from 1995 to 2002. On average, $18.09 \%$ of households had their land reallocated in Zhejiang, 15.47\%

\footnotetext{
${ }^{6} \mathrm{~A}$ one-year lag of input variables is used as excluded instrumental variables in the stage 1 model, so the 1995 data was automatically dropped out. The estimated results presented in the following are from 1996 to 2002.
} 


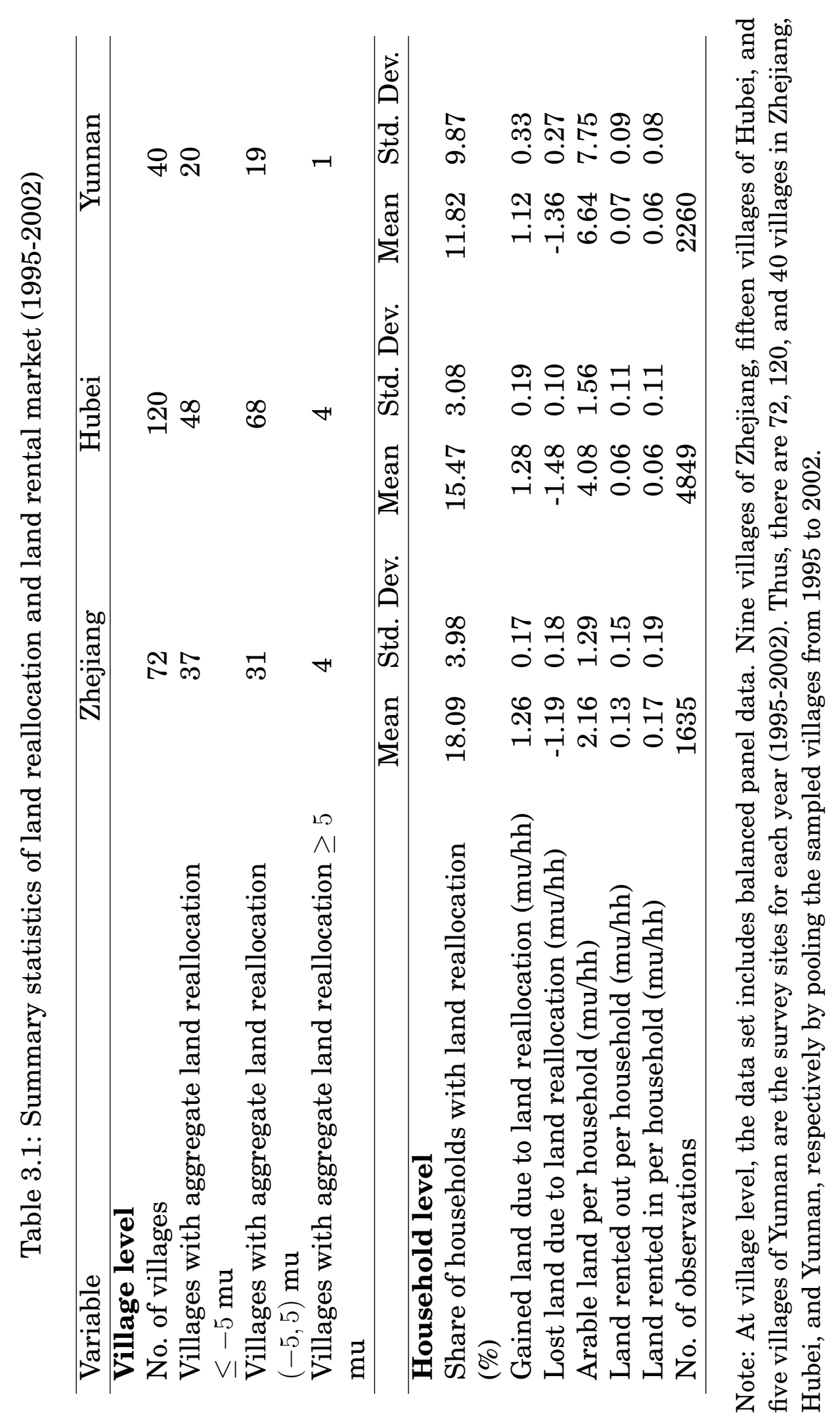


in Hubei, and $11.82 \%$ in Yunnan. This also implies that in all three provinces land reallocation in most cases is probably not a village-wide reallocation but a partial adjustment. As to the magnitude of land reallocation, gained land due to land reallocation is $1.26 \mathrm{mu}$ per household in Zhejiang, $1.28 \mathrm{mu}$ per household in Hubei, and $1.12 \mathrm{mu}$ per household in Yunnan. Lost land due to land reallocation is $1.19 \mathrm{mu}$ per household in Zhejiang, $1.48 \mathrm{mu}$ per household in Hubei, and $1.36 \mathrm{mu}$ per household in Yunnan. However, when compared with the average land endowment of the farm households, the different relative impacts of land reallocation on land endowment become obvious. A farm household in Zhejiang on average has arable land $2.16 \mathrm{mu}$, while the quantity is $4.08 \mathrm{mu}$ in Hubei and $6.64 \mathrm{mu}$ in Yunnan. Reallocated land accounts for more than half of that farm household's arable land in Zhejiang, and that is roughly onethird in Hubei, and one-sixth in Yunnan. Land rented out is on average $0.13 \mathrm{mu}$ per household in Zhejiang, $0.06 \mathrm{mu}$ per household in Hubei, and $0.07 \mathrm{mu}$ per household in Yunnan. Land rented in is on average $0.17 \mathrm{mu}$ per household in Zhejiang, $0.06 \mathrm{mu}$ per household in Hubei, and $0.06 \mathrm{mu}$ per household in Yunnan. Land rental activities are much more important in Zhejiang than in the other two provinces. Figure 3.2 presents a kernel density estimate of arable land changes due to land reallocation by provinces from 1996 to 2002 . There is not much difference in the distribution for the three provinces. Zhejiang shows the narrowest distribution of land being reallocated, while there was a comparatively larger variation in land reallocation in Hubei and Yunnan. There is a relatively fatter left-side tail in Yunnan, reflecting a comparably severe loss of land due to land reallocation for farmers. 


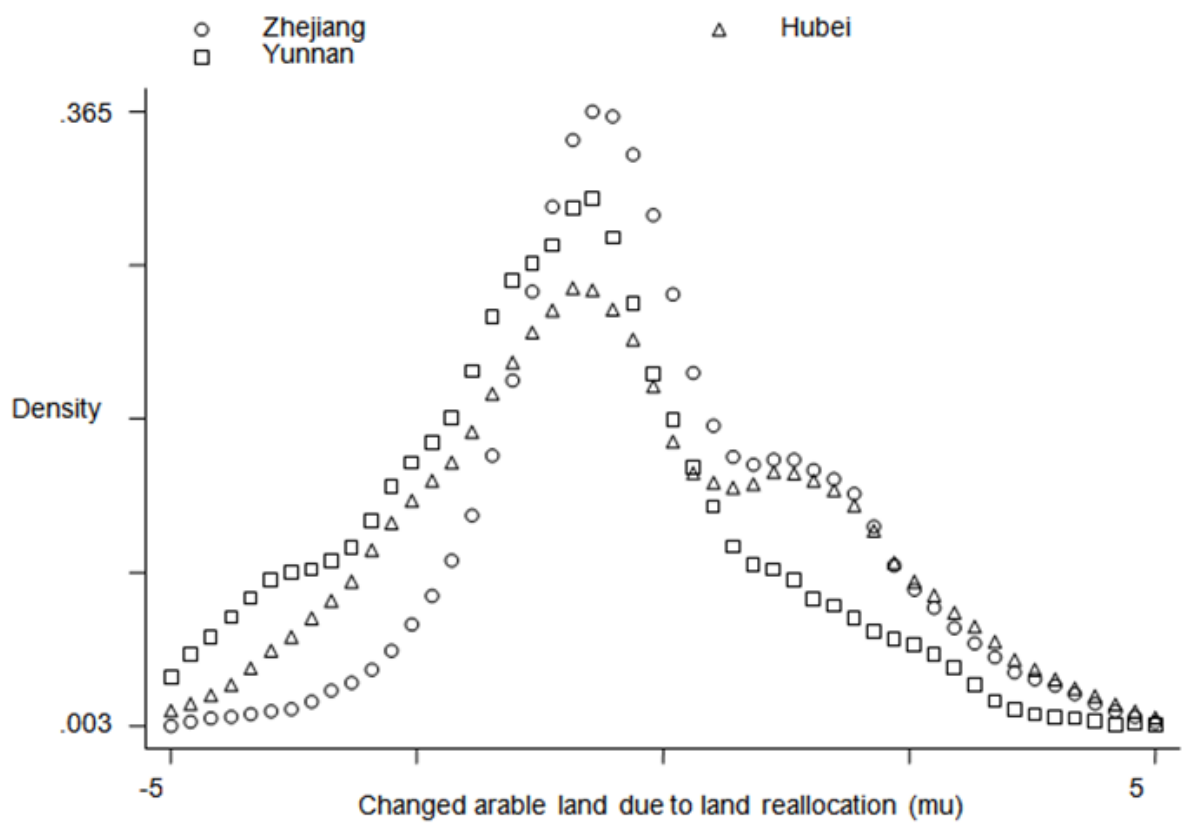

Figure 3.2: The kernel density of changed arable land due to land reallocation by provinces (1996-2002)

Note: Observations with zero value of changed arable land due to land reallocation are not accounted in the figure.

Source: Own figure. 
According to our conceptual framework, the following factors that affect land reallocation are introduced into the stage 1 model. Variables that reflect the social and economic development of the village include annual net income per capita representing the economic conditions of the village; birth and death rate of the village, share of people who migrated into and out of the village (with change of the location of household registration) within the year, which are controlling for effects of demographic change; share of arable land rented out during the year used as the proxy of the land rental market in the local village; area of arable land per capita, which index land endowment of the village; share of households doing business outside the village, and the number of enterprises in the village by end of year, signaling the availability of off-farm employment and income opportunities (one-year lag of these two variables has been used as excluded instruments in the estimation considering the potential endogeneity problem). In addition, two household level variables, number of rural permanent residents and sown area of arable land, are used to capture the effects of household and farm characteristics on land reallocation. Taking into account the potential endogeneity problem of the sown area of arable land, a lag of one period for the production input factors of labor, land, intermediate input, and capital are introduced as excluded instruments. Furthermore, six yearly dummy variables are included to capture the impact of state policy on land reallocation, with the year 1996 as the reference period. ${ }^{7}$

For the stage 2 model, the farming output is measured as an aggregate

\footnotetext{
${ }^{7}$ Data for the year 1995 was dropped because one period of lagged variables is used.
} 
value for grain crops, cash crops, other crops, fruits, silkworm cocoon, tea, crude drugs, and vegetables. The four conventional input variables are labor, land, intermediate input, and capital. Labor input is the total annual working days allocated to planting production. The total sown area for grain crops, cash crops, and other crops is used for the land variable. The intermediate input sums up the purchase value of seeds, fertilizer, agricultural diesel oil, plastics, and pesticides used in agricultural production. Capital is measured as the total original value of fixed-capital assets for agricultural production at the end of the year, and includes draught animals, production tools, and machinery. In addition, a linear time trend variable is introduced to capture changes in technology. Monetary values for all variables are deflated with respect to 1995 constant prices.

Variables explaining the variation in technical inefficiency consist of the predicted value of changed arable land due to land reallocation obtained from the stage 1 estimation. The predicted value is separated into two new variables (with positive and negative values retained respectively) that measure the effects of gaining or losing arable land due to land reallocation on technical inefficiency. We allow the two effects on technical inefficiency to be different in direction and/or in magnitude. Other variables include a dummy variable with value 1 if any of the household members is a township or village cadre, and otherwise 0 ; the share of rural laborers with primary school education, secondary school education, high school education, and above (share of illiterate rural laborers as reference) in a household; the share of rural laborers licensed with profes- 
sional titles; and the share of plots with size between 0.5-1 mu, ${ }^{8} 1-2 \mathrm{mu}$, 2-3 mu, 3-4 mu, 4-5 mu, and larger than $5 \mathrm{mu}$ (share of plots with size smaller than $0.5 \mathrm{mu}$ is used as a reference for this category).

In Table 3.2 and Table 3.3, the descriptive statistics of the variables are listed for the stage 1 and stage 2 models, respectively. From the statistics, we observe very different characteristics and social and economic development levels at both the household and village level across the three provinces. The share of arable land rented out in the village, which is a proxy for the role of activities on the land rental market, is on average 8.109\% in Zhejiang, while only $1.255 \%$ in Hubei and $2.316 \%$ in Yunnan. These values confirm the judgment of relatively big differences in the development of the land rental market across the regions.

In order to avoid numerical difficulties in the maximum likelihood estimations, and to facilitate the interpretation of the parameter estimates, the output variable and the four input variables are divided by their respective sample means; the time trend variable is scaled to have a mean of zero. Hence, estimated first-order parameters of the translog production frontier can be estimated as elasticities at the point of normalization, i.e., at the sample mean.

\footnotetext{
${ }^{8} 1 \mathrm{mu}=(1 / 15)$ hectare in China
} 


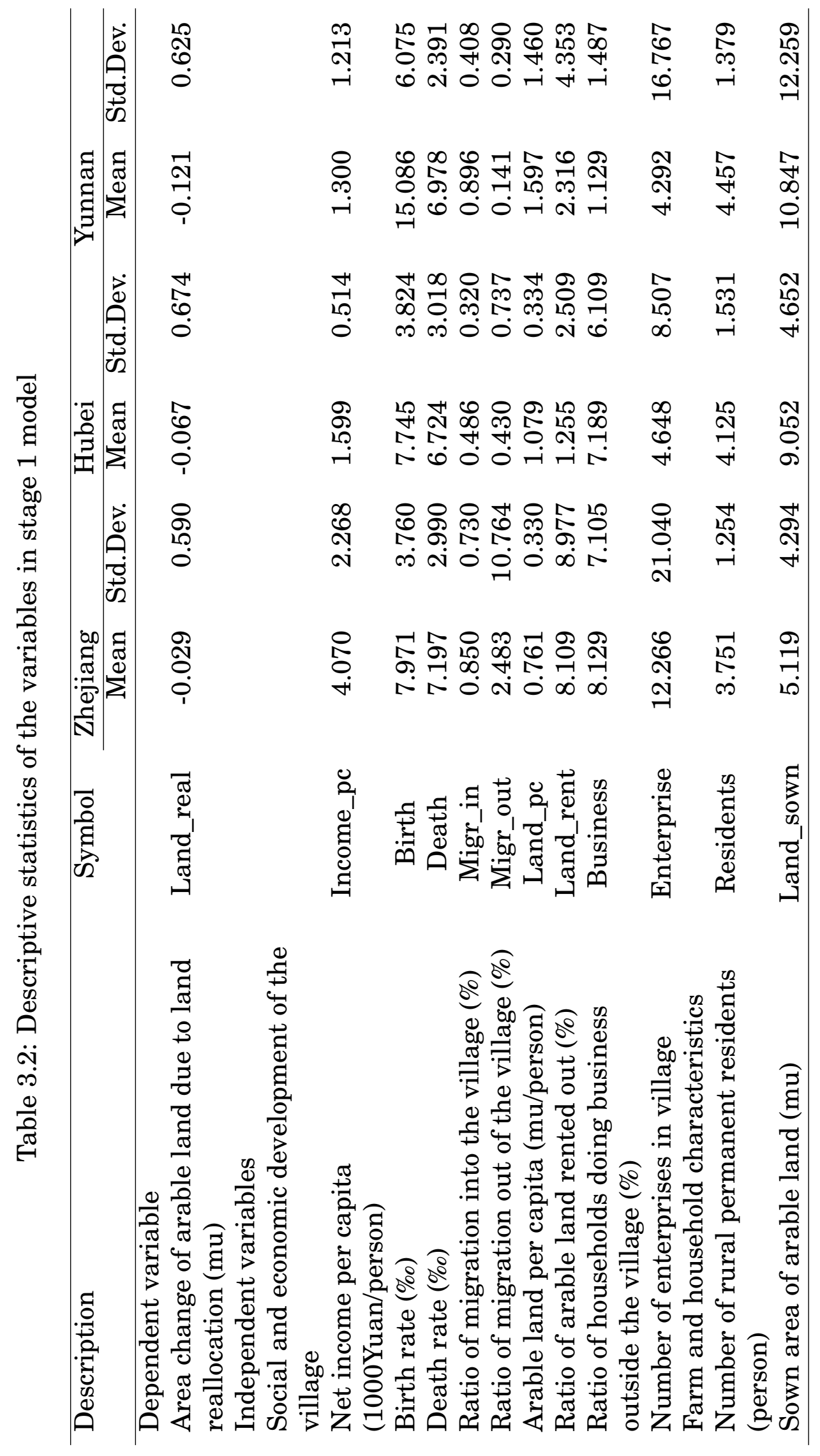




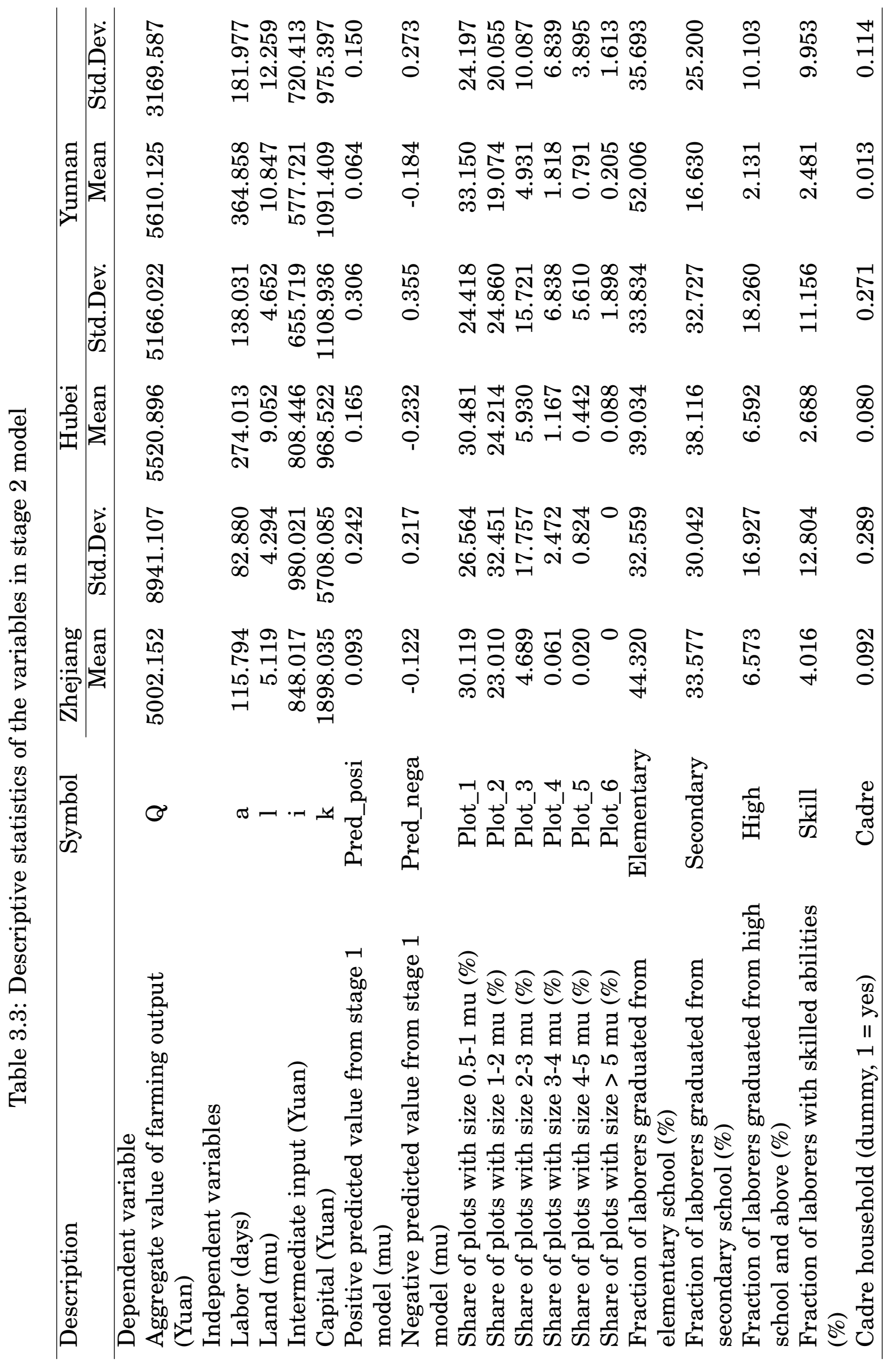




\subsection{Empirical results}

\subsubsection{Fixed-effects model with instrumental variables estimations}

Before presenting the main results, we give an overview of selected diagnostic tests in the lower half of Table 3.4.

Table 3.4: Determinants of land reallocation with

fixed-effects models

\begin{tabular}{|c|c|c|c|c|c|c|}
\hline \multirow{3}{*}{ Income_pc } & \multirow{2}{*}{\multicolumn{2}{|c|}{$\begin{array}{c}\text { Zhejiang } \\
\text { Coefficient }\end{array}$}} & \multicolumn{2}{|c|}{ Hubei } & \multicolumn{2}{|c|}{ Yunnan } \\
\hline & & & Coefficient & & Coefficient & \\
\hline & 0.014 & $(0.020)$ & -0.046 & $(0.056)$ & $0.446 * * *$ & $(0.100)$ \\
\hline Birth & 0.004 & $(0.005)$ & 0.010 & $(0.006)$ & -0.007 & $(0.004)$ \\
\hline Death & -0.008 & $(0.008)$ & 0.011 & $(0.007)$ & -0.006 & $(0.008)$ \\
\hline Migr_in & -0.012 & $(0.030)$ & $0.122^{*}$ & $(0.061)$ & $-0.303^{* *}$ & $(0.093)$ \\
\hline Migr_out & -0.000 & $(0.002)$ & 0.027 & $(0.024)$ & 0.178 & $(0.108)$ \\
\hline Land_pc & 1.273 & $(0.954)$ & 0.186 & $(0.720)$ & $3.083^{*}$ & (1.234) \\
\hline Land_pc2 & -0.362 & $(0.445)$ & 0.280 & $(0.335)$ & $-0.335^{* *}$ & $(0.127)$ \\
\hline Land_rent & -0.005 & $(0.003)$ & $-0.029 *$ & $(0.012)$ & -0.005 & $(0.010)$ \\
\hline Business & 0.008 & $(0.004)$ & $-0.081^{* *}$ & $(0.028)$ & 0.012 & $(0.048)$ \\
\hline Enterprise & -0.000 & $(0.002)$ & $0.038^{* *}$ & $(0.013)$ & 0.006 & $(0.004)$ \\
\hline D_1997 & -0.005 & $(0.048)$ & 0.062 & $(0.053)$ & -0.079 & $(0.042)$ \\
\hline D_1998 & -0.049 & $(0.057)$ & $-0.179 *$ & $(0.072)$ & -0.061 & $(0.062)$ \\
\hline D_1999 & 0.065 & $(0.049)$ & $-0.136^{*}$ & $(0.061)$ & $-0.368 * * *$ & $(0.078)$ \\
\hline
\end{tabular}


Determinants of land reallocation with fixed-effects models (continued)

\begin{tabular}{lcccccc}
\hline & \multicolumn{2}{c}{ Zhejiang } & \multicolumn{2}{c}{ Hubei } & \multicolumn{2}{c}{ Yunnan } \\
\cline { 2 - 5 } D_2000 & $-0.141^{*}(0.064)$ & $-0.180^{*}$ & $(0.073)$ & -0.164 & $(0.094)$ \\
D_2001 & -0.068 & $(0.072)$ & $-0.171^{*}$ & $(0.074)$ & $-0.247^{* *}$ & $(0.094)$ \\
D_2002 & $-0.226^{*}$ & $(0.092)$ & -0.064 & $(0.080)$ & $-0.313^{* *}$ & $(0.099)$ \\
Residents & 0.006 & $(0.024)$ & $0.218^{* * *}(0.050)$ & $0.046^{*}$ & $(0.019)$ \\
Land_sown & $-0.035 \quad(0.022)$ & $-0.174^{* * *}(0.039)$ & $0.004^{* * *}(0.001)$ \\
N & 1619 & 4834 & 2238 \\
F statistic & $F(18,1313)=2.74$ & $F(18,3989)=1.65$ & $F(18,1845)=6.29$ \\
P-value & $<0.001$ & 0.041 & $<0.001$ \\
sigma_u & 0.403 & 0.903 & 1.484 \\
sigma_e & 0.491 & 0.800 & 0.525 \\
rho & 0.403 & 0.560 & 0.889
\end{tabular}

Model diagnostics: results of hypothesis tests with fixed-effects IV estimation

1. Endogeneity test of endogenous regressors

$H_{0}$ : Land_sown can actually be treated as exogenous

$\begin{array}{cccc}\chi^{2} & \chi^{2}(1)=19.676 & \chi^{2}(1)=47.411 & \chi^{2}(1)=3.099 \\ \text { P-value } & <0.001 & <0.001 & 0.078\end{array}$

$H_{0}$ : Business can actually be treated as exogenous
$\chi^{2}$
$\chi^{2}(1)=1.080$
$\chi^{2}(1)=10.051$
$\chi^{2}(1)=1.781$
$\mathrm{P}$-value
0.299
0.002
0.182

$H_{0}$ : Enterprise can actually be treated as exogenous
$\chi^{2}$
$\chi^{2}(1)=0.051$
$\chi^{2}(1)=0.847$
$\chi^{2}(1)=12.081$ 
Determinants of land reallocation with fixed-effects models (continued)

\begin{tabular}{lccc}
\hline & Zhejiang & Hubei & Yunnan \\
\cline { 2 - 4 } P-value & 0.822 & 0.358 & $<0.001$
\end{tabular}

2. IV redundancy test (LM test of redundancy of specified instruments)

$H_{0}$ : Instruments of lagged labor, intermediate and capital input are redundant

$$
\begin{array}{lcc}
\chi^{2} & \chi^{2}(3)=5.424 & \chi^{2}(6)=17.841 \\
\text { P-value } & 0.143 & 0.007
\end{array}
$$

3. Underidentification test (Kleibergen-Paap rk LM statistic)

$H_{0}$ : The specified model is underidentified

$$
\begin{array}{lccc}
\chi^{2} & \chi^{2}(1)=6.095 & \chi^{2}(4)=67.201 & \chi^{2}(1)=30.918 \\
\text { P-value } & 0.014 & <0.001 & <0.001
\end{array}
$$

4. Overidentification test of all instruments (Hansen $J$ statistic)

$H_{0}$ : Instruments used in the model are valid instruments

$$
\begin{array}{lc}
\chi^{2} & \chi^{2}(3)=0.907 \\
\text { P-value } & 0.824
\end{array}
$$

Note: Land_pc2 is the square of arable land per capita (Land_pc).

Standard errors are given in parentheses.

$* \mathrm{p}<0.05, * * \mathrm{p}<0.01, * * * \mathrm{p}<0.001$

We first test the endogeneity of the potentially endogenous regressors.

The test statistics suggest that share of households doing business out- 
side the village (Business) and number of enterprises in the village (Enterprise) both can be treated as exogenous in Zhejiang, whereas Business is endogenous in Hubei, and Enterprise is endogenous in Yunnan; the cultivated area of arable land can actually be treated as exogenous in Yunnan, while an endogenous regressor problem exists in Zhejiang and Hubei. In addition, we perform the IV redundancy test for Zhejiang and Hubei to identify whether the excluded instruments for lagged labor and intermediate and capital inputs are redundant. The results show that these variables are redundant only for Zhejiang. The results of the underidentification and overidentification tests of all the instruments are also listed in Table 3.4. Finally, we examine whether the fixed effects model or random effects model is to be used for the estimations. The resulting Chi-square statistics from both the Breusch-Pagan test and the Hausman test strongly reject the random effects model at the $1 \%$ significance level, suggesting that the unobserved fixed effects are likely correlated with the explanatory variables in the estimations.

The upper half of Table 3.4 reports the estimated results. Demographic change has no effect on land reallocation in Zhejiang, whereas it does impact land reallocation in Hubei and Yunnan. The number of rural permanent residents in the household (Residents) significantly positively affects land reallocation in Hubei and Yunnan, indicating that demographic change within a farm household is one important factor for land adjustments in the village. This is consistent with the initial land allocation policies implemented in rural China, according to which land allocation to the households should be mainly based on numbers of rural residents 
or rural laborers (Liu et al., 1998; Brandt et al., 2002). Among the village level variables that represent demographic change, only the share of people who migrated into the village (Migr_in) is significant. The positive sign of the coefficient in Hubei might indicate that there exists some flexibility with regard to preserved arable land (jidong tian in Chinese), which can be allocated to the newcomers, while the situation might be contrary in Yunnan, judged from the negative parameter estimate of Migr_in for this province. Share of arable land rented out (Land_rent), which is a proxy of the development of the land rental market, has negative effects on land reallocation in all three provinces; however, the coefficients are insignificant in Zhejiang and Yunnan. We thus find at least for Hubei that the land rental market acts as a substitute for administrative land reallocation in optimizing land resources among farm households. The economic conditions of the village (Income_pc) positively affect land reallocation only in Yunnan, but their effect is not significant in Zhejiang and Hubei. Although the coefficients of arable land per capita (Land_pc) and its square (Land_pc2) are not significant in Zhejiang and Hubei respectively, the Wald test shows that they are jointly significant in both provinces. The estimates for the three provinces are in accordance with previous research results that abundant land resources facilitate more intensive land reallocation in the village. Off-farm employment opportunities, as measured by the share of households doing business outside the village (Business) and the number of enterprises in the village (Enterprise), only affect land reallocation in Hubei, while they have no effect in Zhejiang and Yunnan. The negative coefficient estimate for Business in Hubei suggests that off-farm income opportunities alleviate the pres- 
sure of requests for land during land adjustments. The positive estimate for the parameter on Enterprise could be explained by the fact that a fraction of farm households quit agricultural production and work in the enterprises located in the village and, as a result, farm households that stay in agriculture obtain the extra land reallocated from those who exit. Farm size (Land_sown) only affects land reallocation in Hubei and Yunnan. The impact is negative in Hubei and positive in Yunnan, which implies the different effects of land/labor ratio within farm households for these two provinces. The sign of the majority of yearly dummy variables are negative and some of them become statistically significant from 1998 on in all the three provinces, implying that land tenure, to a large extent, has been secured after the announcement of the extension of the land use right for another 30 years.

\subsubsection{The SFA production function}

The translog stochastic frontier production function is estimated in the stage 2 model. Several hypotheses regarding the specification have been tested first. Our results reject the hypothesis that a Cobb-Douglas frontier, with its implicit strong assumptions, e.g., constant partial production elasticities and unit elasticity of substitution between the inputs, is an adequate representation of the agricultural production in the three provinces. The null hypothesis of no technical inefficiency effects in the model is also rejected, indicating that the technical inefficiency term should be considered in the estimations of the technology. 
Table 3.5 presents estimates of the parameters for the translog production function. Over the study period, average technical change is estimated at a yearly rate of $1.6 \%$ in Hubei. Insignificant technical progress is observed on average in Zhejiang, while there seems to be technical regress at the sample mean in Yunnan, as implicated by the significantly negative coefficient for the linear time trend. The overall model quality, as judged by the t-ratios, seems satisfactory. All the first-order coefficients of the inputs have the expected signs, thus indicating positive partial production elasticities at the sample mean.

Table 3.5: Estimated results from the translog stochastic frontier production functions

\begin{tabular}{lrrrrrr}
\hline & Zhejiang & & Hubei & Yunnan \\
\cline { 2 - 7 } & \multicolumn{1}{c}{ Coefficient } & & Coefficient & Coefficient \\
\hline \multicolumn{2}{l}{ Frontier function } & & & & & \\
$\mathrm{t}$ & 0.025 & $(0.013)$ & $0.016^{* * *}$ & $(0.004)$ & $-0.029^{* * *}$ & $(0.007)$ \\
$\ln (\mathrm{a})$ & $0.510^{* * * *}$ & $(0.054)$ & $0.073^{* * *}$ & $(0.020)$ & $0.088^{* *}$ & $(0.033)$ \\
$\ln (\mathrm{l})$ & $0.211^{* * * *}$ & $(0.044)$ & $0.505^{* * *}$ & $(0.022)$ & $0.155^{* * *}$ & $(0.028)$ \\
$\ln (\mathrm{i})$ & $0.247^{* * *}$ & $(0.051)$ & $0.253^{* * *}$ & $(0.014)$ & $0.367^{* * *}$ & $(0.020)$ \\
$\ln (\mathrm{k})$ & 0.026 & $(0.017)$ & 0.000 & $()$. & $0.099^{* * *}$ & $(0.019)$ \\
$t \times t$ & -0.012 & $(0.006)$ & $-0.014^{* * *}$ & $(0.004)$ & 0.003 & $(0.005)$ \\
$0.5 \ln (a) \times$ & $0.190^{* * * *}$ & $(0.046)$ & $0.152^{* * *}$ & $(0.038)$ & 0.072 & $(0.055)$ \\
$\ln (a)$ & & & & & & \\
$0.5 \ln (l) \times$ & 0.013 & $(0.031)$ & $0.250^{* * *}$ & $(0.051)$ & $-0.114^{* * *}$ & $(0.024)$ \\
$\ln (l)$ & & & & & &
\end{tabular}


Estimated results from the translog stochastic frontier production functions (continued)

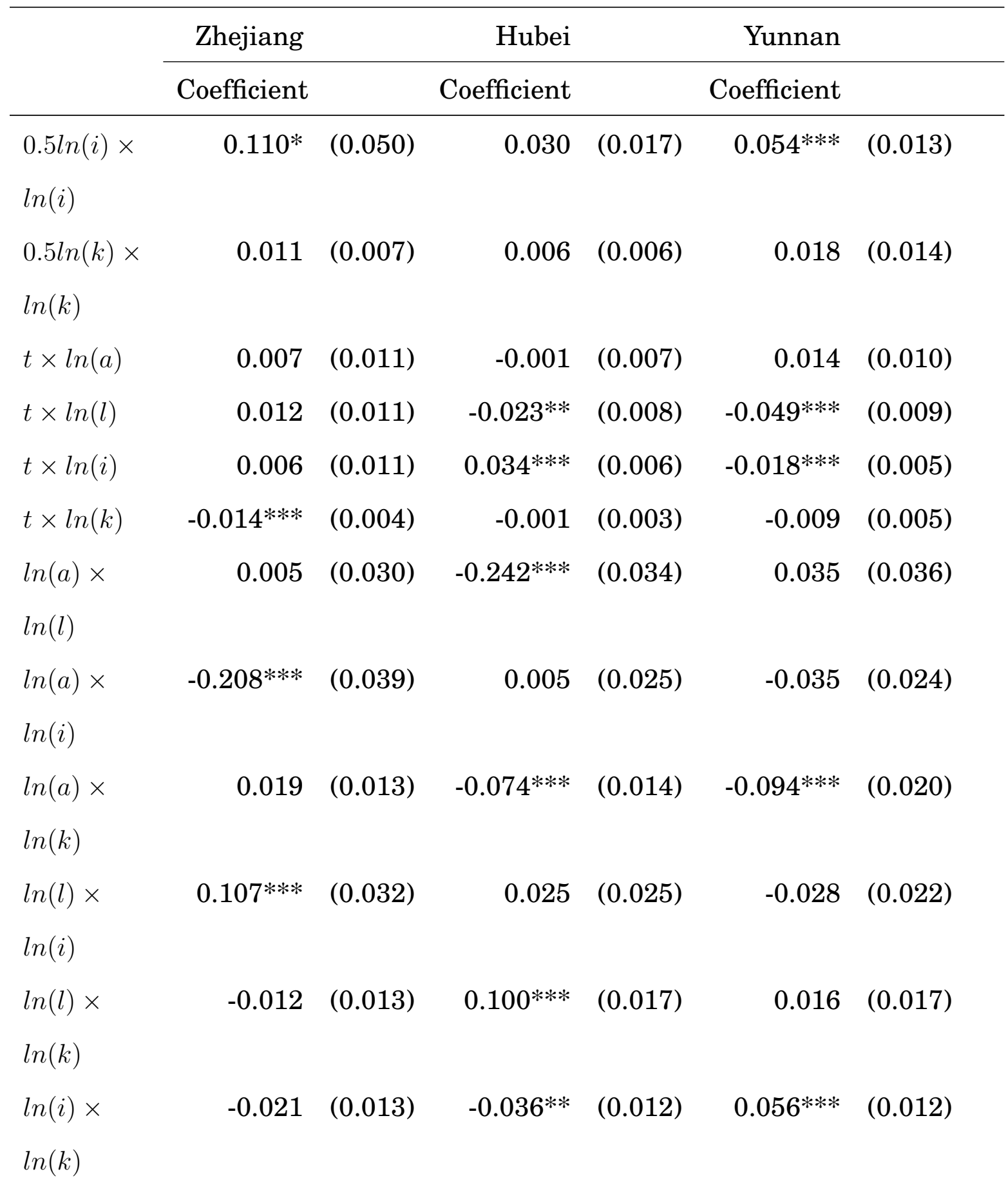


Estimated results from the translog stochastic frontier production functions (continued)

\begin{tabular}{|c|c|c|c|c|c|c|}
\hline & \multicolumn{2}{|l|}{ Zhejiang } & \multicolumn{2}{|l|}{ Hubei } & \multicolumn{2}{|l|}{ Yunnan } \\
\hline & Coefficient & & Soefficient & & Coefficient & \\
\hline intercept & $0.350 * * *$ & $(0.041)$ & -0.011 & $(0.017)$ & $0.260 * * *$ & $(0.027)$ \\
\hline \multicolumn{7}{|c|}{ Inefficiency model } \\
\hline Pred_posi & $3.771 * * *$ & $(0.852)$ & $-2.648 * *$ & $(0.869)$ & $-8.795^{* * *}$ & (1.997) \\
\hline Pred_nega & 8.782 & (8.919) & $2.193^{* * *}$ & $(0.619)$ & 0.568 & $(0.438)$ \\
\hline Plot_1 & 0.009 & $(0.018)$ & -0.001 & $(0.005)$ & 0.005 & $(0.004)$ \\
\hline Plot_2 & $0.045 * * *$ & $(0.013)$ & -0.007 & $(0.006)$ & $-0.039 * * *$ & $(0.009)$ \\
\hline Plot_3 & -0.277 & $(0.270)$ & $-0.097 * *$ & $(0.034)$ & -0.011 & $(0.011)$ \\
\hline Plot_4 & 0.046 & $(0.104)$ & -0.042 & $(0.034)$ & -0.010 & $(0.011)$ \\
\hline Plot_5 & -0.333 & $(276.513)$ & -0.002 & $(0.021)$ & $-0.089 *$ & $(0.040)$ \\
\hline Plot_6 & 0.000 & (.) & -0.212 & $(0.639)$ & -0.009 & $(0.045)$ \\
\hline Elementary & 0.015 & $(0.014)$ & $-0.009 *$ & $(0.004)$ & $-0.021 * * *$ & $(0.003)$ \\
\hline Secondary & 0.017 & $(0.019)$ & $-0.012^{*}$ & $(0.005)$ & $-0.031 * * *$ & $(0.007)$ \\
\hline High & 0.010 & $(0.027)$ & -0.019 & $(0.010)$ & -0.005 & $(0.011)$ \\
\hline Skill & 0.029 & $(0.025)$ & $0.021 * *$ & $(0.008)$ & -0.028 & $(0.038)$ \\
\hline Cadre & -27.767 & (1278.717) & -0.368 & $(0.536)$ & -2.287 & $(2.388)$ \\
\hline intercept & $-8.687 * * *$ & $(1.650)$ & $-2.112^{* * *}$ & $(0.391)$ & $-0.643^{*}$ & $(0.267)$ \\
\hline $\mathrm{N}$ & 1635 & & 4849 & & 2260 & \\
\hline $\log$ & -732.54 & & -2967.04 & & -964.41 & \\
\hline \multicolumn{7}{|l|}{ likelihood } \\
\hline sigma_v & 0.372 & $(0.007)$ & 0.440 & $(0.005)$ & 0.349 & $(0.007)$ \\
\hline
\end{tabular}


Estimated results from the translog stochastic frontier production functions (continued)

\begin{tabular}{rrr}
\hline Zhejiang & Hubei & Yunnan \\
\hline Coefficient & Coefficient & Coefficient \\
\hline
\end{tabular}

Note: $\mathrm{t}=$ time $; \ln (\mathrm{a})=$ natural logarithm of $\mathrm{a} ; \ln (\mathrm{l})=$ natural logarithm of $\mathrm{l}$; $\ln (\mathrm{i})=$ natural logarithm of $\mathrm{i} ; \ln (\mathrm{k})=$ natural logarithm of $\mathrm{k}$.

Standard errors are given in parentheses. $* \mathrm{p}<0.05, * * \mathrm{p}<0.01, * * * \mathrm{p}<0.001$

In terms of the magnitude of these elasticities at the sample mean, the most important factors are labor, land, and intermediate inputs. In particular, the structure of the labor elasticities is consistent with the level of regional development of the three provinces. It can be expected that opportunity costs of labor are relatively low in the less developed provinces of Hubei and Yunnan, which, in turn, implies that farms allocate comparatively more labor to agricultural production than farms in relatively developed coastal regions such as Zhejiang. Our results indicate that agricultural production in Hubei is very land intensive, with an estimated elasticity of 0.51 at the sample mean. The corresponding elasticity of land is still substantial in Zhejiang and Yunnan, with point estimates of 0.21 and 0.16 at the sample mean, respectively. The lowest partial production elasticity is observed for capital. Contrary to labor, this is an indicator 
Table 3.6: Level of technical efficiency from 1996 to 2002 by provinces

\begin{tabular}{lcccccccc}
\hline & 1996 & 1997 & 1998 & 1999 & 2000 & 2001 & 2002 & Average \\
\hline Zhejiang & 0.963 & 0.952 & 0.949 & 0.937 & 0.971 & 0.963 & 0.972 & 0.957 \\
Hubei & 0.911 & 0.912 & 0.912 & 0.909 & 0.916 & 0.918 & 0.915 & 0.913 \\
Yunnan & 0.845 & 0.869 & 0.872 & 0.847 & 0.875 & 0.885 & 0.875 & 0.867 \\
\hline
\end{tabular}

of the relative scarcity of capital in agricultural production. Because the elasticities correspond to ratios of an input's marginal product to its average product, a small elasticity can also be attributed to high average factor productivity. This will be the case when a factor such as capital is scarce in Chinese agriculture. Intermediate inputs account for the most important factor in Yunnan. In addition, the sum of the input elasticities provides information about scale economies with results of $97 \%$ in Zhejiang, $83 \%$ in Hubei, and $71 \%$ in Yunnan. These indicate that the production technology exhibits decreasing returns to scale for the sample mean in Hubei and Yunnan.

\subsubsection{Technical efficiency}

After estimation of the stochastic frontier production function, we calculate technical efficiency for each farm household over the whole observation period. Table 3.6 reports the level of technical efficiency for the three provinces over time and Figure 3.3, Figure 3.4, and Figure 3.5 presents the kernel density distribution of technical efficiency for each of the sampled villages from 1996 to 2002 . Our results show that technical efficiency stays relatively constant with moderate increase during the study period, while the average level of the technical efficiency term mirrors 
the regional level of economic development. Figure 3.3, Figure 3.4, and Figure 3.5 illustrate the variations in technical efficiency across villages and households within the villages in the three provinces. The majority of rural households in Zhejiang province operate close to the agricultural production frontier. However, for the households in Hubei and Yunnan, further growth of agricultural production through the improvement of technical efficiency could be expected.

In the lower part of Table 3.5, we present the determinants for the variation of farm households' inefficiency. The parameters indicate the direction of the effects these variables have on the inefficiency level. Hence, a negative parameter estimate for some variable indicates a positive effect on technical efficiency.

The coefficients of predicted changed arable land due to land reallocation indicate negative effects on technical efficiency in Zhejiang and positive effects in Hubei and Yunnan. The implication is that the impact of land reallocation on technical efficiency is an empirical issue. In the case of Hubei and Yunnan, land reallocation could act as a substitute for the land rental market, which has been shown in the result of Stage 1 model estimation, to optimize the allocation of land resources and hence improve technical efficiency of the farm. A study by Deininger and Jin (2005) suggests that land rental markets are more effective than administrative reallocation in reallocating land to those with lower endowments and have a bigger productivity-enhancing effect. Hence, even though administrative land reallocation partially substitutes for the market mechanism and contributes to the improvement of farm technical efficiency, the develop- 


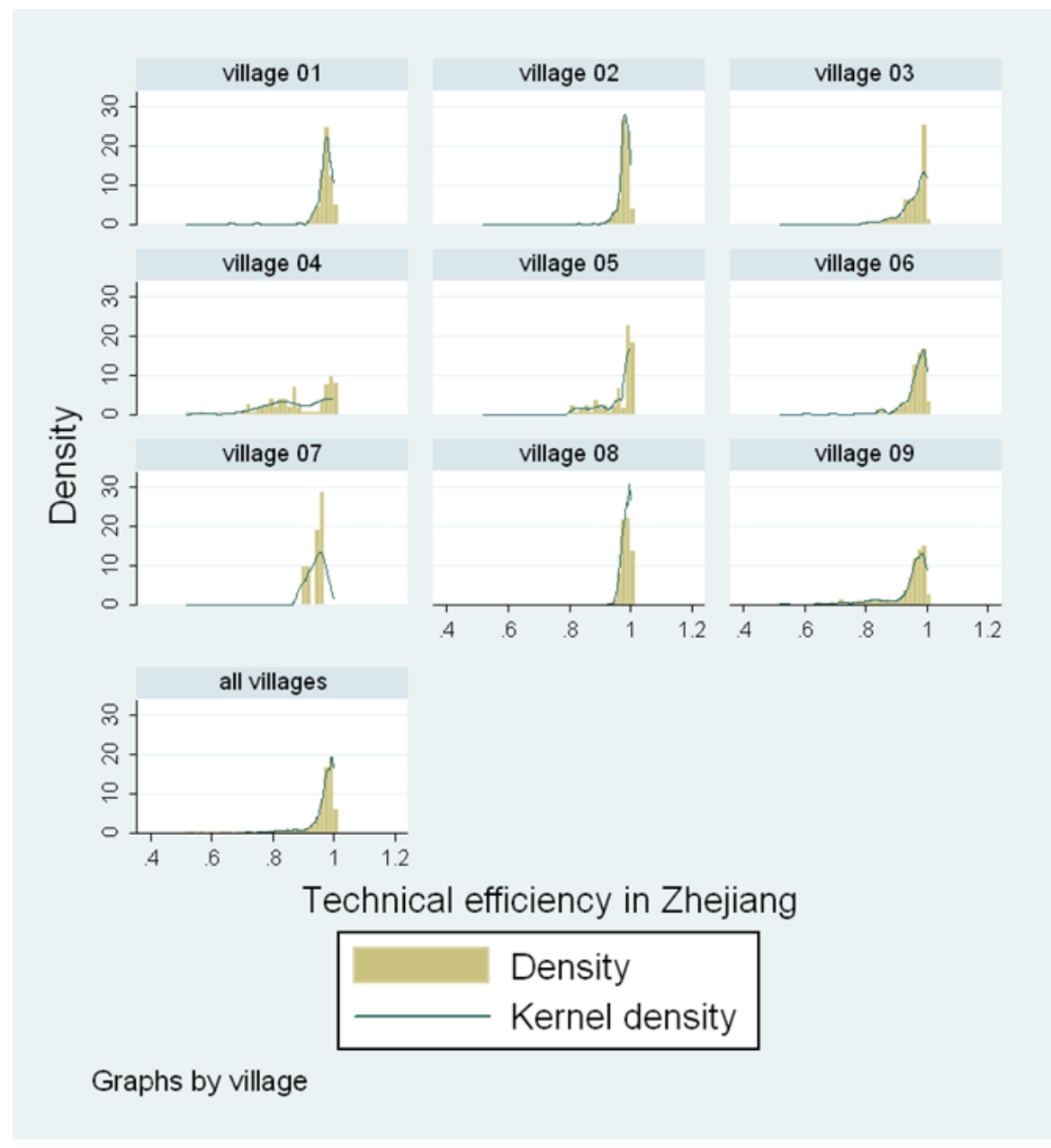

Figure 3.3: The kernel density of technical efficiency across villages in Zhejiang province (1996-2002)

Source: Own figure. 


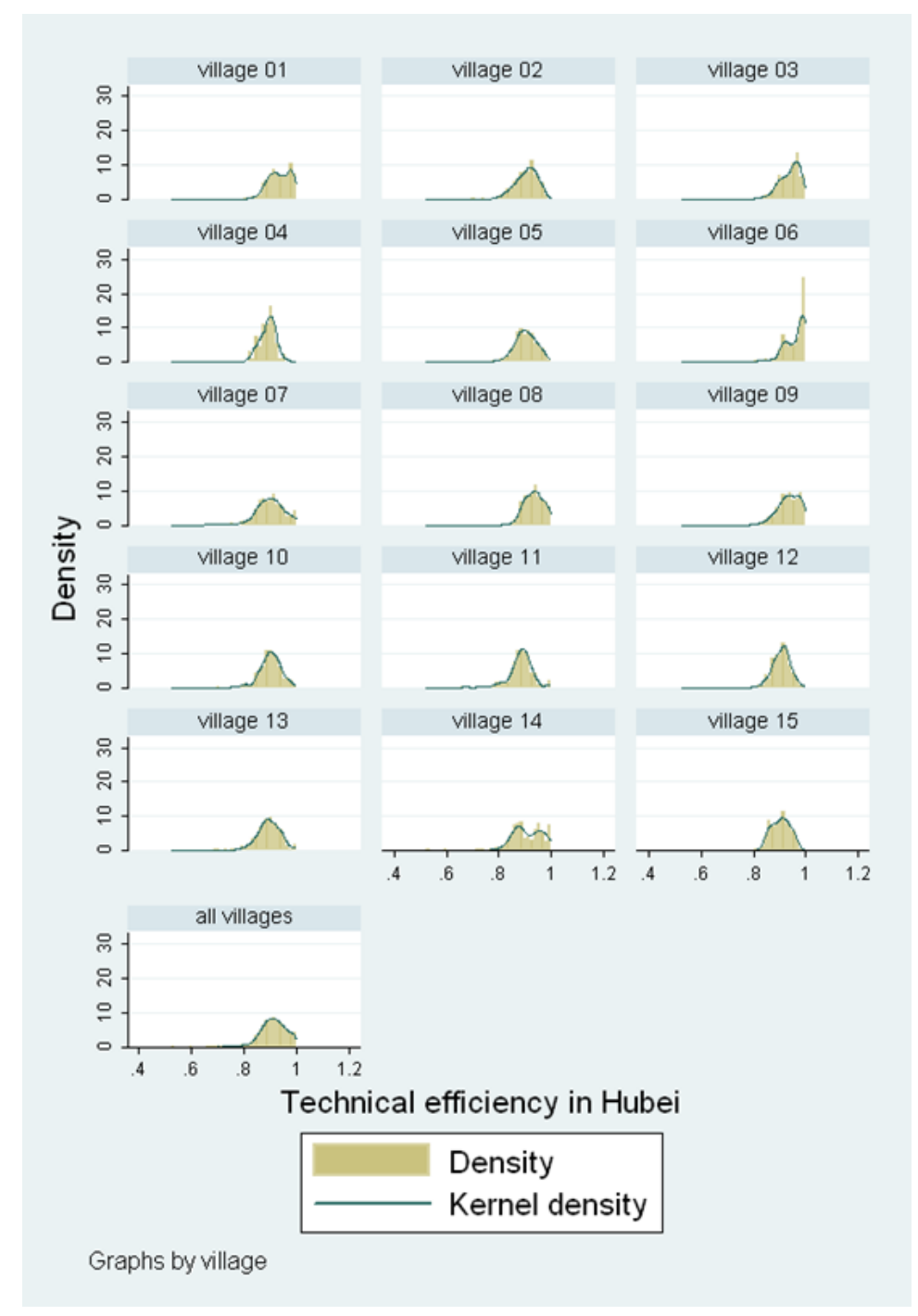

Figure 3.4: The kernel density of technical efficiency across villages in Hubei province (1996-2002)

Source: Own figure. 


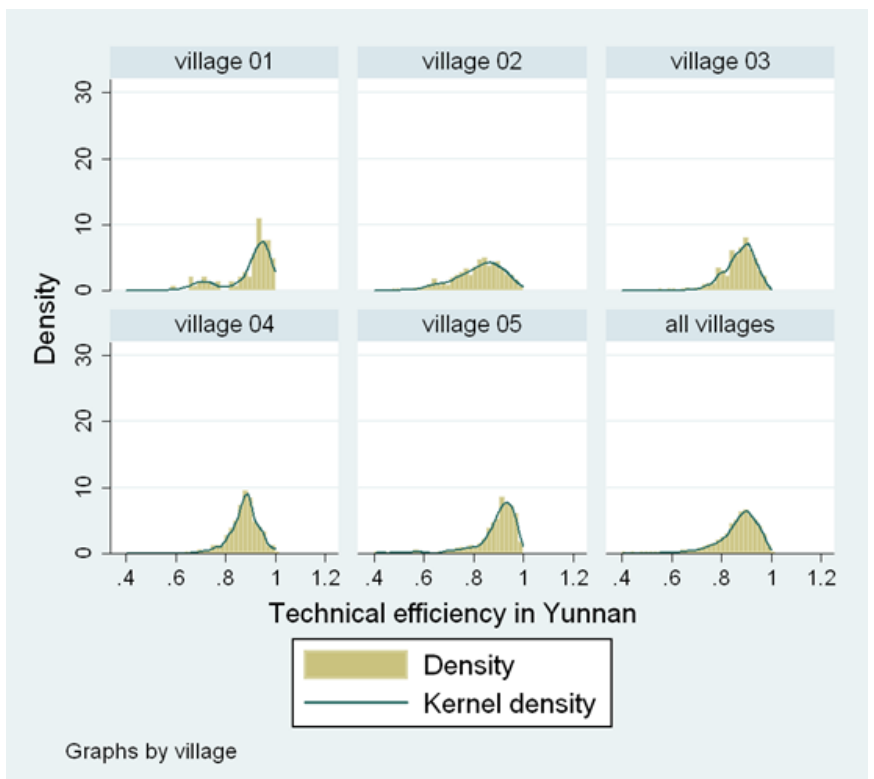

Figure 3.5: The kernel density of technical efficiency across villages in Yunnan province (1996-2002)

Source: Own figure.

ment of the land rental market needs to be encouraged in achieving allocative efficiency. This prescription is also reinforced by the results for Zhejiang, where land rental markets and other related factor markets are already relatively well functioning. Under these circumstances, the administrative land reallocation process exerts a negative effect on the technical efficiency of farmers.

In order to measure the impact of land fragmentation, we introduce six variables for the share of plots with different sizes (see Table 3.3), using the share of plots with size smaller than $0.5 \mathrm{mu}$ as a reference. Even though most of the coefficients are not significant, the prevailing negative signs present information that the larger the plot size, the more efficient the production. Thus, land fragmentation could be a hindrance to the 
improvement of technical efficiency. A dummy variable, which indicates whether any of the household members is a township or village cadre, is used here as a proxy for the management capability of farm households and its effect is not significant in all three provinces. The share of rural laborers with primary, secondary, and high school education and above (share of illiterate rural laborers as reference) all have negative signs in Hubei and Yunnan. Additionally, the higher the level of education, the larger the efficiency scores. The coefficient of share of labor with skill training is significantly positive only in Hubei. This could be explained that skill training increases the chance of finding a job in an urban area; hence, it is a disincentive to working in agricultural production.

\subsection{Conclusion}

Due to China's economic reforms, farmers face an increased risk of land reallocation and adjustment. This raises questions about the impact of land reallocation on farm productivity and efficiency. An in-depth understanding of what determines land reallocation and whether, as well as, to what extent farm production and efficiency are affected by the incidence of land reallocation, could help policy makers introduce more targeted rural development policies. Based on a panel data set from 1995 to 2002 for rural households in Zhejiang, Hubei, and Yunnan provinces, the descriptive statistics show that frequent land reallocation is still common in some villages. Our stage 1 model results indicate that the development of the land rental market is essential because it can serve as a substi- 
tute for administrative land reallocation in optimizing the distribution of land resources. Demographic change does affect land reallocation in some regions. Even though land allocation is officially intended to guarantee equal access to land for all farmers, the negative effects on tenure security are obvious, especially against the background of the ongoing rural-urban migration.

The results from the stochastic frontier production function show that land reallocation does have effects on technical efficiency. The different signs for different provinces also imply that the impact of land reallocation on technical efficiency is an empirical issue. Because of the possibility that administrative land reallocation can partially serve as a substitute for missing or badly functioning land rental markets, land reallocation could facilitate the process of improving land access for more successful farmers; hence, it could improve technical efficiency of agricultural production. But at the same time, in regions where land rental markets and other related factor markets are already relatively well developed, administrative land reallocation seems to distort the market mechanism, undermining market signals, and thus seems to decrease technical efficiency. In addition, our study also indicates that land fragmentation could be a major hindrance to the improvement of technical efficiency while highlighting the important role of a higher level of education, which exerts positive effects on the technical efficiency. 


\section{Chapter 4}

\section{The impact of land security \\ and input allocation on farm}

\section{household income}

The main contents of this chapter are based on the article "The impact of land security and input allocation on farm household income", and this article is a cooperation with Xiaobing Wang and Bernhard Brümmer. 


\subsection{Introduction}

$\mathrm{O}$

NE major element of land reform implemented in rural China during the 1980s and the early 1990s highlights an extremely equal distribution of cultivated land, meaning that land security could not be guaranteed given the variation of household demographics, labor composition or land resources, etc. (Liu et al., 1998; Brandt et al., 2002). After the expiration of the first round of land tenure, mainly in the later part of the $1990 \mathrm{~s}$, the government issued a policy that legally prohibited the transfer of land titles from one rural household to another to secure land use rights with the purpose of intensifying agricultural production (Kung, 2000; Yao, 2000b). However, major differences exist between villages or even within villages in the measures implemented, the degree of implementation, and the overall effects of land security policies, etc.(Zhang et al., 2011). Land periodically reallocated by local leaders is still observed to maintain egalitarianism despite the decrease of cultivated land per capita due to the population growth, the shifts of land planning and management, and the process of land degradation (Deng et al., 2006).

Land security reforms aiming at the creation of optimal land institutions are parallel to reforms in other factor markets, which gradually allow for diversifying the factor allocations among alternative income-generating activities to improve the agent's welfare. When examining government statistics and studies in the literature, the metrics of employment, consistent with the classical two-sector development of the model, shifted from agriculture to non-agriculture and from rural to urban in the evolu- 
tion of land market and use(Lewis, 1954; Fei and Ranis, 1964; de Brauw et al., 2002; Kung, 2002; Glauben et al., 2008; Kreps, 1990, NBSC, various years). Ravallion and van de Walle (2008) argued that one of the major barriers to prosperity in Asia is the willingness and capacity to invest in the usable assets that improve the productive accumulation of farmers when farmers face the uncertainty of land security due to the frequencies and magnitudes of land reallocation. China is no exception. Bowlus and Sicular (2003) attested that farm structures are endogenous instruments to the demand of on-farm labor, suggesting the existence of land allocation constraints in production. Kimura et al. (2011) pointed out that the perception of the land tenure insecurity determined by the market wage also influences the desired level of cultivated land which could be reached through the land rental market.

Well functioning factor markets, which are vital to making full use of scarce resources, are required for the successful transition process in agriculture (Swinnen and Rozelle, 2006). To overcome the constraints caused by the lack of land security, the households' decision whether and how much to allocate inputs such as labor and capital among the production activities is part of interacted economic choices. Without wellfunctioning land sale or rental markets, a household makes simultaneous decisions about its production in both the short and long term(Benjamin, 1992). Specifically, it makes decisions regarding its inputs, which affect its short-term production, and it decides on its investment in household resources, which affect long-term income capacity.

China's vast regional differences may complicate the relationship between 
land security and sustained income growth. China's economy is characterized by significant variations across space in the levels of wealth, factor endowment and markets, which may affect the decisions regarding factor allocations in profit-maximizing households (Nyberg and Rozelle, 1999). For example, in the rapidly developing coastal areas and suburban areas around rapidly growing cities, farm households have become increasingly wealthy through off-farm employment opportunities or even by abandoning agricultural production altogether. In these situations, the farmer's employment is only weakly tied to the land, and thus insecure access to land which may potentially be assigned an inferior quality in future reallocations are not essential to reduce the vulnerability against poverty. In areas that are well off, the factor markets, including the credit markets, are better developed although still imperfect (Cheng et al., 2003). Households in these areas could have many opportunities for non-agricultural investment concerning a trade-off between non-agricultural and agricultural income, which will be influenced by the shrinkage of cultivated land per capita due to the conversion of land to non-farm use.

The land insecurity implemented by Chinese local authorities and the evolution of the factor markets provide a unique opportunity to explore the sources of sustained income growth through a household's joint decisions in factor allocations. To achieve this target, a farm household analysis of income and its affecting factors has been done based on a panel dataset of rural household surveys conducted in the Zhejiang and Hubei provinces by the Ministry of Agriculture from 1995 to 2002. The rest of 
the chapter is organized as follows: Section 4.2 presents the theoretical framework and the following section is devoted to the econometric model. Section 4.4 describes the data source and provides descriptive statistics of variables. Section 4.5 explains the empirical results obtained from the estimation of the normalized quadratic profit functions. The final section concludes the analysis and offers policy implications.

\subsection{Theoretical framework}

To study the impacts that land insecurity and farm households' input allocation decisions have on their income, we start from the profit maximization problem in which the household engages in two production activities: agriculture and non-agriculture. The variable profit function is then defined as:

$$
\Pi=\Pi(p, z)
$$

where $p$ is a vector of netput (output or input) prices, and $z$ is a vector of quasifixed inputs. In the neoclassical production theory setting, it is assumed that the objective of the farm household is the maximization of short-run profit and that the farm household is a price-taker in the output and variable input markets. If the profit function satisfies certain regularity conditions, it is dual to the production function, and its parameters contain sufficient information to describe the farm's production technology at profit-maximizing points in the production possibility set. These 
testable conditions of regularity are that the profit function is continuous, twice differentiable, linearly homogeneous in prices, convex in all prices, concave in fixed inputs, decreasing in the prices of the input, increasing in the prices of the output, and non-decreasing in fixed inputs. Applying Hotelling's Lemma to equation (4.1), the supply functions of output and the derived demand functions of variable input can be obtained by differentiating the profit function with respect to netput prices as:

$$
q_{i}=\frac{\partial \Pi(p, z)}{\partial p_{i}}, \quad i=1, \ldots, n
$$

where $q_{i} s$ are positive for outputs, and negative for variable inputs.

When it comes to the practice of production activities in China's farm households, the assumption of profit maximization needs careful discussion. The farmers are still assumed to be profit maximizers, but they will not always succeed in allocating resources in different sectors and choosing levels of outputs and inputs that will lead to a maximum level of profit due to a series of institutional environment and factor market constraints. The rural reform in China initiated in 1979, especially the implementation of household responsibility system (HRS), liberalized the rural labor force and similar production endowments to some extent. As a result, incentives for agricultural production have been greatly improved, and rural farmers' incomes have also increased correspondingly (Lin, 1992; Fan et al., 2002; Brümmer et al., 2006). In addition to the decentralization of the production system, the united procurement and marketing system was reformed step by step. By the mid-1990s, China's 
agriculture had been transformed from a command-and-control system to a largely free-market one, with more than $90 \%$ of all agricultural products sold at market-determined prices. ${ }^{1}$ In contrast to the impressive improvements in the functioning of product markets, constraints still exist in some important factor markets.

With the process of economic reform, the controls on rural labor mobility were relaxed and rural laborers were allowed to migrate for better paid jobs. But obstacles still exist that hinder the free mobility of rural labor. For instance, rural migrants are discouraged from bringing their families to the cities because of the household registration (hukou) system regulations which register rural and urban households separately and firmly determine access to public services, e.g. education, housing, or public welfare (Brosig et al., 2009; OECD, 2009b). There still exists a certain amount of local protectionism, in which village workers often earn much higher wages than outsiders (Yao, 1999). The introduction of HRS granted land use rights to individual farm households, but left formal ownership of the land in the hands of the government or the local collective. Since the individual farm households do not have legal titles to the land, they face the risk of administrative land reallocation and adjustment. This induced land tenure insecurity reduces the incentives of farm households to invest in the land and hinder the efficient use of labor. Thus, the tenure insecurity may decrease agricultural productivity and hence their income. ${ }^{2}$ There is a great deal of relevant empiri-

\footnotetext{
${ }^{1}$ The rural policy reform in the last 30 years has been reviewed in detail in Fan et al. (2002); Brümmer et al. (2006); OECD (2009a,b).

${ }^{2}$ See Kung (2000); Deininger and Feder (2001); Brandt et al. (2002) for a more detailed discussions on land tenure security and land reallocation issues.
} 
cal research on these issues. As reported in Yang (2004), the relaxation of controls on production endowments permitted farm households to reallocate their inputs from agriculture to nonagricultural activities, and contributed significantly to household income growth. Using a hazard analysis approach, Jacoby et al. (2002) find that higher land expropriation risk significantly reduces the use of organic fertilizer, which has longlasting benefits for soil quality. Applying a stochastic frontier analysis approach, Zhang et al. (2011) argue that in regions where land rental markets and other related factor markets are already relatively well developed, administrative land reallocation seems to distort the market mechanism, undermine market signals, and thus decrease technical efficiency. A study by Deininger and Jin (2005) suggests that land rental markets are more effective than administrative reallocation in reallocating land to those with lower endowments and have a bigger productivity-enhancing effect. Following these analyses, we further study the impact of land insecurity and input allocation and their impact on farm household income. In order to represent deviations from the "real" profit maximization, we add the restrictions related to the institutional environment and factor markets to the previous profit maximization model. Hence, the variable profit function in equation (4.1) is extended as:

$$
\Pi^{c}=\Pi^{c}(p, z ; c)
$$

where $\Pi^{c} \leq \Pi$, and $\Pi^{c}$ will be equal to $\Pi$ if all the constraints are relaxed or deregulated; $c$ is a vector of variables representing the effects of the institutional environment and factor market constraints which have been 
discussed above.

To illustrate, we analyze rural labor market in which farm households allocate their labor input (L) between agricultural (a) and non-agricultural (n) sectors. Then the household aggregate profit is the sum of profits from these two activities, and its profit function is written as:

$$
\Pi=\left[f_{a}\left(L_{a}\right) p_{a}+f_{n}\left(L_{n}\right) p_{n}\right]-w x
$$

where $L=L_{a}+L_{n} ; f_{a}\left(L_{a}\right)$ and $f_{n}\left(L_{n}\right)$ are output quantities of agricultural and non-agricultural production, respectively, $p_{a}$ and $p_{n}$ are the associated output prices; $x$ is a vector of variable inputs and $w$ represents the associated input prices. Then equation (4.4) can be further expressed as:

$$
\Pi=\left[f_{a}\left(L_{a}\right) p_{a}+f_{n}\left(L-L_{a}\right) p_{n}\right]-w x
$$

differentiation with respect to $L_{a}$ gives the following first-order condition for a constrained maximum:

$$
\frac{\partial \Pi}{\partial L_{a}}=f_{a}^{\prime}\left(L_{a}\right) p_{a}-f_{n}^{\prime}\left(L-L_{a}\right) p_{n}=0
$$

then we have:

$$
f_{a}^{\prime}\left(L_{a}\right) p_{a}=f_{n}^{\prime}\left(L_{n}\right) p_{n}
$$

equation (4.7) means that, to achieve the goal of profit maximization, the household needs to adjust the level of its labor input between agricultural and non-agricultural production so that the marginal revenue (MR) of these two activities are equal. Graphically, $L^{*}$ in Figure 4.1 represents 


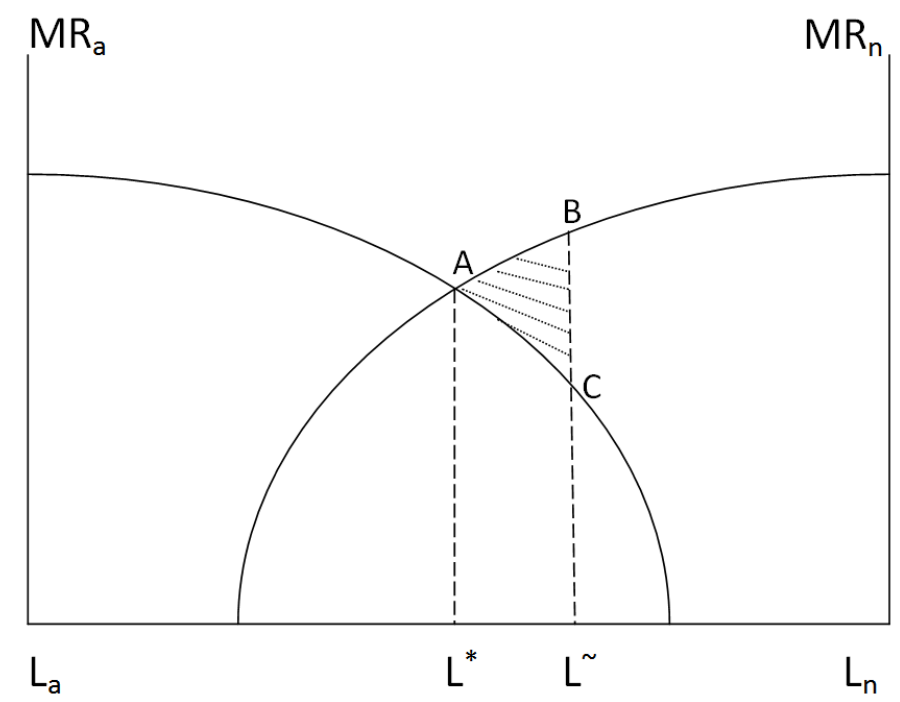

Figure 4.1: Profit loss due to misallocation of labor input Source: Own figure.

the optimal point of the efficiently allocated labor input between these two sectors. Due to the rural labor market constraints which have been discussed above, we could expect that less-than-optimal level of labor input is devoted to non-agricultural production. As a result, the household's labor allocation will be at the point $L^{\sim}$, on the right side of $L^{*}$. And the shaded area $\triangle A B C$ represents the household's loss of profit due to the misallocation of labor input between agricultural and non-agricultural production. This analysis on rural labor market also applies to the household's capital input allocation between agricultural and non-agricultural activities and its crop cultivation structure decision. 


\subsection{Econometric model}

A specific functional form is needed for the estimation of the profit function discussed in Section 4.2. In this study, the normalized quadratic profit function, from the class of second-order flexible functional forms, is applied. The quadratic functional form is locally flexible and its Hessian is a matrix of constants, which means curvature can be maintained globally without altering the flexibility of the function form. It takes the following form:

$$
\begin{aligned}
\Pi^{c} / p_{1}= & \alpha_{0}+\sum_{i=2}^{m} \alpha_{i}\left(p_{i} / p_{1}\right)+\frac{1}{2} \sum_{i=2}^{m} \sum_{j=2}^{m} \alpha_{i j}\left(p_{i} / p_{1}\right)\left(p_{j} / p_{1}\right)+\sum_{i=1}^{n} \beta_{i} z_{i} \\
& +\frac{1}{2} \sum_{i=1}^{n} \sum_{j=1}^{n} \beta_{i j} z_{i} z_{j}+\sum_{i=2}^{m} \sum_{j=1}^{n} \gamma_{i j}\left(p_{i} / p_{1}\right) z_{j}+\sum_{i=1}^{w} \delta_{i} c_{i}
\end{aligned}
$$

where $\Pi^{c} / p_{1}$ is the short-run profit (revenue minus variable costs) divided by the price of netput $1 ;\left(p_{i} / p_{1}\right) \mathrm{s}$ are the prices of the variable netputs divided by the price of variable netput $1 ; z_{i}$ s are the quantities of quasifixed factors and technology proxy; $c_{i}$ s are variables representing the effects of the institutional environment and factor market constraints; and $\alpha, \beta, \gamma, \delta$ are parameters to be estimated. Here the profit function is normalized by the price of netput 1 to ensure linear homogeneity in prices. Symmetry is maintained by requiring $\alpha_{i j}=\alpha_{j i}$ and $\beta_{i j}=\beta_{j i}$. Convexity and monotonicity will be checked after the estimation.

The expected value of parameters $\delta_{i}$ s deserve more detailed discussions. Based on the theoretical framework, four variables (see Table 4.4) representing the effects of the institutional environment and factor market 
constraints are introduced in the model: a dummy variable with a value equal to 1 if the arable land of the farm household has been reallocated within the year (Land_real), a second variable representing the share of sown areas which are used for non-grain crops cultivation (Land_s), a third variable representing the share of household labor input which are allocated to non-agricultural production (Labor_s), and a fourth variable representing the share of fixed-capital assets which are allocated to nonagricultural production (Capital_s). As has already been discussed, frequent land reallocation, which induces land tenure insecurity, will have a negative effect on household income. To maintain food security, the government kept the grain quota procurement system until it was finally eliminated in 2001. But at the same time, the government raised procurement prices to increase farmers' incomes and to meet food security goals. So the impact of farmers' crop cultivation structure on their income depends on the game between market prices and government support policies. Because restrictions still exist that hinder the free mobility of rural labor, the effects of labor input share in non-agricultural production are expected to be positive. As for the effect of capital input share to non-agricultural production, it could be positive or negative. Given the expected positive effects of labor input share, it is positive if capital input and labor input are complementary in production, and it is negative if these two inputs are substitutable. As is discussed in the section on the theoretical framework, in addition to land tenure insecurity's direct effects, it might also have indirect effects on income through its interaction with other input allocations. As a result, the products of Land_real with the other three control variables are also introduced into the model. 
Applying Hotelling's Lemma to equation (4.4), the supply functions of output and the derived demand functions of variable input can be obtained by differentiating the profit function with respect to the normalized netput prices as:

$$
q_{i}=\frac{\partial\left(\Pi^{c} / p_{1}\right)}{\partial\left(p_{i} / p_{1}\right)}=\alpha_{i}+\sum_{j=2}^{m} \alpha_{i j}\left(p_{j} / p_{1}\right)+\sum_{j=1}^{n} \gamma_{i j} z_{j}
$$

where $q_{i}$ is positive for the supply of outputs and negative for the demand for variable inputs. The numeraire equation is quadratic in prices:

$$
\begin{array}{r}
q_{1}=\Pi^{c} / p_{1}-\sum_{i=2}^{m}\left(p_{i} / p_{1}\right) \frac{\partial\left(\Pi^{c} / p_{1}\right)}{\partial\left(p_{i} / p_{1}\right)}=\alpha_{0}-\frac{1}{2} \sum_{i=2}^{m} \sum_{j=2}^{m} \alpha_{i j}\left(p_{i} / p_{1}\right)\left(p_{j} / p_{1}\right) \\
+\sum_{i=1}^{n} \beta_{i} z_{i}+\frac{1}{2} \sum_{i=1}^{n} \sum_{j=1}^{n} \beta_{i j} z_{i} z_{j}+\sum_{i=1}^{w} \delta_{i} c_{i}
\end{array}
$$

The uncompensated (Marshallian) price elasticities are computed as:

$$
\eta_{i j}=\frac{\partial q_{i}}{\partial p_{j}} \times \frac{p_{j}}{q_{i}}=\frac{\partial q_{i}}{\partial\left(p_{j} / p_{1}\right)} \times \frac{\left(p_{j} / p_{1}\right)}{q_{i}}=\alpha_{i j} \frac{\left(p_{j} / p_{1}\right)}{q_{i}}
$$

The price elasticities for the numeraire could then be calculated by applying the property of homogeneity of degree zero in prices for the supply functions of output and the derived demand functions of variable input. 


\subsection{Data source and descriptive statistics}

\subsubsection{Data Source}

The database used in this study is drawn from fixed-point survey data series across the Zhejiang and Hubei provinces in China, conducted annually by rural survey teams. ${ }^{3}$ The two provinces covered were chosen to reflect the diversity of China's agricultural production. The Zhejiang province is located in the southern wing of the Yangtze River Delta in China, which was an early beneficiary of China's "open door" policies after 1978. In the Zhejiang province, the arable land accounts for 2.125 million hectares, or $1.6 \%$ of the country (NBSC, 2001). Since 1978, Zhejiang has experienced rapid growth and diversification of the economy. From 1978 to 2002, its GDP achieved a yearly growth rate of $13 \%$ on average, and thus it jumped in rank from 12th to 4th out of all 31 Chinese provinces in terms of economic performance. The GDP per capita rose to 16,570 Yuan (2,004 USD) in 2002 with an annual increase of $12.1 \%$, while the per capita net income of rural residents reached 4,940 Yuan (597 USD) with an annual growth rate of $8.7 \%$. The sectoral composition of the province's economy has changed dramatically compared to other provinces over the course of economic reforms. Agriculture accounts for

\footnotetext{
${ }^{3}$ The rural survey teams of the Ministry of Agriculture of China conducted the primary trial survey at the beginning of 1983 in nine provinces. After 1984, the survey was extended to 28 provinces (excluding Tibet and Taiwan; later the survey included Hainan and Chongqing after they separated from Guangdong and Sichuan provinces, respectively, as well as Tibet. Thus, the survey finally covers 31 provinces and is conducted annually), covering 71 counties, 93 townships, 272 villages and 37,422 rural households. For financial reasons, the survey was not conducted in 1992 and 1994. By agreement, we have obtained access to the household data of Zhejiang and Hubei provinces from 1995 to 2002.
} 
only $33 \%$ of provincial employment compared to a national average of $64 \%$. Tertiary industry accounts for $33 \%$ (NBSC, 2004). Zhejiang is developing rapidly, and today it is one of the richest provinces in China.

Hubei, which is often called the "Land of Fish and Rice," is a central province in China. Hubei is the traditional heartland of Chinese agricultural production whereas Hubei was chosen as one of the thirteen major trial grain production provinces to directly subsidize grain producers starting in 2004. The arable land in the Hubei province accounts for 4.950 million hectares, or $3.8 \%$ of the country (NBSC, 2001). $42.37 \%$ of those in the labor force still undertake some kinds of agricultural work in the Hubei province. Hubei's economy ranks 12 th in the country and its nominal GDP for 2006 was 749.7 billion yuan (96.9 billion USD) with a per capita of 13,169 yuan (1,709 USD). It is expected that Hubei will benefit greatly after the completion of the "Three Gorge Dam" project conducted in the western part of Hubei.

Before summarizing the descriptive statistics of the variables used in the study, we provide a brief description of the fixed-pointed survey. The survey is based on a multistage, random-cluster process to attain rich information about the effect of rural reform on agricultural production and rural development. Counties, which are below province-level administrative units, were stratified by income level and selected according to a weighted sampling scheme. The villages within the counties were then randomly chosen according to geographic diversification (plain, hilly, or mountainous area), location (suburb of a city or not), and economic features defined as mainly agriculture, forestry, husbandry, fishery or oth- 
ers. Subsequently, the household data of the respective villages are randomly selected from the comprehensive household list kept by the village leader. To maintain longitudinal household information, the same households were interviewed each time the survey was conducted. If the household was dropped from the survey and was not recorded on the household list in the village, a new sample household was recruited from the same village with another ID and remained in the survey for the following years if it was qualified. ${ }^{4}$ Local enumerators train assistants from the village and rural households to maintain daily diaries that completely record all economic activities. An enumerator assistant is then assigned to a group of ten households and helps the households complete their diaries. The assistants also check the diaries once a month. Every quarter of a year, the local enumerators collect and check the completed forms. At the end of the year, the forms are returned and entered into a nationallydesigned coding program. Households receive payments of between 50 to 200 Yuan (around 6 to 24 USD) from the local government for their efforts. Close supervision of the data collection process and careful checks of consistency ensure that this dataset is of relatively high quality. Thus, the unbalanced panel data set includes 8,703 observations from 1995 to 2002, in which around 500 households from the Zhejiang province and 900 from the Hubei province participated .

\footnotetext{
${ }^{4}$ The household was dropped from the survey either due to the emigration of the whole family from the village to an urban area or to another town or village, or because the family members died after several years in the survey.
} 


\subsubsection{Descriptive statistics}

The summary of statistics of the characteristics of farm households in Zhejiang (Table 4.1) and Hubei (Table 4.2) allow the comparison of the structure of households participating in agricultural and non-agricultural production over time. Total income per household is near the national average in 2002 in Hubei, while it is significantly above average in Zhejiang. Agricultural production activities generate by far the biggest component of household income in landlocked province Hubei-about 57\%while in the more diversified economy of coastal Zhejiang, it represents around $40 \%$ for the whole sample period. Even though the proportion of non-agricultural income has increased at a faster rate in Hubei than in Zhejiang, Hubei's non-agricultural income in 2002was still far behindthe level seen in Zhejiang in 1995. In the pursuit of profit-maximization, households are more concerned with non-agricultural production activities in Zhejiang than in Hubei. On average, the share of labor input in non-agricultural production in Zhejiang is over 57\% of the time allocation of a household's labor, measured in the unit of days; however, it is still less than 34\% in Hubei, even though workers there have been more likely to engage in off-farm employment since 1995. Entering the 1990s, the impediments to non-agricultural activities had been largely relaxed, farm households could locate and maintain capital in non-agricultural business under their control. The fact that capital accumulation in nonagricultural business is much less in Hubei than that in Zhejiang is driven by the lower level of capital endowment and the smaller proportion of non-agricultural capital in Hubei. 


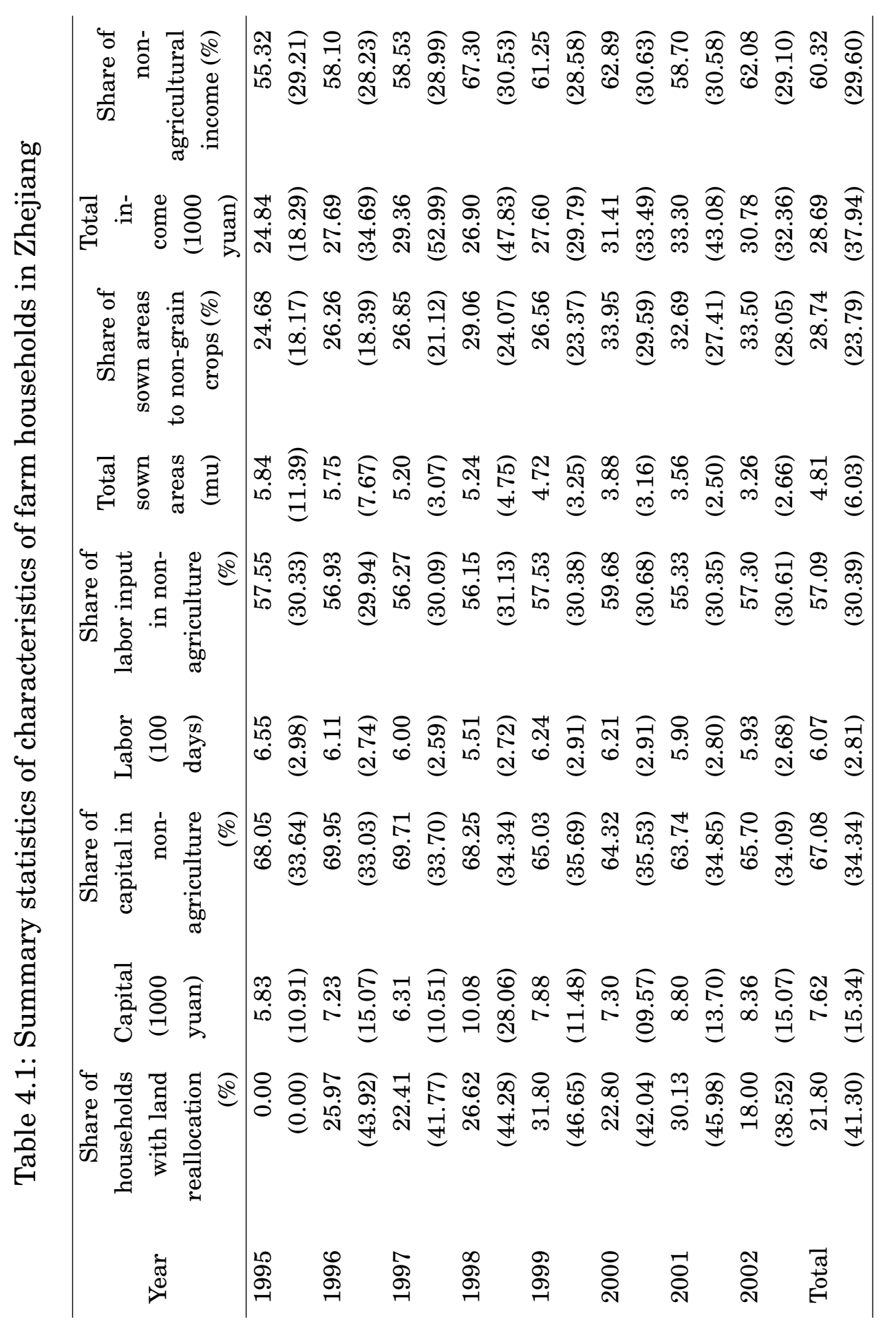




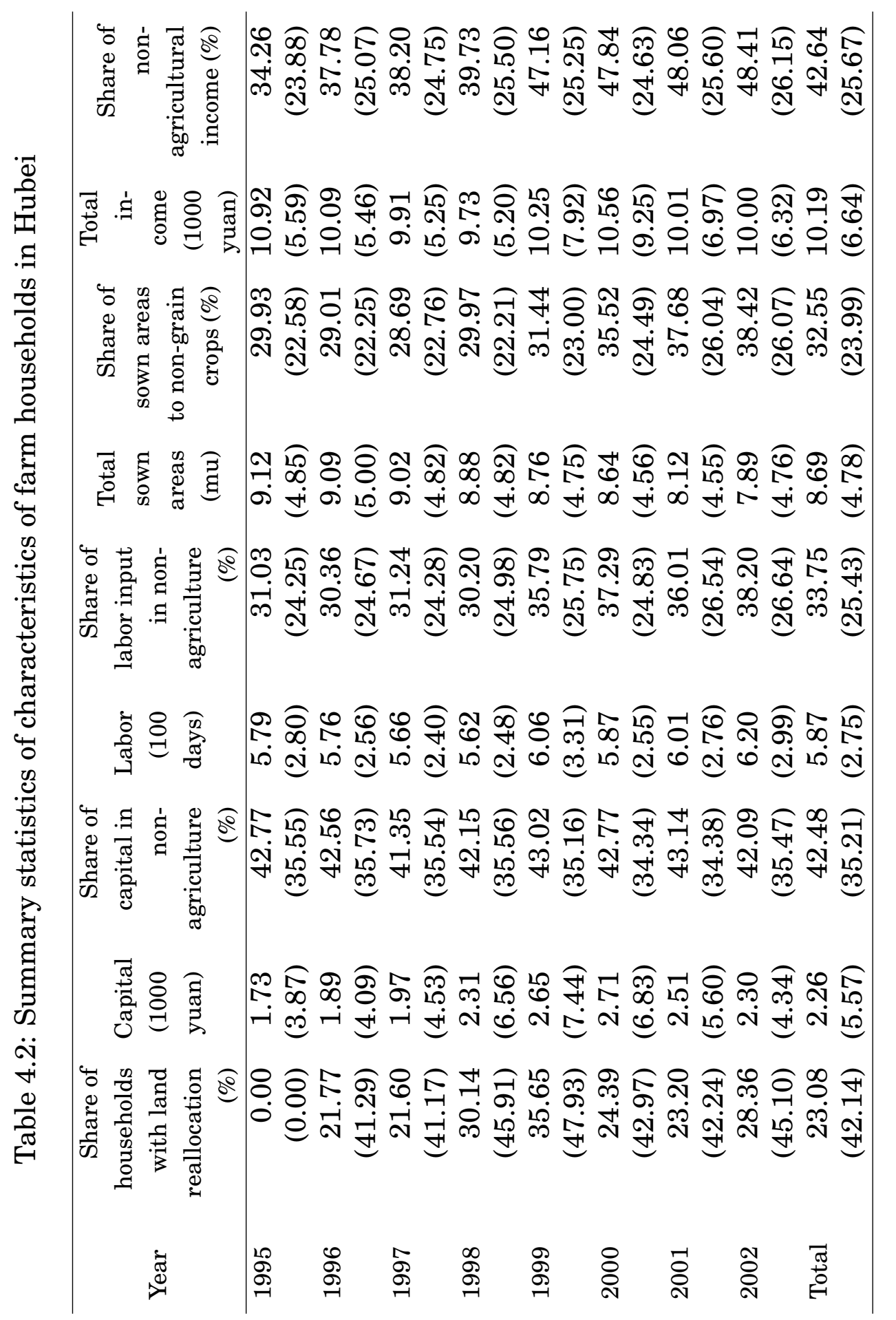

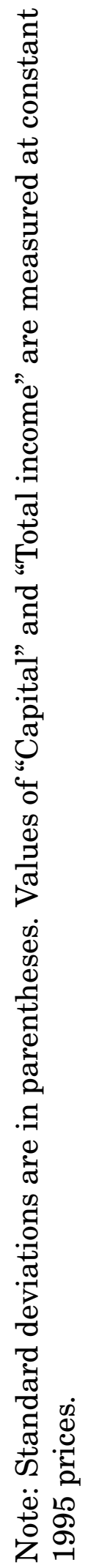


It is well-known that agricultural sectors in China are dominated by small scale farms and that these farms face a certain risk of shrinkage of cultivated land and land insecurity. Average farm sizes in the sample reflect that average land area per household in South East China is below the national average of nearly 0.6 ha (NBSC, 2003). Average of total sown area is $8.69 \mathrm{mu}^{5}$ in Hubei and $4.81 \mathrm{mu}$ in Zhejiang. ${ }^{6}$ From 1995 to 2002 , the reduction of sown area per household is $2.6 \mathrm{mu}$ in Zhejiang, which is twice as much as that in Hubei. This also suggests that in the well-off areas, the farmers are less dependent on agricultural production. Agricultural production is also diversified into grain crops and other high-profit crops like oilseeds, vegetables, fruits and husbandry production. Our data also show that the non-grain cropping has been intensified in both Zhejiang and Hubei over time given the constraints of land endowment. The prevalence of land reallocation was reflected in our data in the two provinces because on average, more than $20 \%$ of households experienced land reallocation in the period of time from 1995-2002. The dimension of land reallocation varied over time and between provinces with the evidence that more than $30 \%$ of sampled households have experienced land reallocation in different years. The land reallocation rate in our data is lower than that (75\%) in the study by Kimura et al. (2011). This is because they recorded the land reallocation starting from the very beginning of the implementation of HRS, while our statistics were obtained later, even after the expiration of the first round of land tenure

\footnotetext{
${ }^{5} 1 \mathrm{mu}=1 / 15$ hectare in China.

${ }^{6}$ In the two provinces, the cropping pattern generally involves sowing twice per year on one plot of cultivated land, for example, harvesting wheat in summer and rice in autumn.
} 
contracts.

The dependent variable used in the normalized quadratic profit functions is the net income from the non-agricultural employment and agricultural production, which aggregates the profit of producing physical products from crop, livestocks and other agricultural products. A time trend is included to capture technological progress. The descriptive statistics of the variables presented in Table 4.3 reveal several important variations of output and inputs across provinces. It is reported that the rural household in Zhejiang earns more income, on average, from both agricultural and non-agricultural activities. The former include outputs from farming, forestry, husbandry and fishery while the latter are obtained from the diversified off-farm employment such as manufacturing, construction, transportation and other services, etc. In agricultural production, households in Zhejiang have less land than those in Hubei in the unit of mu and use the same level of intermediate input. This implies that the technologies applied in agricultural production are to a larger extent region-specific due to the different constraints of land endowment. Here, intermediate inputs in the value term include grain and cash crop seeds, fertilizer, agricultural diesel oil, plastics and pesticides in agricultural production. The labor input is the total number of annual working days of all of the rural labor, including both on- and off-farm employment activities. Capital input measured in the unit of yuan is defined as fixed-capital assets of the household at the end of the year and includes draught animals, production tools, production buildings, and machinery for agriculture, industry and transportation. Capital input and quanti- 


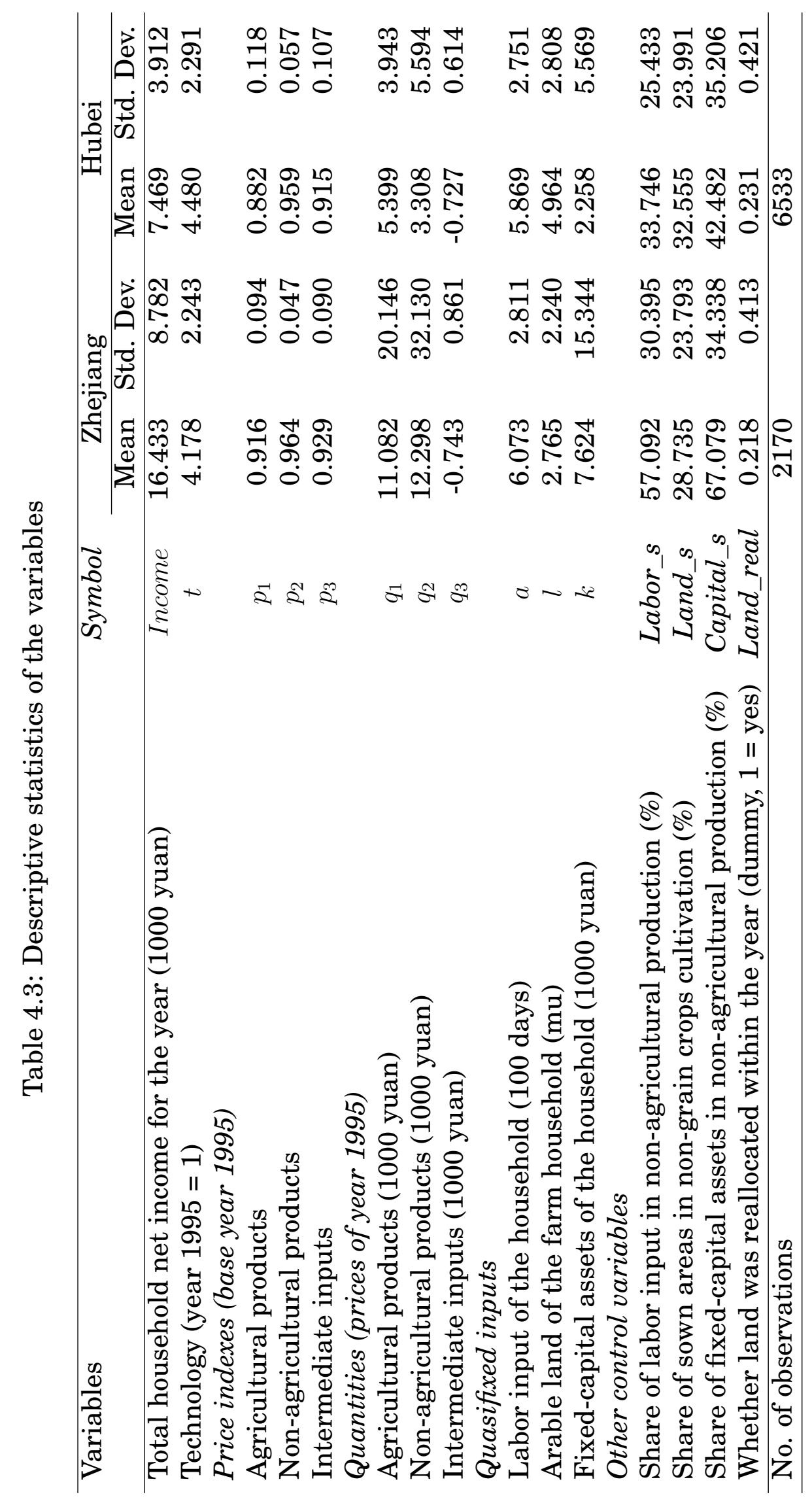


ties of the three composite netput categories are measured at constant 1995 prices.

Divisia price indexes are calculated for the three composite netput categories (two outputs and one input). The producer price indexes of each netput within the three composite netput categories are drawn from the China Statistical Yearbook (NBSC, various years) and the China Rural Statistical Yearbook (NBSC, various years), and have been converted into cumulative (chained) indexes with the base year 1995 equal to 1 . The Divisia price indexes are then computed with value shares of netputs as weights.

\subsection{Estimation results}

Before the estimation, in order to avoid numerical difficulties in the maximum likelihood estimations and to facilitate the interpretation of the parameter estimates, the normalized profit, the two normalized netput prices and the three quasifixed input variables are scaled to have a mean of zero, respectively. As a result, at the sample mean, the transformed variables take the value zero. Hence, in the estimation results, the firstorder coefficients of the normalized netput prices variables can be interpreted as quantities of the supply of output or the derived demand of variable input, and that of the quasifixed input variables can be interpreted as their shadow prices at the sample mean. Because a panel dataset is used in this study, the fixed effects (FE) model and the random effects 
(RE) model have been estimated separately, and the results of the Hausman test strongly reject the random effects model at the $1 \%$ significance level, suggesting that the unobserved time-invariant farm household effects are correlated with the explanatory variables in the estimations. Consequently, the following discussions are based on the results from the fixed effects model estimation. The estimated results of the normalized quadratic profit functions for the Zhejiang and Hubei provinces are presented in Table 4.4 .

Table 4.4: Results of the normalized quadratic profit functions with fixed effects model estimates

\begin{tabular}{|c|c|c|c|c|}
\hline & Zhejiang & & Hubei & \\
\hline$p_{2}^{*}$ & $8.893^{*}$ & $(4.278)$ & $12.324^{* * *}$ & $(1.072)$ \\
\hline$p_{3}^{*}$ & -6.847 & $(5.996)$ & $-4.519 * * *$ & (1.327) \\
\hline $\mathrm{t}$ & $0.839 * * *$ & $(0.133)$ & 0.060 & $(0.043)$ \\
\hline a & $1.484^{* * *}$ & $(0.088)$ & $0.491^{* * *}$ & $(0.029)$ \\
\hline 1 & 0.085 & $(0.195)$ & $0.296 * * *$ & $(0.040)$ \\
\hline $\mathrm{k}$ & $0.120 * *$ & $(0.046)$ & $0.230 * * *$ & $(0.025)$ \\
\hline Land_real & -0.164 & $(1.180)$ & -0.370 & $(0.228)$ \\
\hline Land_s & -0.003 & $(0.009)$ & 0.004 & $(0.004)$ \\
\hline Capital_s & 0.009 & $(0.010)$ & $-0.006^{*}$ & $(0.003)$ \\
\hline Labor_s & $0.060 * * *$ & $(0.009)$ & $0.025 * * *$ & $(0.003)$ \\
\hline Land_real×Land_s & -0.009 & $(0.016)$ & $-0.010 *$ & $(0.004)$ \\
\hline Land_real×Capital_s & 0.006 & $(0.011)$ & $0.008 * *$ & $(0.003)$ \\
\hline
\end{tabular}


Results of the normalized quadratic profit functions with fixed effects model estimates (continued)

\begin{tabular}{|c|c|c|c|c|}
\hline \multicolumn{3}{|c|}{ Zhejiang } & \multicolumn{2}{|l|}{ Hubei } \\
\hline Land_real×Labor_s & -0.007 & $(0.012)$ & $0.010 *$ & $(0.004)$ \\
\hline $0.5 p_{2}^{*} \times p_{2}^{*}$ & 248.725 & $(167.968)$ & 40.360 & $(23.857)$ \\
\hline $0.5 p_{3}^{*} \times p_{3}^{*}$ & 38.705 & $(90.483)$ & $34.614^{* * *}$ & $(9.303)$ \\
\hline$p_{2}^{*} \times p_{3}^{*}$ & 30.677 & $(85.531)$ & 0.879 & $(12.967)$ \\
\hline $0.5 \mathrm{t} \times \mathrm{t}$ & 0.219 & $(0.125)$ & 0.078 & $(0.041)$ \\
\hline $0.5 a \times a$ & -0.052 & $(0.029)$ & $-0.027 * * *$ & $(0.006)$ \\
\hline $0.5 \mathrm{l} \times \mathrm{l}$ & 0.002 & $(0.012)$ & $0.018 *$ & $(0.008)$ \\
\hline $0.5 \mathrm{k} \times \mathrm{k}$ & -0.002 & $(0.002)$ & $-0.005^{* * *}$ & $(0.001)$ \\
\hline $\mathrm{t} \times \mathrm{a}$ & 0.079 & $(0.042)$ & $0.038 * *$ & $(0.014)$ \\
\hline $\mathrm{t} \times \mathrm{l}$ & 0.103 & $(0.071)$ & 0.010 & $(0.014)$ \\
\hline $\mathrm{t} \times \mathrm{k}$ & $0.024 *$ & $(0.011)$ & $0.012^{*}$ & $(0.006)$ \\
\hline$a \times l$ & -0.042 & $(0.032)$ & 0.009 & $(0.007)$ \\
\hline $\mathrm{a} \times \mathrm{k}$ & 0.004 & $(0.005)$ & -0.004 & $(0.002)$ \\
\hline $1 \times \mathrm{k}$ & 0.017 & $(0.012)$ & $-0.012^{* *}$ & $(0.004)$ \\
\hline$p_{2}^{*} \times \mathrm{t}$ & -5.664 & $(4.039)$ & 0.434 & $(0.841)$ \\
\hline$p_{2}^{*} \times \mathrm{a}$ & 1.759 & $(1.446)$ & -0.257 & $(0.343)$ \\
\hline$p_{2}^{*} \times 1$ & $-6.650 * *$ & $(2.296)$ & -0.314 & $(0.336)$ \\
\hline$p_{2}^{*} \times \mathrm{k}$ & -0.636 & $(0.335)$ & -0.167 & $(0.148)$ \\
\hline$p_{3}^{*} \times \mathrm{t}$ & -1.137 & $(3.721)$ & $-1.409 *$ & $(0.714)$ \\
\hline$p_{3}^{*} \times \mathrm{a}$ & 0.153 & (1.578) & -0.614 & $(0.331)$ \\
\hline
\end{tabular}


Results of the normalized quadratic profit functions with fixed effects model estimates (continued)

\begin{tabular}{lrrrr}
\hline & \multicolumn{1}{c}{ Zhejiang } & \multicolumn{3}{c}{ Hubei } \\
\hline$p_{3}^{*} \times \mathrm{l}$ & -0.265 & $(2.501)$ & $-0.877^{* *}$ & $(0.331)$ \\
$p_{3}^{*} \times \mathrm{k}$ & $0.616^{*}$ & $(0.301)$ & 0.025 & $(0.139)$ \\
\hline \# Observations & 2170 & 6533 & \\
sigma_u & 8.855 & 2.608 & \\
sigma_e & 6.171 & 2.981 & \\
rho & 0.673 & 0.433 & \\
log likelihood & -6795.890 & & & \\
& & & 15845.555 & \\
\end{tabular}

Endogeneity test of endogenous regressors

$H_{0}$ : Land_s can actually be treated as exogenous
$\chi^{2}$
$\chi^{2}(1)=0.085$
$\chi^{2}(1)=0.029$
P-value
0.771
0.865

$H_{0}$ : Capital_s can actually be treated as exogenous
$\chi^{2}$
$\chi^{2}(1)=2.578$
$\chi^{2}(1)=0.603$
P-value
0.108
0.438

$H_{0}$ : Labor_s can actually be treated as exogenous

$\chi^{2} \quad \chi^{2}(1)=0.240 \quad \chi^{2}(1)=2.094$

P-value $\quad 0.624 \quad 0.148$

Note: $p_{2}^{*}$ and $p_{3}^{*}$ are normalized prices, where $p_{2}^{*}=p_{2} / p_{1}$ and $p_{3}^{*}=p_{3} / p_{1}$.

Standard errors are given in parentheses.

$* \mathrm{p}<0.05, * * \mathrm{p}<0.01, * * * \mathrm{p}<0.001$ 
Table 4.5: The Hessian matrix and its eigenvalues

\begin{tabular}{rrrrrr}
\hline \multicolumn{3}{c}{ Zhejiang } & \multicolumn{3}{c}{ Hubei } \\
\hline \multicolumn{2}{c}{ The Hessian } & Eigenvalues & \multicolumn{1}{c}{ The Hessian } & Eigenvalues \\
\hline 248.725 & 30.677 & 253.115 & 40.360 & 0.879 & 40.491 \\
30.677 & 38.705 & 34.316 & 0.879 & 34.614 & 34.483 \\
\hline
\end{tabular}

Given the structure of the model, the three share variables (Land_s, Capital_s and Labor_s) reflect household production choices and might cause endogeneity problems in the estimation. Although the use of the fixed effects model estimation could partially overcome these problems, the instrumental variables estimations have been done to test for the endogeneity of the potentially endogenous regressors. In the model, a oneyear lag of these three variables is used as an excluded instrument in the estimation considering the potential endogeneity problem, and the test results are given in the lower part of Table 4.4. The test statistics suggest that all of the three share variables (Land_s, Capital_s and Labor_s) can be treated as exogenous in the Zhejiang and Hubei provinces. As was already discussed in the econometric model, one merit of the quadratic functional form is that the Hessian matrix of its second-order partial derivatives only contains constants and hence its curvature properties are global. Eigenvalues of the Hessian for the Zhejiang and Hubei provinces are checked and the results are listed in Table 4.5. Since the Hessian is positive semidefinite for both provinces, the normalized quadratic profit function is convex at all points of the sample. 
Since the two normalized netput prices and the three quasifixed input variables have been scaled, the coefficients of $p_{2}^{*}$ can be interpreted as quantities of the supply of non-agricultural products, and the absolute value of the coefficients of $p_{3}^{*}$ can be interpreted as quantities of the derived demand for intermediate inputs, at the sample mean. From the estimation results, the two normalized prices $p_{2}^{*}$ and $p_{3}^{*}$ all have correct signs, and they are strongly significant at a level of 5\% except for $p_{3}^{*}$ of the Zhejiang province. The coefficients of technology $(t)$ are both positive, and the significant effect on farm household income is only observed in the Zhejiang province.

As for the three quasifixed inputs, the coefficients, which can be interpreted as their shadow prices at the sample mean, all have correct signs, and they are strongly significant at a level of 5\% except for arable land input (l) in the Zhejiang province. The shadow price of labor in the Zhejiang province is much higher (almost threefold) than that in the Hubei province, which is in accordance with the economic development level of the two provinces. In China, the Zhejiang province is located on the coast and is one of the richest provinces, while the Hubei province represents the middle-income region in the central part of the country. Rural enterprises, especially restructured township and village enterprises (TVEs), have always been privileged in the coastal provinces, since they have relatively easy access to both export markets and to large domestic markets in the densely populated and relatively rich eastern provinces (OECD, 2009b). Therefore, the concentration of rural enterprises in the Zhejiang province is much stronger than that in the Hubei province in terms of em- 
ployment, value of production, and assets. The same story applies to the interpretation of the difference in shadow price of capital input for the two provinces. For farm households in China, non-agricultural incomes are very important to their level of net incomes. In our sample, on average roughly $60 \%$ of total income comes from non-agricultural activities for farm households in the Zhejiang province, while the number is $43 \%$ in the Hubei province. So in the estimated results, it is not very surprising to see that the shadow price of arable land in the Zhejiang province is small and not statistically different from zero at the $5 \%$ significance level.

The coefficients of Land_real, which index land tenure insecurity, are negative but not statistically significant for both provinces. Direct effects of administrative land reallocation on farm household income are therefore not observed in our sample. The coefficients of Land_s are also not significant, which indicates that farmers' choice of crop cultivation structure has not significantly affected their income in our sample. The coefficient of Capital_s is not statistically significant for the Zhejiang province, but it is significant and negative for the Hubei province. The insignificance of Capital_s in the Zhejiang province indicates that, statistically, a one percent increase of capital input share in non-agricultural activities or a one percent decrease of that in agricultural activities will not bring any more profit at the $5 \%$ significance level. In other words, the sectoral allocation of capital input between agricultural and non-agricultural production could be seen as already at the optimum for farm households in the Zhejiang province. In contrast, the negative sign for the Hubei province 
shows that a less-than-optimal level of capital input is devoted to agricultural production, and farm households' income will increase if they allocate more capital from non-agricultural activities to agricultural use. The coefficients of Labor_s are positive and statistically significant at a $0.1 \%$ level for both provinces. The results indicate that the rural labor market has not yet reached the optimum, and a less-than-optimal level of labor input is devoted to non-agricultural activities, which is consistent with the findings from Yang (2004). Judged from the magnitude of the coefficients, the same adjustment level of labor from agricultural to non-agricultural activities will bring more profit to farm households in Zhejiang than in Hubei.

As for the indirect effects of land tenure insecurity on rural income through the interactions with other input allocations, the coefficients of the interaction terms are all not statistically significant at 5\% level for the Zhejiang province, which means that there are also no indirect effects of land tenure insecurity on the farm household income observed in our sample. In contrast, the coefficients of the interaction terms are all statistically significant for the Hubei province. The effect of the interaction term of Land_real with Land_s is negative, which means that allocating more arable land from non-grain crops to grain crops production will bring additional profit to farm households whose lands have been administratively reallocated compared to those whose lands have not. The effects of the interaction terms of Land_real with Capital_s and Labor_s are both positive. The results could be interpreted that an adjustment of labor and capital inputs from agricultural to non-agricultural activities will bring 
Table 4.6: Uncompensated (Marshallian) price elasticities of outputs and variable inputs at the sample means

\begin{tabular}{rrrrrrr}
\hline & \multicolumn{3}{c}{ Zhejiang } & \multicolumn{3}{c}{ Hubei } \\
\cline { 2 - 7 } & $\mathrm{p}_{1}$ & $\mathrm{p}_{2}$ & $\mathrm{p}_{3}$ & $\mathrm{p}_{1}$ & $\mathrm{p}_{2}$ & $\mathrm{p}_{3}$ \\
\hline $\mathrm{q}_{1}$ & 1.120 & -0.940 & -0.179 & 2.568 & -2.202 & -0.366 \\
$\mathrm{q}_{2}$ & -0.348 & 0.277 & 0.071 & 0.164 & -0.163 & -0.001 \\
$\mathrm{q}_{3}$ & 0.165 & -0.139 & -0.026 & 0.006 & 0.015 & -0.021 \\
\hline
\end{tabular}

additional profit to farm households whose lands have been administratively reallocated compared to those whose lands have not.

After the estimation, the uncompensated or Marshallian price elasticities of outputs and variable inputs are calculated and reported at the sample means for both provinces in Table 4.6. Under the assumption of profit maximization, own price elasticities of output supply must be positive and own price elasticities of input demand must be negative. From Table 4.6 we can see that all own price elasticities have the correct sign except for the non-agricultural products in the Hubei province. Since roughly $24 \%$ of the observations in the Hubei province have zero nonagricultural products, we suspect this might be the source of the wrong sign of the non-agricultural products supply elasticity. To control for the effects of those farm households who do not have non-agricultural activities, we introduced a dummy variable into the model with value equal to 1 if positive non-agricultural products are observed for the farm household and the interaction term of the dummy variable with the normalized price of non-agricultural products. Yet after the re-estimation, the calculated own price elasticity of the non-agricultural products is still negative. The results indicate that own price elasticities for agricultural prod- 
ucts are elastic while own price elasticities for non-agricultural products and intermediate inputs are inelastic for both the Zhejiang and Hubei provinces.

\subsection{Concluding remarks}

In this study, the normalized quadratic profit function is used to analyze profit maximization problems in farm households in rural China. Additional variables have been introduced to capture the effects of a series of institutional environment and factor market constraints, including land insecurity, crop cultivation structure, labor input and capital input allocations between agricultural and non-agricultural productions. A panel dataset covering two distinct provinces and eight years allows us to study factors affecting farm household income and do some regional comparisons.

Our results indicate that, although the official controls on rural labor mobility have been relaxed, the rural labor market has not yet reached the optimal level, and a less-than-optimal level of labor input is devoted to non-agricultural activities for farm households in both provinces. The estimated results suggest that those government policy choices which help further facilitate the outflow of labor from agriculture into other economic sectors, through outmigration for example, will bring significant income effects to farm households. In contrast to the optimized rural capital market for farm households in the Zhejiang province, households in the Hubei province have not efficiently allocated their capital input between 
agricultural and non-agricultural productions, and their income will increase if they allocate more capital from non-agricultural to agricultural use. At the same time, the finding that the farmers' choice of crop cultivation structure has no significant effect on their income reflects that the united procurement and marketing system has been largely deregulated during the research period and farmers could adjust their crop cultivation structure according to the market prices. Although the grain quota procurement system still existed until 2001, the government had concurrently raised procurement prices for grain substantially to increase farmers' income and to meet food security goals.

In the Zhejiang province, we observe that land tenure insecurity, which is induced by administrative land reallocation, has neither direct nor indirect effects on farm household income through the interactions with other input allocations. The explanation for this is that, on the one hand, off-farm income has accounted for a large proportion of household net income, as is already shown in the descriptive statistics, so income dependence on land has decreased to some extent. On the other hand, according to the research results from Zhang et al. (2011), the development of the land rental market can serve as a substitute for administrative land reallocation in optimizing the distribution of land resources, and the Zhejiang province is a case with a relatively well developed land rental market. So we could say that the negative effects of land tenure insecurity have been largely offset by the positive effects of a relatively well functioning land rental market. In the Hubei province, although the direct effects of land tenure insecurity are not observed, the indirect effects 
through the interactions with the other three input allocations are all significant. The negative effects of the interaction term of Land_real with Land_s indicate that administrative land reallocation will disturb farm households' decisions regarding the adjustment of crop cultivation structure and hence affect their income growth. Similarly, frequent land reallocation, which induces land tenure insecurity, will further distort the market mechanism, reinforce farm households' misallocations of the inputs, impede their adjustment process to the optimal allocation of inputs and hence hinder income growth. 


\section{Chapter 5}

\section{Summary}

$\mathbf{1}^{\mathrm{HE}}$ work covered in this thesis is motivated by the impressive per-

1 formance of China's agricultural production since the reform in 1979 and the currently hotly disputed issues on rural land policy reform. With three implicitly connected research topics being proposed, both theoretical discussions and empirical estimations have been comprehensively conducted in the thesis. This study contributes to the literature explaining China's agricultural productivity and efficiency change in the last three decades, the ongoing assessment of land tenure security under China's unique land tenure system, and, specifically, the impact of land tenure insecurity on farm household productive efficiency and thus in farm household income. The next section summarizes the main research results from Chapters 2, 3, and 4. Section 5.2 presents the policy implications. 


\subsection{Main results}

Research topic 1: Our estimation results show that, on the national average, the best performance in terms of technical efficiency is exhibited in the first reform phase (1979-1984), while technical efficiency deteriorated substantially during the second phase and remained at a lower level for the third and fourth reform phases. In the last two phases, technical efficiency initially continued to decrease but then increased again in 2007 and 2008. For the comparison of the six regional groups, the trend of divergence in terms of performance of technical efficiency is obvious in the whole sample period. Technical efficiency for the coastal provinces has remained high during all of the reform phases except for a small drop in the third phase. The performance of technical efficiency for the northwestern provinces is quite poor, and the gap between them and other regions is increasing as reforms continue to be implemented. Another region to which our attention has been drawn is the northeastern provinces. Their level of technical efficiency was very high among the six regions in the first four phases, but their score decreased substantially in the fifth phase, and they now rank second to last in the six regions. The performance of the other three regional groups are relatively consistent with the national average level. From the analysis of TFP change and its decomposition, we find that the impressive improvement of TFP change (222\%) over the last three decades is dominated by the outstanding performance of technical change (360.5\%). At the same time, both technical efficiency change $(-18.5 \%)$ and scale effects $(-3.6 \%)$ have worked against improvement in TFP change. This result is consistent with the findings of many previous 
studies (Wu, 1995; Kalirajan et al., 1996; Mao and Koo, 1997; Wu et al., 2001; Chen et al., 2008) that the main source of China's agricultural productivity growth since the reform is from technical progress and not from efficiency change.

Research topic 2: Our stage 1 model results indicate that the development of the land rental market is essential because it can serve as a substitute for administrative land reallocation in optimizing the distribution of land resources. Demographic change, measured on both the village level and the household level, has no effect on administrative land reallocation in the Zhejiang province, whereas it does impact land reallocation in the Hubei and Yunnan provinces. The estimated results of the effects of the government policy suggest that land tenure, to a large extent, has been secured after the announcement of the extension of the right to land use for another 30 years.

The results from the stochastic frontier production function show that administrative land reallocation does have effects on technical efficiency. The estimated coefficients indicate that it has negative effects on technical efficiency in the Zhejiang province and positive effects in the Hubei and Yunnan provinces. Judging from the average yearly efficiency scores, our results show that technical efficiency stays relatively constant with a moderate increase during the study period, while the average level of the technical efficiency term mirrors the regional level of economic development. In addition, the variations in technical efficiency across villages and over households within the village are observed. The majority of rural households in the Zhejiang province operate close to the agricultural 
production frontier. However, for the farm households in the Hubei and Yunnan provinces, further growth of agricultural production through the improvement of technical efficiency could be expected. This result is consistent with that of regional comparisons in terms of technical efficiency in the first topic of research.

Research topic 3: Our estimation results indicate that, although the official controls on rural labor mobility have been relaxed, the rural labor market has not yet reached the optimum, and that a less-than-optimum level of labor input is devoted to non-agricultural activities for farm households in both the Zhejiang and Hubei provinces. In contrast to the already optimized rural capital market for farm households in the Zhejiang province, households in the Hubei province again did not efficiently allocate their capital input between agricultural and non-agricultural productions, and their income will increase if they allocate more capital from non-agricultural to agricultural use. At the same time, the result that farmers' choices of crop cultivation structure have no significant effect on their income shows that the state-monopolized procurement and marketing system has been largely deregulated during the research period and farmers could adjust their crop cultivation structure according to the market prices. Although the grain quota procurement system still existed until 2001, the government had concurrently raised procurement prices for grain substantially to increase farmers' income and to meet food security goals.

In the Zhejiang province, we observe that land tenure insecurity, which is induced by administrative land reallocation, has neither a direct nor 
indirect effect on farm household income through its interactions with other input allocations. In the Hubei province, although direct effects of land tenure insecurity are not observed, the indirect effects through its interactions with the other three input allocations are all significant, which means that land tenure insecurity reduced farmers' income by the way of affecting input allocative efficiency.

\subsection{Policy implications}

Research topic 1: Connecting the performance of technical efficiency with the government's agricultural policy in different reform phases, we argue that the implementation of a new institutional arrangement aiming at factor market reform has contributed to a high level of technical efficiency. A good example is the implementation of HRS in the first reform phase. HRS liberalized the rural labor forces and other production endowments, which greatly motivated farm household agricultural production. After the first phase, reform policies were mainly designed to solve pricing and marketing problems of agricultural products without including further reform of some important input markets. The negative side effects of these policies have been illustrated by the poor performance of technical efficiency in the following phases. Hence, in addition to the series of policy designs concerning rural social welfare that aim to increase farmers' income and to eliminate the rural-urban divide which the government has stressed since the early $2000 \mathrm{~s}$, other reform polices focusing on rural factor markets, such as the reform of the household 
registration system (hukou system) and the reform related to the land tenure system concerning farmers' rights to land, need to be introduced or furthered in order to improve productive efficiency in farm households.

In addition, the ever-growing efficiency gap between the western provinces and the other regions suggests that agricultural production for the western regional groups was not able to gradually catch up with the production frontier, and therefore more preferential policies should be carried out in these regions to improve their technical efficiency. The outstanding performance of technical change for all provinces has reflected the success of the government's long-term efforts on investment in agricultural technology and rural infrastructure. At the same time, we also notice that the rank of performance in terms of technical change for the six regional groups is almost the exact opposite to that of technical efficiency change. This comparison illustrates that, although having experienced faster technical progress because of the government's support, those regions are still characterized by less efficient agricultural production. The implication is that these regions still have the potential of agricultural productivity growth if corresponding policies are implemented to improve technical efficiency.

In contrast to technical efficiency change and technical change, the pattern of the annual average growth rate of the scale effects for the 28 provinces does not show any regional differences. Ten provinces have positive growth rates and are dispersed throughout all of the six regional groups. The fact that almost two-thirds of the provinces have experienced negative growth rates in the scale effects suggests that there is still room 
for the structural adjustment of agricultural production.

Research topic 2: The different signs of coefficients of land reallocation for different provinces imply that its impact on technical efficiency is an empirical issue. Because of the possibility that administrative land reallocation can partially serve as a substitute for missing or badly functioning land rental markets (which has been shown in the result of Stage 1 model estimation), land reallocation could facilitate the process of improving land access for more successful farmers; hence, it could improve the technical efficiency of agricultural production. But at the same time, in regions where land rental markets and other related factor markets are already relatively well developed, administrative land reallocation seems to distort the market mechanism, undermine market signals, and thus seems to decrease technical efficiency.

Although land reallocation could act as a substitute for the land rental market to optimize the allocation of land resources and hence improve technical efficiency of the farm, a study by Deininger and Jin (2005) suggests that land rental markets are more effective than administrative reallocation in reallocating land to those with lower endowments and enhance productivity to a greater extent. Hence, the development of the land rental market needs to be encouraged to achieve allocative efficiency. This recommendation is reinforced by our results for Zhejiang, where land rental markets and other related factor markets are already relatively well functioning. Under these circumstances, the administrative land reallocation process exerts a negative effect on the technical efficiency of farmers. 
Research topic 3: In the Zhejiang province, the finding that land tenure insecurity has no significant effect on farm household income implies that, on the one hand, since off-farm income has accounted for a large proportion of household net income, as is already shown in the descriptive statistics, household income dependence on land has decreased to some extent. On the other hand, according to the research results from Zhang et al. (2011), the development of the land rental market can serve as a substitute for administrative land reallocation in optimizing the distribution of land resources. The Zhejiang province is one case with a relatively well developed land rental market. So we could say that the negative effects of land tenure insecurity have been largely offset by the positive effects of a relatively well functioning land rental market.

In the Hubei province, the observed indirect effects of land tenure insecurity on rural income through the interactions with other input allocations indicate that the administrative land reallocation will disturb the decisions of farm households regarding the adjustment of crop cultivation structure and hence negatively affect their income growth. This is consistent with the argument of Yao (2010), who asserts that farmers in some localities are forced to plant certain cash crops because the local government can then collect agricultural special product tax. Similarly, periodic land reallocation, which induces land tenure insecurity, will further distort the market mechanism, reinforce misallocations of the inputs by farm households, impede their adjustment process to the optimal allocation of inputs, and hence hinder their income growth.

In addition, the estimated results from both the Zhejiang and Hubei 
provinces suggest that the government should improve the social and economic environment to help further facilitate the outflow of labor from agriculture into other economic sectors, for example through outmigration. This will have significant effects on farm household income. 


\section{Bibliography}

Aigner, D., Lovell, C. A. K., and Schmidt, P. (1977). Formulation and estimation of stochastic frontier production function models. Journal of Econometrics, 6(1):21-37.

Bauer, P. W. (1990). Recent developments in the econometric estimation of frontiers. Journal of Econometrics, 46(1-2):39 - 56.

Benjamin, D. (1992). Household composition, labor markets, and labor demand: Testing for separation in agricultural household models. Econometrica, 60(2):287-322.

Benjamin, D., Brandt, L., and Giles, J. (2005). The evolution of income inequality in rural china. Economic Development and Cultural Change, 53(4):769-824.

Bowlus, A. J. and Sicular, T. (2003). Moving toward markets? labor allocation in rural China. Journal of Development Economics, 71(2):561-583.

Brandt, L., Huang, J., Li, G., and Rozelle, S. (2002). Land rights in rural China: Facts, fictions and issues. The China Journal, 47:67-97.

Brosig, S., Glauben, T., Herzfeld, T., and Wang, X. (2009). Persistence of full- and part-time farming in southern China. China Economic Review, 20(2):360-371.

Brümmer, B., Glauben, T., and Lu, W. (2006). Policy reform and productivity change in Chinese agriculture: A distance function approach. Journal of Development Economics, 81(1):61-79.

Chen, P.-C., Yu, M.-M., Chang, C.-C., and Hsu, S.-H. (2008). Total factor productivity growth in China's agricultural sector. China Economic Review, 19(4):580 - 593.

Cheng, E., Findlay, C., Zhu, G., and Watson, A., editors (2003). Rural Financial Markets in China. Asia Pacific Press. 
Coelli, T. (1995). Estimators and hypothesis tests for a stochastic frontier function: A monte carlo analysis. Journal of Productivity Analysis, 6:247-268. 10.1007/BF01076978.

Coelli, T. J., Rao, D. S. P., and Battese, G. E. (1998). An Introduction to Efficiency and Productivity Analysis. Kluwer Academic Publishers, Boston.

Curtiss, J. (2002). Efficiency and Structural Changes in Transition A Stochastic Frontier Analysis of Czech Crop Production. Shaker Verlag $\mathrm{GmbH}$, Germany.

de Brauw, A., Huang, J., Rozelle, S., Zhang, L., and Zhang, Y. (2002). The evolution of China's rural labor markets during the reforms. Journal of Comparative Economics, 30(2):329-353.

Deininger, K. and Feder, G. (2001). Land institutions and land markets. In Gardner, B. L. and Rausser, G. C., editors, Handbook of Agricultural Economics, volume 1 of Handbook of Agricultural Economics, chapter 6, pages 288-331. Elsevier.

Deininger, K. and Jin, S. (2005). The potential of land rental markets in the process of economic development: Evidence from China. Journal of Development Economics, 78(1):241-270.

Deng, X., Huang, J., Rozelle, S., and Uchida, E. (2006). Cultivated land conversion and potential agricultural productivity in China. Land Use Policy, 23(4):372 - 384.

Dong, X.-Y. (1996). Two-tier land tenure system and sustained economic growth in post-1978 rural China. World Development, 24(5):915 - 928.

Doornik, J. (2007). Object-oriented matrix programming using ox, 3rd ed. london: Timberlake consultants press and oxford: www.doornik.com.

Fan, S. (1991). Effects of technological change and institutional reform on production growth in Chinese agriculture. American Journal of Agricultural Economics, 73(2):pp. 266-275.

Fan, S. (1997). How fast have China's agricultural production and productivity really been growing?: new measurement and evidence. EPTD discussion papers 30, International Food Policy Research Institute (IFPRI). 
Fan, S. (1999). Technological change, technical and allocative efficiency in Chinese agriculture: the case of rice production in jiangsu. EPTD discussion papers 39, International Food Policy Research Institute (IFPRI).

Fan, S., Zhang, L., and Zhang, X. (2002). Growth, inequality, and poverty in rural China: the role of public investments. Research reports 125, International Food Policy Research Institute (IFPRI).

Fan, S. and Zhang, X. (2002). Production and productivity growth in Chinese agriculture: New national and regional measures. Economic Development and Cultural Change, 50(4):819-38.

Fei, J. C. H. and Ranis, G. (1964). Development of the Labor Surplus Economy: Theory and Policy. RICHARD D IRWIN INC.

Førsund, F. R., Lovell, C. A. K., and Schmidt, P. (1980). A survey of frontier production functions and of their relationship to efficiency measurement. Journal of Econometrics, 13(1):5-25.

Fried, H. O., Schmidt, S. S., and Lovell, C. A. K., editors (1993). The Measurement of Productive Efficiency: Techniques and Applications. Oxford University Press, USA, 1 edition.

Gabre-Madhin, E. Z., Barrett, C. B., and Dorosh, P. A. (2003). Technological change and price effects in agriculture. MTID discussion papers 62, International Food Policy Research Institute (IFPRI).

Glauben, T., Herzfeld, T., and Wang, X. (2008). Labor market participation of Chinese agricultural households: Empirical evidence from zhejiang province. Food Policy, 33(4):329 - 340.

Greene, W. H. (1993). The econometric approach to efficiency analysis. In Fried, H. O., Lovell, C. A. K., and Schmidt, S. S., editors, The Measurement of Productive Efficiency: Techniques and Applications. Oxford University Press, USA.

Griliches, Z. (1963). The sources of measured productivity growth: United states agriculture, 1940-60. Journal of Political Economy, 71:331.

Huang, J. and Rozelle, S. (1995). Environmental stress and grain yields in China. American Journal of Agricultural Economics, 77(4):pp. 853864.

Jacoby, H. G., Li, G., and Rozelle, S. (2002). Hazards of expropriation: Tenure insecurity and investment in rural China. American Economic Review, 92(5):1420-1447. 
Jin, S. and Deininger, K. (2009). Land rental markets in the process of rural structural transformation: Productivity and equity impacts from China. Journal of Comparative Economics, 37(4):629 - 646.

Kalirajan, K. P., Obwona, M. B., and Zhao, S. (1996). A decomposition of total factor productivity growth: The case of chinese agricultural growth before and after reforms. American Journal of Agricultural Economics, 78(2):pp. 331-338.

Kimura, S., Otsuka, K., Sonobe, T., and Rozelle, S. (2011). Efficiency of land allocation through tenancy markets: Evidence from China. Economic Development and Cultural Change, 59(3):pp. 485-510.

Kodde, D. A. and Palm, F. C. (1986). Wald Criteria for Jointly Testing Equality and Inequality Restrictions. Econometrica, 54(5):1243-48.

Kreps, D. M. (1990). A Course in Microeconomic Theory. Financial Times Prentice Hall.

Kumbhakar, S. C. and Lovell, C. A. K. (2003). Stochastic Frontier Analysis. Cambridge University Press.

Kung, J. K.-s. (2000). Common property rights and land reallocations in rural China: Evidence from a village survey. World Development, 28(4):701-719.

Kung, J. K.-s. (2002). Off-farm labor markets and the emergence of land rental markets in rural China. Journal of Comparative Economics, 30(2):395 - 414 .

Lambert, D. K. and Parker, E. (1998). Productivity in Chinese provincial agriculture. Journal of Agricultural Economics, 49(3):378-392.

Lerman, Z., Csaki, C., and Feder, G. (2004). Agriculture in Transition: Land Policies and Evolving Farm Structures in Post Soviet Countries (Rural Economies in Transition). Lexington Books.

Lewis, W. A. (1954). Economic development with unlimited supplies of labour. The Manchester School, 22(2):139-191.

Li, C. (2005). Big power's worry: China's food problem. Daguo [National Interest], 5. (in Chinese).

Li, G., Rozelle, S., and Brandt, L. (1998). Tenure, land rights, and farmer investment incentives in China. Agricultural Economics, 19(1-2):6371 . 
Lin, J. Y. (1992). Rural reforms and agricultural growth in China. The American Economic Review, 82(1):34-51.

Lin, J. Y. and Zhang, F. (1999). The effects of China's rural policies on the sustainability of agriculture in China. EEPSEA Special and Technical Paper sp199901t3, Economy and Environment Program for Southeast Asia (EEPSEA).

Liu, S., Carter, M. R., and Yao, Y. (1998). Dimensions and diversity of property rights in rural China: Dilemmas on the road to further reform. World Development, 26(10):1789-1806.

Mao, W. and Koo, W. W. (1997). Productivity growth, technological progress, and efficiency change in Chinese agriculture after rural economic reforms: A dea approach. China Economic Review, 8(2):157 174.

Martin, W. and Mitra, D. (2001). Productivity growth and convergence in agriculture versus manufacturing. Economic Development and Cultural Change, 49(2):403-22.

Meeusen, W. and Broeck, J. v. D. (1977). Efficiency estimation from cobbdouglas production functions with composed error. International Economic Review, 18(2):pp. 435-444.

Moutinho, N. and Machado, F. S. (2003). An international comparison of productivity change in agriculture and the economy as a whole. CEF.UP Working Papers 0309, Universidade do Porto, Faculdade de Economia do Porto.

Murillo-Zamorano, L. R. (2004). Economic efficiency and frontier techniques. Journal of Economic Surveys, 18(1):33-77.

Nyberg, A. J. and Rozelle, S. (1999). Accelerating China's Rural Transformation. World Bank Publications.

OECD (2005). OECD Review of Agricultural Policies : China. OECD Publishing, illustrated edition edition.

OECD (2009a). Agricultural Policies in Emerging Economies 2009: Monitoring and Evaluation. OECD Publishing.

OECD (2009b). OECD Rural Policy Reviews: China 2009. OECD Publishing, pap/psc mu edition. 
OECD - Territorial Development Service (2001). Regional disparities and trade and investment liberalisation in China. In the OECD-China Conference on Foreign Investment in China's Regional Development, 11-12 October 2001, Xi'an, China.

Ravallion, M. and van de Walle, D. (2008). Land in Transition: Reform and Poverty in Rural Vietnam (Hardcover) (Equity and Development). World Bank Publications.

Schaffer, M. E. (2007). Xtivreg2: Stata module to perform extended iv/2sls, gmm and ac/hac, liml and k-class regression for panel data models. Statistical Software Components, Boston College Department of Economics.

Schmidt, P. (1985). Frontier production functions. Econometric Reviews, $4: 289-328$.

Sicular, T. (1988). Plan and market in China's agricultural commerce. Journal of Political Economy, 96(2):283-307.

Swinnen, J. and Rozelle, S. (2006). From Marx and Mao to the Market: The Economics and Politics of Agricultural Transition. Oxford University Press, USA.

Tan, S., Heerink, N., Kruseman, G., and Qu, F. (2008). Do fragmented landholdings have higher production costs? evidence from rice farmers in northeastern jiangxi province, p.r. China. China Economic Review (1043951X), 19(3):347 - 358.

Tan, S., Heerink, N., and Qu, F. (2006). Land fragmentation and its driving forces in China. Land Use Policy, 23(3):272 - 285.

Wu, H. X. (1997). Reform in China's agriculture : trade implications. East Asia Analytical Unit, Department of Foreign Affairs and Trade, Canberra.

Wu, S., Walker, D., Devadoss, S., and Lu, Y.-c. (2001). Productivity growth and its components in chinese agriculture after reforms. Review of Development Economics, 5(3):375-391.

Wu, Y. (1995). Productivity growth, technological progress, and technical efficiency change in China: A three-sector analysis. Journal of Comparative Economics, 21(2):207 - 229.

Yang, D. T. (2004). Education and allocative efficiency: household income growth during rural reforms in China. Journal of Development Economics, 74(1):137-162. 
Yao, Y. (1999). Rural industry and labor market integration in eastern China. Journal of Development Economics, 59(2):463-496.

Yao, Y. (2000a). China's rural land institution: an analytical framework. Zhongguo Shehui Kexue [Social Science in China], 2:54-65. (in Chinese).

Yao, Y. (2000b). The development of the land lease market in rural China. Land Economics, 76(2):252-266.

Yao, Y. (2010). Economic reform and institutional innovation. Gale Asia, Singapore.

Zhang, Y., Wang, X., Glauben, T., and Brümmer, B. (2011). The impact of land reallocation on technical efficiency: evidence from china. Agricultural Economics, 42(4):495-507. 